STONE CENTER ON SOCIO-ECONOMIC INEQUALITY

WORKING PAPER SERIES

No. 36

The Concentration of Personal Wealth in Italy 1995-2016

\author{
Paolo Acciari \\ Facundo Alvaredo \\ Salvatore Morelli
}

April 2021

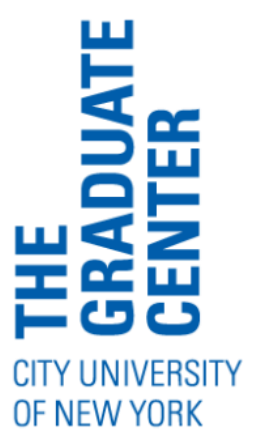




\title{
The concentration of personal wealth in Italy 1995-2016
}

\author{
Paolo Acciari, Facundo Alvaredo, Salvatore Morelli*
}

\begin{abstract}
Italy is one the countries with the highest wealth-to-income ratio in the developed world. Yet, despite the growing policy interest, knowledge about the size distribution of wealth is currently limited. In this paper we expand our windows of observation on the distribution of personal wealth using a novel source on the full record of inheritance tax files. The data cover up to $63 \%$ of the deceased population and are available between 1995 and 2016, a period of substantial economic turbulence and structural reform for the Italian economy. Our benchmark results rely on the distribution of the net wealth observed in the National Accounts balance sheets. Unlike available statistics estimated from household survey data, our results point to a strong rise in wealth concentration and inequality since the mid-1990s. Whereas the level of wealth concentration in Italy is in line with those of other European countries, its time trend appears more in line with the U.S. experience. Moreover, Italy stands out as one of the countries with the strongest decline in the wealth share of the bottom $50 \%$ of the adult population. We explore the role of household wealth portfolios, accumulation patterns during the life cycle, and inheritance flows, its concentration, and taxation patterns as main drivers of the trends observed. A range of alternative series of wealth concentration helps us better understand the role of adjustments and imputations and is based on a multi-series approach, i.e., comparing the pieces of information given by different and competing sources.
\end{abstract}

Keywords: Wealth inequality, wealth distribution, top wealth shares, distributional national accounts, estate concentration, inheritance and gifts, inheritance tax

JEL Codes: D3, H24, N3, G50

${ }^{*}$ PA: Italian Ministry of Economy and Finance Department of Finance; FA: Paris School of Economics, INET at Oxford and IIEP-UBA-Conicet; SM: University of Roma Tre - Law Department, the Stone Center on Socio-Economic Inequality at the GC-CUNY, and CSEF. Corresponding author: salvatore.morelli@uniroma3.it. We are grateful to the Department of Finance of the Italian Ministry of Economy and Finance for providing technical support and access to the data. The views expressed in the paper are the authors' responsibility only. We are grateful to many scholars for fruitful discussions and feedbacks at different stages of the project: Charlotte Bartels, Yonatan Berman, Giovanni D'Alessio, Riccardo De Bonis, Carolyn Fisher, Giacomo Gabbuti, Janet Gornick, Elena Granaglia, Arthur Kennickell, Clara MartinezToledano, Marco Ranaldi, Alfonso Rosolia, Peter Van de Ven, Giovanni Vecchi, Gabriel Zucman. We thank Francesco Bloise, Demetrio Guzzardi, and Ercio Muñoz for excellent research assistance. An anonymous referee from the Italian Department of Finance as well as participants at several conferences provided helpful comments. We acknowledge financial support from the Stone Center on Socio-Economic Inequality at the Graduate Center CUNY (SM), INET (FA and SM), and the ERC (FA). SM acknowledges support during visiting periods from the Fondazione Lelio e Lisli Basso, the Department of Social Policy and Intervention and the Nuffield College at the University of Oxford. 


\section{Introduction}

The stock of private wealth is equivalent to seven years of national income in Italy as of 2019, making it one of the countries with the highest wealth-to-income ratio in the developed world. ${ }^{1}$ Yet, very little is known about how this stock is distributed across the population. This paper provides novel estimates of the distribution of personal wealth, with a particular focus on high-end wealth groups, thus contributing to a growing body of literature focusing on this topic. We make use of a newly assembled microdata set from the administration of the inheritance tax that provides information on the wealth holding of the deceased from 1995 to 2016 and that has not been systematically exploited so far. We first estimate the wealth of the living population through the application of the mortality multiplier method; this is further complemented with household survey (to take into account the wealth of the population not represented in the tax records) and the national balance sheet (to impute tax-exempt and underreported assets), allowing us to walk in the direction of distributing the personal wealth from the national accounts (NA) as discussed in the work by Alvaredo et al. (2020).

We consider the use of the inheritance tax data as a fundamental step to widen the windows of observation on the wealth distribution of Italy. Even if other sources and methods provide direct or indirect information about wealth holdings, few of them are, currently, easily applicable to the Italian case. ${ }^{2}$ Italy does not have a wealth tax besides the property tax, whereas tax-based distributional information on investment income (even if it could be extracted from the income tax) is not readily available, making the application of the capitalization method impossible at present.

This work provides the first set of comprehensive estimates of wealth distribution and concentration that complement those from the Survey of Households on Income and Wealth (SHIW), administered by the Bank of Italy since the late 1980s. The use of different data sources for the study of wealth inequality is essential, as every source is open to challenge and has different advantages and shortcomings. Moreover, the use of household surveys is generally deemed to be less suited to capture the wealth holdings at the very top for a variety of reasons, namely the lack of over-sampling of wealthy households, and differential non-response and under-reporting rates across wealth classes (Kennickell, 2019, Vermeulen, 2017). On the contrary, the use of inheritance tax data increases the probability of better covering high-end wealth groups, despite the existence of tax avoidance and evasion behaviours. The administrative data guarantee a relatively high coverage of the asset holdings of more than half of decedents - more than $60 \%$ in recent years. This is the result of the combination of the very high homeownership rate with a key administrative feature of the tax, which is strictly connected to the upkeep of the cadastral (real estate) register: all inheritances involving the transfer of real estate property are obliged to file a return, even

\footnotetext{
${ }^{1}$ See wid.world.

${ }^{2}$ There are at least six potential sources of evidence to study the distribution of personal wealth: (i) administrative data on the wealth of the living derived from annual wealth taxes; (ii) administrative data on investment income, capitalized to yield estimates of the underlying wealth; (iii) administrative data on individual estates at death, multiplied up to yield estimates of the wealth of the living; (iv) household surveys; (v) lists of large wealth holders, such as the Forbes list; and (vi) population censuses.
} 
when no tax is due (and even when the inheritance tax itself was abolished between 2001 and 2006).

Our estimates suggest, even without applying adjustments for underreporting, that the wealth levels in the upper tail are substantially above what household surveys capture, and that the level of wealth concentration is also higher and with a different trend. This is also true once the survey-based calculations reflect the same unit of observation and similar wealth definition employed in tax-based data. According to the SHIW, the share accruing to the richest $1 \%$ of adults (half a million individuals) has remained roughly unchanged between 1995 and 2016, at around 14\% (these numbers are in line with existing literature such as Brandolini et al., 2004, Cannari and D'Alessio, 2018). Our estimates, instead, imply that the share of the top $1 \%$ increased from $16 \%$ in 1995 to $22 \%$ in 2016 (notably, of a much larger aggregate). The share accruing to the richest 5,000 adults (the top $0.01 \%$ ) almost tripled, increasing from $1.8 \%$ to $5 \%$.

As a preview of the main results, Figure 1 shows a stark inversion of fortunes since 1995. The richest $0.1 \%$ saw a twofold increase in their real average net wealth (from $€ 7.6$ million to $€ 15.8$ million at 2016 prices), making its share double, from $5.5 \%$ to $9.3 \%$ (equivalent to a change from 55 to 93 times their proportionate share). In contrast, the poorest $50 \%$ controlled $11.7 \%$ of total wealth in 1995 , and $3.5 \%$ recently. This corresponds to a $80 \%$ drop in the average net wealth (from $€ 27,000$ to $€ 7,000$ at 2016 prices). Strong concentration increases were also recorded for the richest 10\%, whose share went up from $44 \%$ in 1995 to $56 \%$ in 2016 . In 1995, the share of the middle $40 \%$ was very similar to that of the top $10 \%$, but it declined over time by almost 5 percentage points instead.

Figure 1: The inversion of fortunes between 1995 and 2016

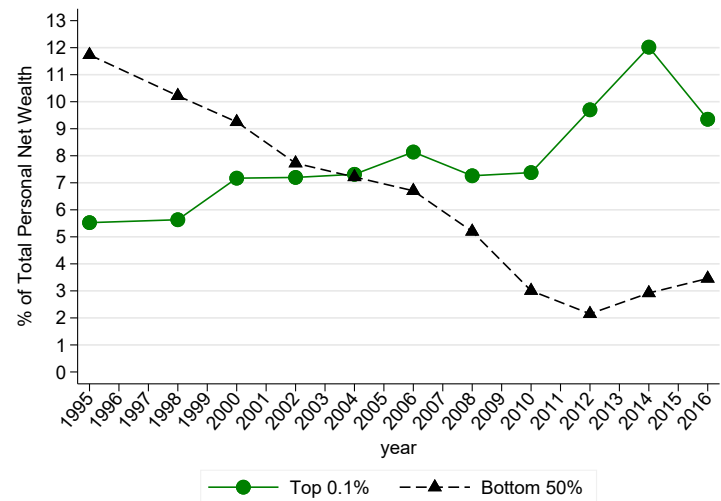

(a) Top $0.1 \%$ and bottom $50 \%$ shares

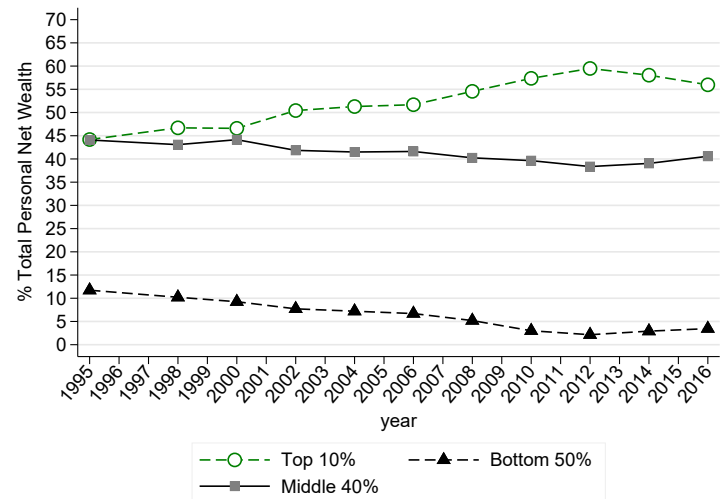

(b) Top 10\%, Middle 40\%, and Bottom 50\% shares

Note: The graphs show the shares of total personal net wealth accrued by the bottom $50 \%$ of the adult population (25 million individuals in 2016) ranked by total net wealth holdings, the richest $0.1 \%(50,000$ individuals), the top $10 \%$, the middle $40 \%$, and the bottom $50 \%$, benchmark definition.

The use of tax data does not come without costs; several adjustments are applied. First, 
the valuation of real estate has to be corrected to bring cadastral values reported for taxation purposes in line with market prices. Second, the distribution of decedents needs to be reshaped into the distribution of identified living wealth holders through the application of the mortality multiplier method. Third, allowance for the wealth of the unidentified population in the tax data is estimated with household surveys. Fourth, not all assets are taxable, and their reporting may not be mandatory; this - requiring imputation of their value - may be due to underreporting, differences in valuation, tax avoidance and evasion, as well as non-reporting due to lack of fiscal incentives to do so (e.g., completing in detail the complex tax form on the nature and composition of the estate might be regarded as an unnecessary burden when the resulting inheritance is below the taxable threshold). ${ }^{3}$

The benchmark approach adopted here is to distribute in full the balance sheet of the household sector from the NA. This is based not on the assumption that the balance sheet gives the correct numbers (as discussed in Section 1), but that they provide a reasonable indicator (enshrined in official statistics) of the development of aggregates over time, as well as offer the possibility of better cross-country comparison. Such a methodological decision comes at the cost of imputing the wealth not observed in the tax records and the household surveys. As this involves a number of controversial decisions, we also produce series based on tax and survey data before imputations, and also after inclusion of unreported offshore wealth as well as households' durables. In our view, this multi-series approach, that is, one that offers the possibility of comparing the pieces of information given by different and competing data sources, is preferable to the alternative option of looking at one and only one series resulting from the combination of those sources. This allows us to present the benchmark series in the context of a wider range of values, representing different methods of estimation used in the literature. On the one hand, this is useful to convince readers that the series of imputations, albeit important, may not drive the key findings about the evolution of wealth concentration, at least in the case of Italy. On the other hand, the approach is also crucial to compare our estimates to existing historical series that are not up-scaled to the NA (Gabbuti and Morelli, 2020 for Italy, Piketty et al., 2006 for France, Alvaredo and Saez, 2009 for Spain, Alvaredo et al., 2018 for the UK, and Roine and Waldenström, 2015 for Finland, Norway, the Netherlands, Sweden, and Switzerland etc.) as well as to recent work for the U.S., France, Spain, and Germany (Albers et al., 2020, Batty et al., 2019, Garbinti et al., 2016, Martínez-Toledano, 2017, Saez and Zucman, 2016) which follow the Distributional National Accounts (DINA) framework (Alvaredo et al., 2016, 2020). The level of wealth concentration observed in Italy appears to be in line with other European countries; however, its time evolution is closer to that found in the U.S. By contrast, whereas the Italian middle $40 \%$ share remains relatively high, the share of the bottom $50 \%$ experienced the strongest decline since the mid-1990s when compared to other countries.

Our series are triangulated with external evidence from the global Forbes rich list. Using Forbes we can track the evolution of the share of the 5 richest individuals since 1988, or the 10 richest individuals since 2001. Similarly, our series are triangulated with estimates from the Credit Suisse (based on the work by Davies et al., 2017, combining the Forbes rich list

\footnotetext{
${ }^{3}$ Assets are sometimes reported despite their tax-exemption status (e.g., government bonds), resulting in a partial adjustment.
} 
data on billionaires with the household survey data). The picture based on Forbes and the Credit Suisse is broadly consistent with the evidence assembled here, but this should not be interpreted as resolving our reservations about the statistical validity of rich lists.

The paper also attempts to shed light on the determinants of wealth inequality trends. In doing so, the paper makes additional contributions to the literature. Our estimates suggest that although average wealth grows with age, the dispersion of wealth within each age (and gender) group is not too dissimilar from that in the overall population. Moreover, we also provide new evidence that asset portfolios are highly heterogeneous across the distribution. Wealthy Italians hold the greatest portion of their portfolios in financial and business assets, adults between the median and 90th percentiles, in the form of real estate (mostly housing), whereas poorer adults hold the biggest share of gross wealth in current and saving accounts, valuables, and they also hold an important share of debt. In line with these findings, the wealth shares of all groups above the 90th percentile are mostly driven by the dynamics of non-housing assets. By contrast, both housing and non-housing net assets appear to play a more important role for the rest of the population. Lastly, we provide new evidence on the growing role of inheritance and gifts inter vivos as a share of national income, as well as their increasing concentration at the top. The estates are based on the value of wealth left at death fully adjusted to allow for underreporting of assets as well as for the missing wealth of non-filers (in this sense the estimates presented here differ from those in Acciari and Morelli (2020)). Associated to these trends, we estimate that wealthy inheritors were subject to an overall decreasing tax burden over the past twenty years. On the one hand, a lower proportion of inheritances generated by large bequests are subject to taxation today with respect to mid 1990s. On the other hand, the average tax burden of large bequests has also shrunk substantially over the same period of time, undermining the progressivity of the inheritance and gift tax.

The paper is structured as follows. The first section describes the concept of net wealth, and the nature of the aggregate wealth of the household sector. Section two dwells on the structure of the inheritance tax in Italy, the available data, and the mortality multiplier method. The section also describes the valuation of specific asset classes as well as the nature of the wealth of the missing population and that of tax-exempt assets. The third section shows the main empirical findings about the evolution of wealth inequality and concentration in Italy, including the comparison of our estimates with those available in other countries. The fourth section triangulates our evidence with that available from alternative sources of data. Section five discusses the role of different factors in driving wealth concentration in Italy. The sixth and last section presents a series of robustness checks. Our concluding remarks follow.

\section{The macro dimension: the growing relevance of personal wealth in Italy}

According to the national balance sheets, Italian households are among the wealthiest and least indebted among the rich economies. The average net wealth per capita, taken as the sum of all financial and real assets minus liabilities, was $€ 21,000$ (2016 prices) in 1966, and 
had experienced an eight-fold increase to $€ 167,000$ by the end of 2006 , just before the onset of the financial crisis. Since then, as shown in Figure 2, it dropped to $€ 143,000$ in 2016. Such a remarkable drop of $16 \%$ did not occur in any of the other advanced economies with the exception of Spain.

Figure 2: The growing relevance of households per capita net wealth

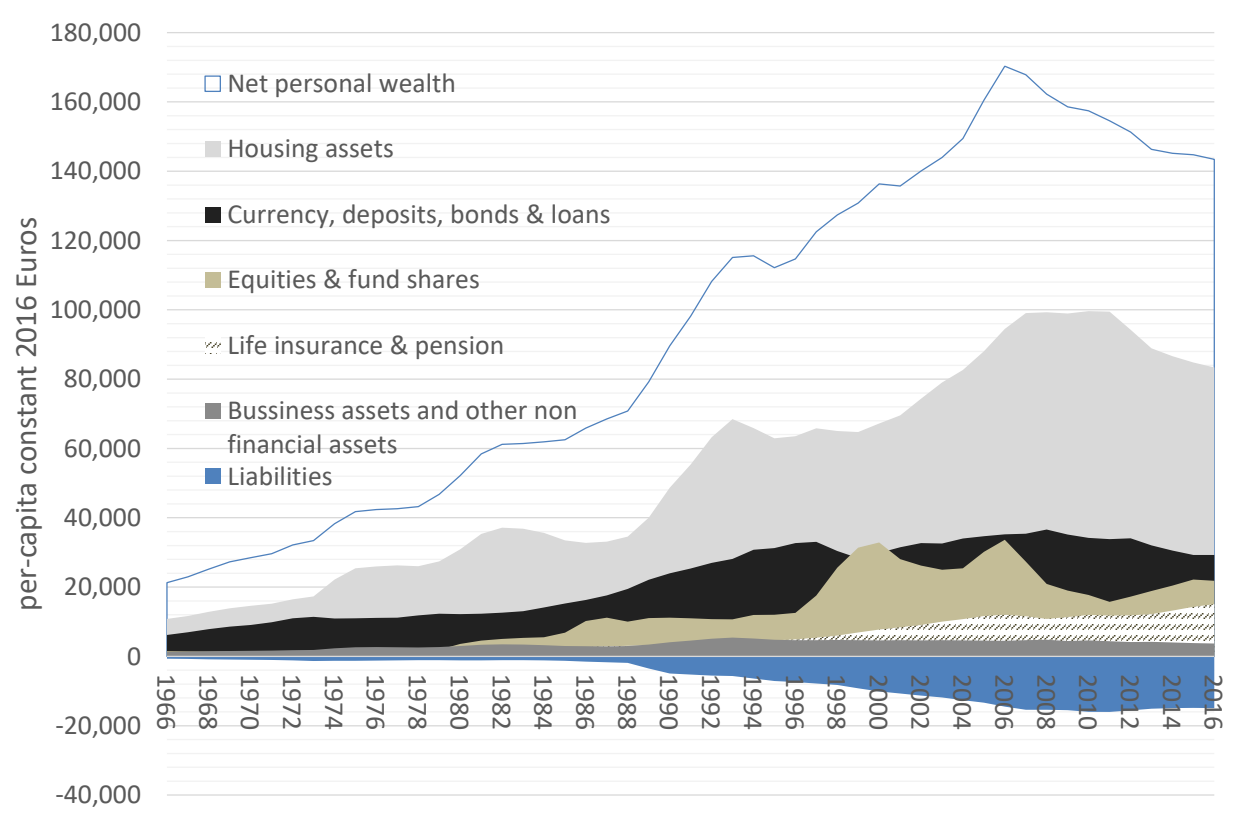

Note: The graph shows estimates of assets and liabilities held by the household sector excluding the non-profit sector serving households. The series is derived assembling data from Bank of Italy, ISTAT, and

WID.world. The appendix provides more information about how we reconstruct the series.

Over the last five decades, about half of the gross wealth of the personal sector (the household sector excluding non-profit organizations) has been composed of housing and land assets. The weight of direct holding of equities, investment funds and indirect holding of financial securities via life insurance and private pension funds increased from $14 \%$ to $23 \%$ in the same period. Saving and current accounts, currency, and bonds decreased from $24 \%$ to $17 \%$, as did business assets and other non-financial assets, from $5.8 \%$ to $3.5 \%$. These huge mountains of assets mirror into very shallow waters of per capita indebtedness. Personal debt is approximately $€ 15,000$ per capita in recent years, and although its share in total gross wealth has almost doubled since 1995, it remains one of the lowest indebtedness levels currently recorded in the rich world, in contrast to the situation of the debt of the public sector. 
Comparisons with other countries could take purchasing power parity (PPP) into account. This would transform Italian wealth holdings for 2016 to approximately $€ 150,000$, which can be compared to Japan and France $(€ 150,000)$, Germany and Spain $(€ 140,000)$, the UK $(€ 180,000)$ and the U.S. $(€ 190,000)$.

Italy is also one of the countries with the highest ratios of aggregate private wealth to national income. More than seven years of national income are needed to account for the net worth of the household and non-profit sectors. This ratio was close to 2 around 1970 (and close to 6 in other rich countries like France, Japan, and the UK, or to 5 and 4 as the case for the U.S. and Germany). This may also mean that wealth in Italy is becoming less and less affordable, other things being equal, as one needs more and more years of income to accumulate assets.

The meaning of net wealth. As remarked in 2007 by the Governor of Bank of Italy, Mario Draghi, "Changes in the functioning of advanced capitalist economies, as well as in the ageing of the population, contribute to shift the emphasis from income to wealth...On account of greater job insecurity or reduced social expenditure, wealth takes on a new significance for household prosperity. Personal wealth has a crucial role in cushioning against life's uncertainties, and the possibility of relying on a buffer stock makes people feel less vulnerable. But the implications are even more far-reaching, as wealth is a crucial determinant of what people can do at the beginning of their lives. For all these reasons, it is imperative that in the future we monitor the evolution of wealth in the same way that we have been monitoring the evolution of income (Draghi, 2007). Wealth holding, by shaping one's current and future consumption and earning potential, represents a unique determinant of the well-being and the living standards of individuals and households. The implications of wealth holding go well beyond the direct effects on consumption opportunities. Specific assets, such as company shares, may convey direct or indirect control over productive resources and, similarly, may also provide substantial power of influence in society as well as a clear mark of status. The level of individual wealth holding also affects risk-taking behavior, and grants or prevents access to specific investment, education, or job opportunities. Hence, the aggregate level of wealth, its composition, and its distribution affect the functioning of the economy and the structure of society, and may also guide the structure of tax policies (e.g., wealth would increase the ability to pay of individuals beyond their relative standing in the income distribution).

The main concept of net wealth used in this paper refers to the current value of all assets, tangible and intangible, that are under the control of the household sector, with the exclusion of the non-profit sector serving households, that provide economic benefits to the holders, and over which property rights can be exercised. The assets may be financial, such as current or savings accounts, stocks, bonds, and life insurance reserves, or real assets, such as land, houses and unincorporated personal businesses (e.g. pass-through businesses). Thus, our definition of personal net wealth is aligned with that of the national balance sheet according to the System of National Accounts (SNA 2008) and the European System of Accounts (ESA 2010). ${ }^{4}$ This definition is grounded in conventional, neoclassical economic

\footnotetext{
${ }^{4}$ The assets recorded in the balance sheets are economic assets, which are defined as "a store of value
} 
theory, where wealth represents a store of value for present and future consumption. It is worth stressing, however, that there is not a unique definition of wealth, and that the methods of valuation matter substantially.

The use of the NA definition bears a number of problems. The first main limitation comes from the fact that the concept of wealth under the SNA excludes certain assets that are particularly relevant for specific groups of the distribution. NA do not fully capture the wealth that households own outside of the country of residence, which may well disproportionally benefit the very top (e.g., foreign real estate, unreported offshore bank deposits, portfolios of financial securities managed by foreign financial institutions, or valuables and works of art held abroad in vaults and "freeports").

Also, NA do not account for social security pension wealth or unfunded defined pensions, which, instead, would likely add to the bottom and the middle of the distribution. Either the inclusion or the exclusion of these assets in the definition of wealth gives rise to a number of conceptual issues. Future benefits from public pensions cannot be disposed of, transferred to other people, or used as collateral, and are not under the control of the rights' holders. In this sense, Saez and Zucman (2016) argue that "although social security matters for saving decisions, the same is true for all promises of future government transfers. Including social security wealth would thus call for including the present value of future Medicare benefits, future government education spending for one's children, etc., net of future taxes" (p. 526). Consequently, when researchers study the distribution of wealth from the perspective of the control over productive resources and the concentration of power, the exclusion of assets which are not under the direct control of individuals may appear as justified. However, this is more difficult to be accepted when the objective is to study the inequality of welfare and the planning of one's life, proxied by the economic resources available for intertemporal consumption purposes; pension assets can have important behavioral relevance as people may substitute future rights with alternative forms of private savings accumulation in order to face future consumption needs (Feldstein, 1974).

Antiques, art, and valuables are included in the SNA definition, but consumer durables (e.g., vehicles, electronic goods, and other household possessions) are not. For the household sector, these are considered within the consumption section of the NA instead. According to the SHIW, the total value of the means of transportation and other durables (furniture, furnishings, appliances) owned by households was $€ 366$ billion in 2016, i.e., $4 \%$ of personal wealth. Such assets are generally more evenly distributed across the population than total net wealth, and their inclusion may reduce the estimated wealth inequality, as we describe further below. ${ }^{5}$

The second main limitation of the SNA is the market valuation of assets: the cash value that can be recovered (and therefore consumed) by selling the asset on a well-functioning

representing the benefits accruing to the economic owner by holding or using the entity over a period of time. It is a means of carrying forward value from one accounting period to another" (ESA 2010, p. 170).

${ }^{5}$ The value is $€ 565.2$ billion according to the "consumer durables" supplementary series estimated in the the National balance sheet for the household sector and the non-profit sector serving households. 
market. Such a valuation method is problematic for assets that cannot be sold, either because a market does not exist or because the asset itself may not be marketable. Indeed, this is a valid qualification for shares of non-quoted incorporated businesses whose value cannot be dictated by the market, as they may never be or have never been sold. In this case, the use of book value (based on the business balance sheet) is a viable option but can lead to the underestimation of the total value of private business wealth, as discussed in Smith et al. (2019). ${ }^{6}$ Similarly, the account balance of defined contribution private retirement plans cannot be sold in the market or easily accessed for liquidation, and are generally transferable to other beneficiaries only in part. However, the accumulated sum of these private reserves is included in the balance sheet as "insurance technical reserves." This class of assets also contains the reserves that insurers are required to hold for future payment of life insurance benefits. Similarly, the reserves held by firms for future payments of severance payments on behalf of workers are also included (in Italy this form of "compulsory savings" is called Trattamento di Fine Rapporto, TFR).

The third important limitation refers to the valuation of the housing stock. Countries do not apply a common methodology for the estimation of real estate in the NA (which gives rise to comparability issues), and the methods employed are less refined than those applied to financial assets. In the case of Italy, housing wealth is "estimated as the product of three factors: a) the number of dwellings owned by households; b) the average floor area in square meters of dwellings; c) the average price per square meter of the dwellings owned by households. The value of housing wealth is then increased by the value of public residential properties sold to households" (Banca d'Italia, 2014, p. 19). ${ }^{7}$

\section{From the wealth of the decedents to the wealth of the living}

\subsection{The inheritance tax in Italy}

The inheritance tax (Imposta sulle successioni e le donazioni) is applied to all worldwide taxable assets inherited, net of liabilities and deductible expenses, from a deceased person domiciled in Italy. ${ }^{8}$ It applies to the amount received by each heir and not to the amount of total wealth left at death, as is the case for the estate taxes levied in the U.S. or the UK. Different rates apply depending on the degree of kinship. For spouses and direct descendants or ascendants, the rate is $4 \%$ above any inheritance share whose net value is higher than $€ 1$ million. ${ }^{9}$ For brothers and sisters, the rate is $6 \%$ above $€ 100,000$. For relatives within the fourth degree, direct relatives in law, side relatives in law within the third degree, the rate is $6 \%$ with no exemption threshold; $8 \%$ applies on all other parties with no exemption

\footnotetext{
${ }^{6}$ The market value of quoted shares of a business operating in the same sector may be helpful to obtain proxy valuations. Similarly, current earnings can be multiplied by a price to earning ratio relevant for a public firm with similar characteristics and operating in the same sector.

${ }^{7}$ The value of housing can be further separated from the value of the underlying land, which can account for the largest share of the valuation of the stock. Very few countries report the land value separately from that of the housing stock (the UK is one).

${ }^{8}$ Only the net value of assets located in Italy is included in the tax base in the case of a person not deemed domiciled in Italy for tax purposes.

${ }^{9}$ In the presence of a disabled heir the tax-exempt threshold is $€ 1.5$ million.
} 
threshold. The same rates and structure correspond to inter vivos gifts. ${ }^{10}$ Until 2016 the exemption threshold was reduced in an amount equal to the capitalized lifetime donations received by each heir from the same deceased. This provision (called coacervo) limited the scope for avoidance of the tax by means of gifts by integrating the taxation of gifts and inheritance. $^{11}$

The administration of the tax is linked to the upkeep of the cadastral register, as other taxes are due on transactions of real estate rights (e.g., registration duty as well as mortgage and cadastral taxes). This administrative feature, combined with high homeownership rates, means that the inheritance data cover more than $50 \%$ of the decedents for every year under investigation, even when the inheritance tax was abolished between 2001 and 2006. The coverage rate was $63 \%$ in 2014 , the highest on record. ${ }^{12}$ A variety of exemptions permit the reduction of the effective tax bill beyond the statutory description. Indeed, many asset transfers are not subject to taxation: reserves accumulated in private pension, life insurance funds, shares of family business passed to a surviving spouse or direct descendants, postal saving bonds, and government bonds. The tax-exempt status implies, in many cases, but not always, that such holdings are not reported in the tax returns and need to be partially or fully imputed. The treatment of tax-exempt assets is discussed in the next section.

The period under investigation witnessed substantial changes to the tax code. Three major reforms were enacted in 2000, 2001, and 2006. Before 2000, the tax was a mix between a progressive estate tax (with marginal rates ranging from $3 \%$ to $27 \%$ ), and an inheritance tax (with a further graduation of marginal rates up to $33 \%$ ) that applied only to recipients different from the spouse and direct relatives. ${ }^{13}$ In 2001 the inheritance and gift taxes were abolished, followed by a reintroduction in 2006 .

\subsection{The inheritance tax data}

Data used in this paper come from the universe of inheritance tax returns, referred to as "successions" opened between 1995 and 2016 (evaluated at the year of death). The tax return is filed by the estate executor (one of the heirs, or a legal representative) within twelve months of the death and submitted to the tax office in the province where the deceased

\footnotetext{
${ }^{10}$ In 2000 and 2001, the gift tax rates were 1 percentage point lower than the inheritance tax rates.

${ }^{11}$ It is not yet clear if this provision is still in force, as the supreme court issued non-unanimous judgments on this between 2016 and 2019. A system purely based on lifetime capital receipts, irrespective of the identity of the donor, would be more effective in reducing tax avoidance. Indeed, currently a single heir can receive different inheritances and still pay zero taxes as long as each inherited share is below the exemption threshold. It is also important to note that in case the coacervo is definitively abandoned by the jurisprudence, inheritance tax avoidance schemes through inter vivos gifts will be substantially easier.

${ }^{12}$ The coverage rate dropped to $61 \%$ in 2015 also due to unexpectedly high mortality rates in that year. Total deaths in 2015 amounted to 648,000, approximately 40,000 above the average number of deaths in 2012-2016. The relative (small) decline of the coverage rate after 2014 may also be due to a change in legislation (passed at the end of 2014) that increased the non-filing threshold from 50,000 Italian Lira (i.e., $€ 25,823)$ to $€ 100,000$ (the threshold defining the net value above which the filing is required for those estates without any real estate properties or rights).

${ }^{13}$ In October 1999 the first tax bracket was eliminated and the tax exemption threshold increased from approximately $€ 125,000$ to $€ 175,000$.
} 
had residence. ${ }^{14} \mathrm{~A}$ dedicated official at the local branch of the tax authority processes the returns in order to assess the tax liability. At the same time, legal proof of ownership and third-party assessments of asset valuation are often required, enhancing the accuracy of the information and reducing the scope for tax evasion. ${ }^{15}$

We determine the net wealth of the decedent by adding all reported financial and real assets and subtracting all liabilities. We also add the market value of assets sold within six months from death, which was reported between 1990 and 2000; this is typically negligible and does not affect the results.

The microdata were transformed into detailed tabular form by the statistical office of the Ministry of Economics and Finance and shared with us. The tabulations have 34 net wealth ranges, from negative values to the highest range worth $€ 20$ million or more. The demographic information is provided by seven 10-year age groups, three gender groups (i.e., males, females, and gender not stated), and three geographical areas (south and islands, north, and center). Four asset classes are identified: Housing and land; business assets, equity, and debt securities; other assets (including current and saving deposits, valuables, etc.); and liabilities and deductible expenses. ${ }^{16}$ The data, therefore, lump together business assets (a form of real assets) with financial assets.

\subsection{The application of the mortality multiplier method}

The distribution of the taxable wealth of the decedents, provided by the inheritance tax data, is different from that of the wealth of the living. A number of adjustments are required: differential mortality multipliers have to be applied to transform the estate data into estimates of wealth-holding; an estimate of the wealth of those not covered by the tax (the missing wealth of the missing/non identified population), as well as that of the exempted assets, is necessary; and real estate valuation has to be converted from cadastral to market prices.

Re-weighting the population of the deceased. The inheritance tax returns are mandatory only if rights on real estate are transferred at death, or if the net value of the estate of the deceased is above $€ 25,000$. Hence, only a fraction of total deaths are observed in

\footnotetext{
${ }^{14}$ The time limit was 6 months until 2003. The last data update in this paper was obtained in May 2020. A set of 2,600 tax returns presented in 2018 with the new electronic form, but related to deaths occurred in 2016, were included in the data. In principle, there could be a very small number of tax returns submitted or revised even 10 or 20 years after death as more precise information about the estate comes to light, but these amendments are not taken into account in the statistics. Every year-specific database becomes consolidated for our purposes if two years have passed since the year of death.

${ }^{15}$ For instance, financial institutions need to certify the balances of all accounts; the cadastral office certifies the cadastral value of buildings, land, or dwellings; a certified copy of the most recent balance sheets needs to be attached to prove the book value of any company; and the official certification of ownership of quoted stocks should also be provided. Similarly, all the expenses and liabilities that are reported for deduction purposes need to be appropriately documented.

${ }^{16}$ Starting from 2017, the paper module for inheritance tax returns has been gradually replaced by an electronic form that includes a considerable amount of additional detail about the composition of the estates.
} 
the tax records: in 2013, 365,000 estates out of 600,000 adult deaths. Although incomplete, such coverage, is very high compared to evidence in other rich countries: in the UK, this number is below $50 \%$, whereas in the U.S. it is lower than $0.5 \%$.

In 1995, 30 percent of estates belonged to individuals aged 80 years old and above; the number has grown to 60 percent in recent years. Similarly, males are over-represented across all age groups, except the oldest group. To re-weigh the decedent population we apply mortality multipliers, obtained by inverting the mortality rates, which are therefore treated as if they were sampling rates of the living population. The application of mortality multipliers has a long tradition in economics and statistics and leads to the derivation of the identified wealth and population (for a description of the method, see Atkinson and Harrison, 1978). We use detailed annual mortality tables published by the Italian Statistical Institute (ISTAT), available for each age, gender, and geographical location. ${ }^{17}$ Given the large number of decedents covered, the re-weighting of inheritance records allows the method to account for a substantial fraction of the living population (50\%) and personal net worth $(80 \%$ of the NA in recent years, and 65-70\% in the mid-1990s), and this only including the correction of the market price of housing assets. The total net wealth in the SHIW, representative of the entire population, is very similar to that identified from tax records between 1995 and 2006 ; however, it only accounts for $65-70 \%$ of the NA total afterwards.

The valuation of real estate. The value of land, buildings, and dwellings is reported at cadastral values for tax purposes; this generally underestimates market prices. ${ }^{18}$ In order to overcome this problem, we have applied, with the support of the statistical office of the Ministry of Economy and Finance, a proportional adjustment to bring the cadastral values in line with market ones. The yearly adjustment factor is defined as the ratio of the (average) market price and cadastral valuation at the national level. ${ }^{19}$ This procedure generates a total housing and land stock very close to the national balance sheets (see Figure $3(\mathrm{~b})$ ). The average estate, valued at market prices, as reported in the tax records and after the adjustment of cadastral values, increased from $€ 209,000$ in 1995 to $€ 332,000$ in 2007; it remained relatively constant until 2012, and then started to decrease to approximately $€ 293,000$ in 2016 (2016 prices).

Due to the prevalence of homeownership in Italy, the number of inheritance tax filers who declare real estate assets is above $90 \%$. Similarly, the declared estate value is also mostly composed of real estate assets: Whereas $91 \%$ of estates were composed of housing and land in 1995, this fraction declined to $78 \%$ in 2016 . This is also the result of the tax exemption of a number of financial assets. However, the high share of housing and land does not mean that our data are not able to capture large financial wealth holdings at the very top of the wealth distribution. Indeed, as reported in Acciari and Morelli (2020), "the relative composition of declared portfolios changes drastically depending on the size of the

\footnotetext{
${ }^{17}$ Appendix D provides the description of the mortality data. We also give a more detailed discussion about how mortality multipliers affect the age distribution of wealth holdings.

${ }^{18}$ This is particularly the case for older buildings whose value typically has not been updated for many decades. The likely sell-up value is reported only for those buildings under construction or for those for which no cadastral rent has been attributed yet.

${ }^{19}$ See Appendix E.
} 
estate.... In 2016, only $10 \%$ of total gross estate is composed of housing and land for the group of richest $0.01 \%$ of total decedents, a group whose total declared net estate is at least $€ 17$ million. For this group, nearly $90 \%$ of total gross estate value is held in financial securities and privately held business assets. Meanwhile, for estates below the 99th percentile, housing and land account for at least $75 \%$ of total gross estate value."

The wealth of the missing population. The tax data are representative of the living adults whose wealth arrangements are such that they come to the notice of the tax authority in the event of their death. The need to estimate the amount of missing wealth (i.e., wealth held by those not identified by the tax records, some $50 \%$ of adults) is a necessary step if we want to assess the size and the distribution for the entire population. The SHIW is the basis for this. In order to be consistent with the distribution at the individual level, we allocate household wealth to adult members of the household. ${ }^{20}$ The missing population is taken as that of non-homeowners, with net wealth below the reporting threshold for the tax (the number of homeowners in the SHIW and the population identified via the mortality method, for each age class, is very close). ${ }^{21}$ The working assumption here, following the tax code, is that such individuals and their wealth holdings are likely not to be represented in the inheritance tax records in the event of death.

The estimated missing population and their wealth holding are appended to the multipliedup tax data. The total population thus derived turns out to be slightly smaller but extremely close to the population within each age class above 20 years old in the SHIW. The remainder (mostly young people) is assumed to own zero net wealth. Additional marginal adjustments warrant that the final numbers are in line with the SHIW by age, gender, and location.

Tax-exempt assets. Italian legislation grants full exemption to financial assets invested as private pension and life insurance funds, postal saving bonds (i.e., Buoni Fruttiferi Postali), and a number of national and extra-national government securities. ${ }^{22}$ The list of exempted assets also includes vehicles in the national registry, credits towards the state, properties that are listed as cultural and historical heritage, and all family businesses and control shares of companies that are transferred to direct descendants or to a spouse. ${ }^{23}$ The value of tax-exempt assets considered here, imputed to the population, is taken from the NA

\footnotetext{
${ }^{20}$ The transformation from household to personal wealth is described in Appendix K, and follows D'Alessio, 2018.

${ }^{21}$ To account for underreporting of wealth in the SHIW, we also proportionally adjust reported wealth in the survey data using the ratio of wealth values between the balance sheet and SHIW. This is done for each asset class that is available both in SHIW and in the balance sheet for the household sector only.

${ }^{22}$ There are now 134 countries whose tax authorities have "adequate" exchange of information with Italy. As a result, these countries are included in the so-called "white list," necessary to get access to more favorable tax treatment.

${ }^{23}$ The tax exemption status is valid under the condition that the business is run and the control share is maintained for at least 5 years from the wealth transfer at death. Nonetheless, and similarly to what happens to any real estate rights, the value of business assets has to be reported in the inheritance tax returns and will be deducted from the final liability. The remaining exempted assets are generally not reported on tax records. It is also worth mentioning that inherited or donated assets of any kind may be fully exempted if the recipient belongs to one of these categories: religious entities, NGOs, political parties, state, regional or local authorities, and research institutions.
} 
household sector balance sheet as the value of insurance technical reserves net of their liabilities (i.e., the total value of assets accumulated in pension, life insurance, and severance payment funds), plus $50 \%$ of Italian government securities. Indeed, the reporting of government bonds is often advised by tax accountants and frequently occurs in those cases where securities are bundled with other assets within investment funds (e.g., banks and other financial intermediaries are required to provide detailed descriptions of investment funds and accounts following death of a legal owner). Such investment bundles can be fully reported on the inheritance tax form, and the tax authority would then compute the relevant tax deductions. ${ }^{24}$

Trusts. Trusts are not taxable under the inheritance tax, as the property of the settled assets is transferred from the settlors to the trustees. Very little is known about the amount of wealth held in trusts in Italy, but their use is not as widespread as in the U.S. or the UK. Using the universe of income tax files, we have capitalized the reported capital income from trusts (Redditi da capitale imputati ai trusts) using similar rates as in Kopczuk and Saez (2004) for the U.S. and in Alvaredo et al. (2018) for the UK, getting a total of $€ 200-300$ million. ${ }^{25}$ This is a very small amount, and we do not impute it to the population.

Liabilities. The concept of net worth used in this paper subtracts all liabilities from real and financial assets. The existence of very high tax exempt thresholds reduces the incentive for detailed reporting of liabilities for most of the (non-taxable) estates. To overcome this limitation, in our benchmark series, the unobserved value of liabilities reported in the national balance sheets is imputed proportionally to the population according to the distribution of liabilities reconstructed from the tax data, complemented with observations about the missing population, using the survey data as described above.

A less relevant limitation of tax records comes from the fact that liabilities may be reported together with deductible expenses, which include the costs of a funeral or medical treatments paid by the heirs during the last six months of the deceased person's life. It is not possible to appropriately add the deductible expenses back to the value of the individual estate, but the entity of these expenses is negligible (e.g., only a small fixed amount of funeral costs that can be deducted for tax reasons but no specific threshold is specified for health related costs).

\subsection{Combining different sources of data}

The process of adding the wealth of the identified population (including the price adjustment to real estate), the wealth of the missing population, and the imputation of exempted assets, shown in Figure 3, generates a total wealth that is between $80 \%$ and $100 \%$ of the balance sheet of the household sector in the NA, with very similar trends.

In seeking to align the benchmark series to the National Accounts, the remaining gap

\footnotetext{
${ }^{24}$ We consider $100 \%$ of government securities during the years where the estate, gift, and inheritance tax was not in place (e.g., the period included between October 2001 and October 2006).

${ }^{25}$ The rate of return used in the capitalization exercise is $5.6 \%$.
} 
Figure 3: Total personal net wealth and total gross housing and land wealth: from inheritance tax records to National Accounts

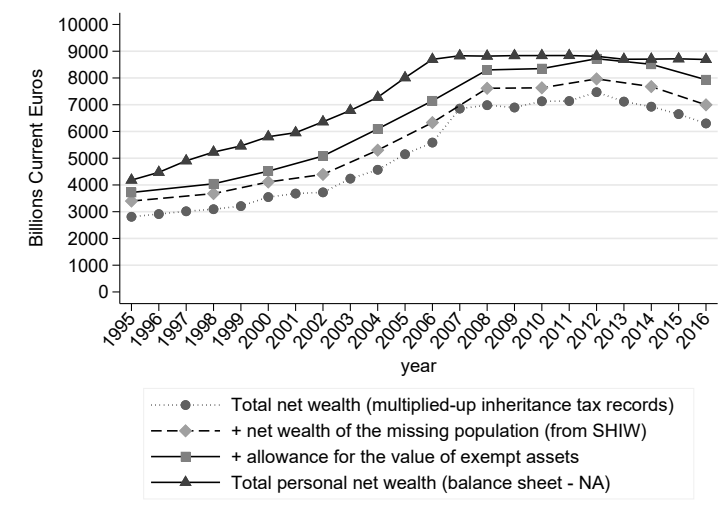

(a) Total personal net wealth

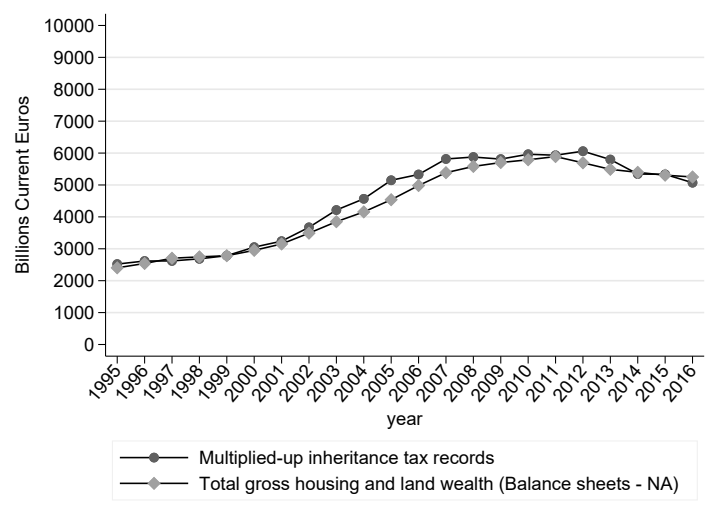

(b) Gross housing and land wealth only

Note: Panel (a) compares the different wealth aggregates, from that identified using the estate multiplier method (scaling-up the reported wealth at death), to the total net wealth of the household sector from the national balance sheets. Panel (b) compares the total gross value of the housing and land stock as identified from the inheritance tax records to that reconstructed from the balance sheet of the household sector from the NA.

of total assets and liabilities must be imputed. This benchmark approach is justified on the grounds that the NA provide a reasonable indicator of the development of wealth over time, preserving a high degree of cross-country comparability, not on the assumption that the NA give the correct numbers. On the one hand, the imputation of the wealth gap is a controversial exercise, riddled with difficulties and uncertainty. On the other hand, the adjustment to NA is advantageous in as much as it deals indirectly with any residual misreporting, mis-valuation, or tax avoidance and evasion ignored in the previous steps. In any case, it should be stressed that some of the difference between NA and other wealth data sources are rooted in definitional issues and not on quantitative misalignment only.

For all these reasons, we will also discuss how estimates behave once we deviate from the benchmark in a variety of ways (e.g. excluding imputations). This type of exercise is not commonly reported in existing studies of wealth inequality, but we argue that it is essential to increase transparency about how final measures of concentrations are derived, and should not be relegated to a marginal appendix.

\section{The growing inequality of wealth holdings}

\subsection{Benchmark series}

One of the immediate advantages of our benchmark approach, similar to what can be done with household surveys as opposed to the strict application of the estate or the capitalization methods, is the possibility of analyzing the size distribution for the whole population. 
Our data can be used to observe how the shape of the wealth distribution has changed over time. Figure 4 shows that the Lorenz curve shifted outward from 1995 to 2016 (panel (a)), and also plots the difference between these two curves over time (panel (b)). The difference is always negative for every wealth group, as the Lorenz curve in 2016 always lies below that of 1995. Therefore, any possible standard indicator would point to the same direction: wealth inequality has increased in Italy over the time period considered. ${ }^{26}$

Figure 4: Increasing wealth inequality over time

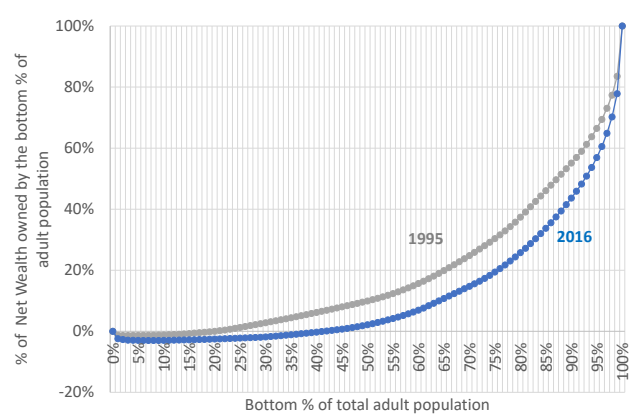

(a) Lorenz curves: 1995 and 2016

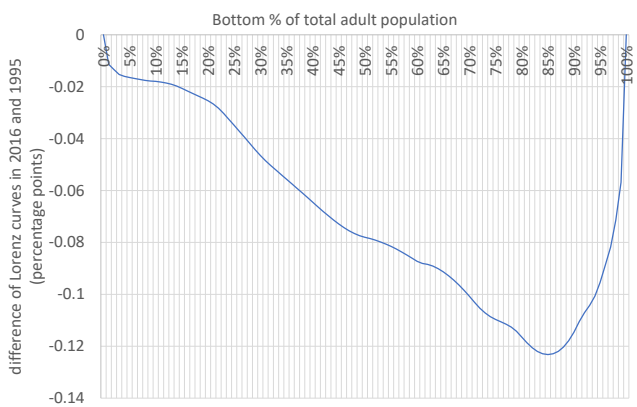

(b) Difference between Lorenz curves: 2016-1995

Note: Panel (a) compares the Lorenz curves in 1995 and 2016. Panel (b) shows the difference between these two Lorenz curves.

We can illustrate this point with the evolution of the Gini coefficient, which recorded a 14 percentage point increase, from $62 \%$ in 1995 to $76 \%$ in 2016 . A practical interpretation considers the change in the net wealth per adult, which increased from $€ 137,000$ to $€ 176,000$ over the same period: this means that if we take any two adults from the population at random, the expected difference of their wealth holding increased from $€ 171,000$ to $€ 268,000 .{ }^{27}$ This is a substantial change if compared with alternative available from the SHIW. Cannari and D'Alessio (2018) show a Gini of per capita wealth that has very similar levels to our benchmark estimates for the mid-1990s and remains relatively flat throughout the period (see also Figure 7).

We can zoom in on the upper wealth brackets. The top $1 \%$ (adults with at least $€ 1.5$ million approximately and average net wealth holdings of $€ 3.8$ million) controlled about $22 \%$ of net wealth in 2016, a share that has increased by 6 percentage points since 1995 (Figure 5). Panels (a) and (b) of Figure 5 also demonstrate the importance of looking within

\footnotetext{
${ }^{26}$ This result follows from Atkinson et al. (1970) under the simple condition that the inequality indicator considered is consistent with the Pigou-Dalton principle of transfers. Such principle requires, loosely speaking, that any transfer that takes from the rich and gives to the poor, under the condition that the rich remain richer than the poor, would lead inequality to decrease.

${ }^{27} \mathrm{~A}$ Gini coefficient of $\mathrm{G}$ percent means that, if we take any two individuals randomly, the expected difference is $2 \mathrm{G}$ percent of the mean. A rise in the Gini coefficient from 50 to 70 percent implies that the expected difference has gone up from 100 to 140 percent of the mean.
} 
Figure 5: The evolution of top wealth shares. Italy 1995-2016

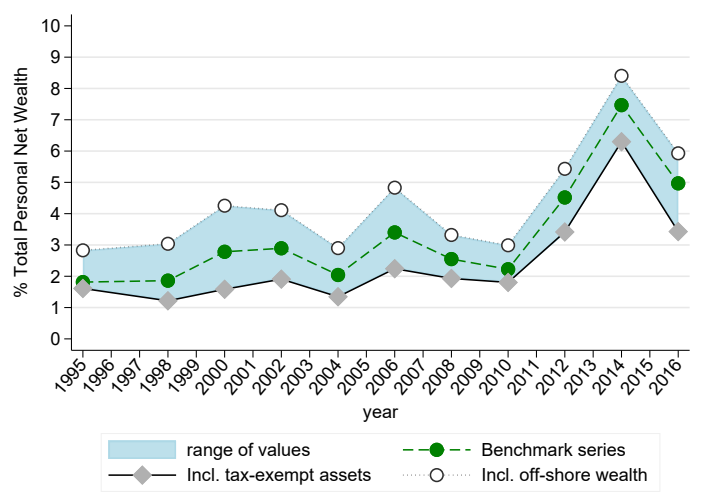

(a) Top $0.01 \%$

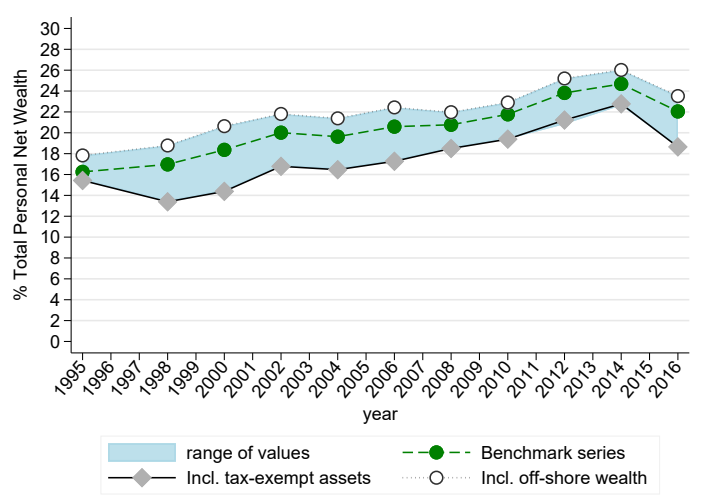

(c) Top $1 \%$

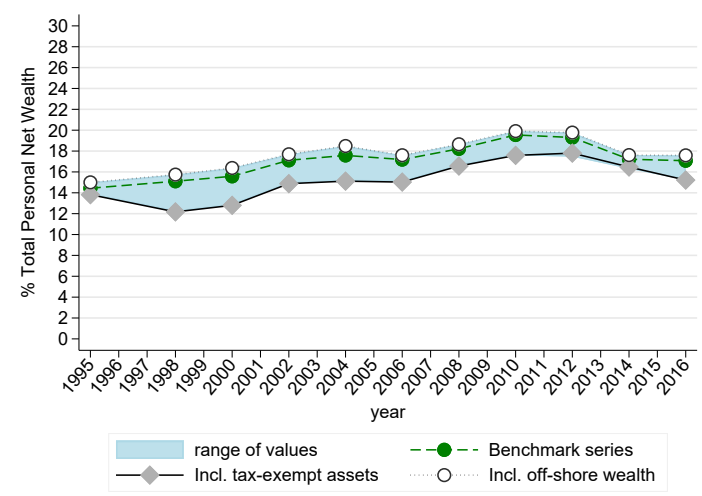

(b) Top $1-0.99 \%$

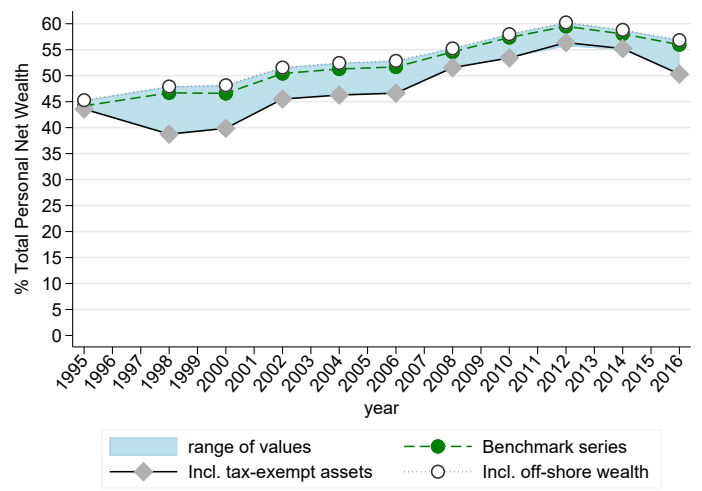

(d) Top $10 \%$

Note: The graphs show the evolution of the shares of total personal net wealth for four subgroups of the adult population between 1995 and 2016. Each panel shows three series. The middle line is the benchmark

(distribution of balance sheets). The lower line only allows for tax exempt assets before adjustment to

National Accounts. The upper line includes the imputation of unreported offshore financial assets after adjustment to NA.

the top $1 \%$, as top groups are highly heterogeneous. The share of the top $0.01 \%$ more than doubled between 1995 and 2016, increasing from $1.8 \%$ to $5 \%$. Such a tiny group held 500 times their proportionate share in 2016, with a minimum net worth of approximately $€ 20$ million and average net worth of $€ 83$ million, approximately equivalent to 470 times the average net worth. The share of those in the top $1 \%$ but not in the top $0.01 \%$ has been rising gradually from 1995 to 2012 , going from $14.4 \%$ to $19 . \%$, before declining again and stabilizing around $17 \%$.

The ranges of values depicted in the figures (they are not confidence intervals in the statistical sense) signal that the adjustments required to reach the benchmark series are not the only ones that can be adopted. Yet, the estimated wealth concentration and its evolution is rather robust to the inclusion or exclusion of our adjustments to the data. The 
upper limit represents the top share including the allowance for unreported financial assets held in offshore tax havens. The bottom of the range, instead, represents the top share estimated with inheritance tax records including only the adjustment for tax exempted assets and using a consistent external total (e.g., independent from the reported wealth in the tax records).

Unreported offshore wealth. A fraction of financial wealth remains unreported or unrecorded in official statistics and tax agencies. Zucman (2013) argued that this represents $10 \%$ of world GDP. With related procedures, Pellegrini et al. (2016) estimated the total value of undeclared debt and equity securities in Italy to be $€ 161.4$ billion in 2007, excluding the value of undeclared bank deposits. In order to consider a less incomplete measure of financial assets held offshore, we add to this number the amount of undeclared bank deposits held by the non-banking sector in offshore centers as also reported in Pellegrini et al. (2016) (based on the cross-border banking statistics released by the Bank of International Settlements). For this, we assume that half belongs to individuals, and allocate to Italy the country's share of global GDP. ${ }^{28}$ The resulting estimate of unreported financial wealth held offshore by Italian investors is $€ 187.2$ billion in 2007 , or some $2-3 \%$ of personal wealth. ${ }^{29}$ This is extrapolated backward and forward according to the the evolution of the European offshore financial wealth given in Alstadsæter et al. (2018), to cover the period 1995-2016.

If we assume that the share of undeclared wealth as well as its relative distribution across the wealth distribution in Italy is the same of what was estimated for Denmark and Norway by Alstadsæter et al. (2019), then the share held by the top 1\% increases by 1 to 2 percentage points throughout with respect to the series before this adjustment. This is a sizable effect that becomes even more visible at the very top. The richest one in one thousand individuals saw their share increase by approximately $65 \%$ in 1995 (from $1.8 \%$ to 3\%) and by $14 \%$ in 2016 (from $5 \%$ to $6 \%$ ). The inclusion of unreported offshore financial wealth is surrounded by much uncertainty, however, it does not appear to substantially affect the trend of the wealth concentration over the period of investigation.

\subsection{Comparison with other countries}

Estimates of wealth concentration that are comparable to our benchmark series currently exist for a handful of countries, namely France, Germany, Spain, and the U.S. (the comparison with existing country series that do not follow the strategy of up-scaling to the NA is given in Figure 15(b)). Figure 6 displays three concentration indicators: top 10\%, bottom $50 \%$, and middle $40 \%$. Italy, in the mid-1990s, had one of the (relatively) best-positioned middle $40 \%$ groups, and one of the lowest concentration levels. Similarly, the bottom 50\%

\footnotetext{
${ }^{28}$ The same share was assumed in Johannesen and Zucman (2014) and appears consistent with more recent works by García Luna and Hardy (2019) who found that at end-March 2019, households (including nonprofit institutions serving households) accounted for $51 \%$ of Swiss banks' cross-border liabilities. In the same work, if considering all the countries in the sample, households account for only $14 \%$ of banks' cross-border liabilities.

${ }^{29}$ Incidentally this is very similar to the 2007 value reported for Italy in Alstadsæter et al. (2018), €191.3 billion, or $\$ 262.2$ billion USD.
} 
held $12 \%$ of wealth in 1995 compared to $8 \%$ in France, $7 \%$ in Spain, 5\% in Germany, and $1 \%$ in the U.S. Twenty years later, Italy appears to have experienced the largest drop in total wealth held by the bottom $50 \%$, and, although the levels of wealth concentration are now closer to other European countries, its relative increase over time bears more similarity to the dynamics of the U.S. However, the middle $40 \%$ in Italy controls approximately $40 \%$ of total net wealth compared to around $30 \%$ in the U.S.

The notable decline in the share of the bottom 50\% may seem surprising from the perspective of the given international comparison. However, it is consistent with the large increase in aggregate wealth together with the fact that such group has not benefited proportionally from the elements pushing upwards the average wealth: they own at best zero-return financial assets, have very little net real estate, or are heavily indebted mortgage-wise. The stability of the bottom $50 \%$ share in Spain and France is likely the mechanical result of the different treatment applied in those studies: wealth bottom-coded at zero (no negative wealth), and smoothing in the lower part of the distribution.

Figure 6: Wealth concentration: a cross-country comparison

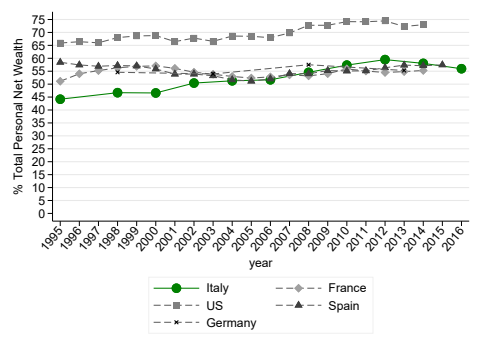

(a) Top $10 \%$ - time series

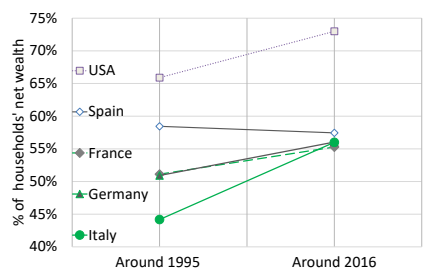

(d) Top $10 \%$ - summary

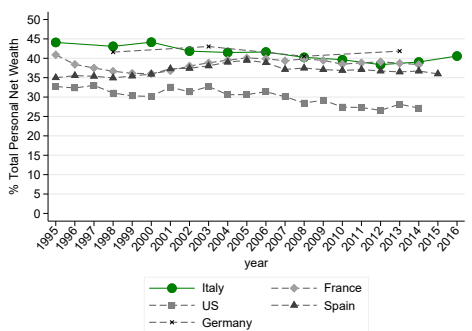

(b) Middle $40 \%$ - time series

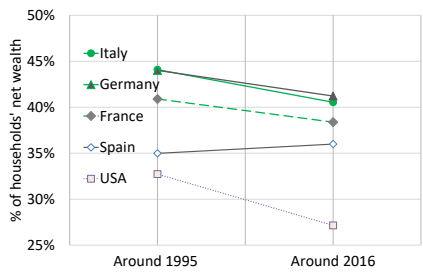

(e) Middle $40 \%$ - summary

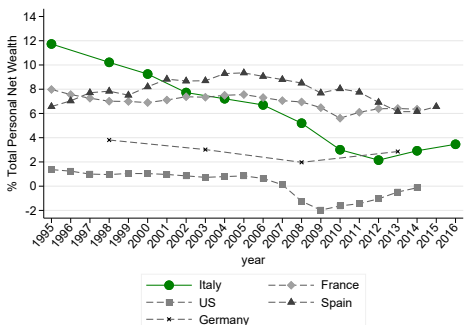

(c) Bottom 50\% - time series

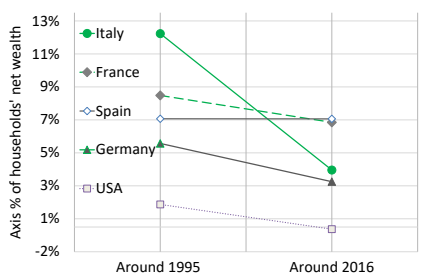

(f) Bottom 50\% - summary

Note: The figure compares the evolution of wealth inequality from around 1995 to around 2016 for countries for which we have series comparable to our benchmark. Italy is based on the authors' results, Spain comes from Martínez-Toledano, 2017, France from Garbinti et al., 2016, Germany from Albers et al., 2020, and the U.S. from Saez and Zucman, 2016. "Around 1995," refers to 1995 for all countries except Germany (for which it refers to 1993). "Around 2016" refers to 2014 for France and the U.S., to 2015 for Spain, to 2016 for Italy, and to 2018 for Germany. 


\section{Triangulation with other sources}

We now consider external evidence to assess the reliability of our estimates of the concentration of wealth in Italy. We provide series based on a variety of sources, from household surveys to rich lists and banking sector reports.

Household surveys. Household surveys provide essential information about the distribution of wealth inequality, especially when assets registries and comprehensive individual capital income data are absent or not easily accessible, as for the case of Italy. The SHIW has existed in Italy since 1989. The comparison with tax data requires changing the unit of analysis, moving from households to individuals. Household wealth needs to be allocated to each adult member using the relevant information from the survey questionnaire, as done in D'Alessio (2018) and mentioned in Section 3.3. Furthermore, to bring the estimate in line with our wealth concept, an estimate of private insurance funds and pension assets are added to individuals declaring payments of any insurance premium or private pension contribution. As shown in Figure 7, moving from the household to the individual reduces the share of the bottom $50 \%$ by 5 percentage points (panel (b)), a large change, and increases the share of the top $1 \%$ by 2 percentage points (panel (a)). The concentration at the top is only marginally different if we adopt the more approximate methodology of splitting household wealth equally among the head of the household and his or her partner (equal-split series).

The level and dynamics of wealth concentration are very similar across tax- and surveybased estimates until 2000, when they begin to diverge. According to the SHIW, the top $1 \%$ share remained roughly constant between 1995 and 2016, whereas it increased by approximately 6 percentage points according to our benchmark $(7(\mathrm{a}))$. This is not surprising, as household surveys are not necessarily well-suited to capturing the right tail of a very skewed wealth distribution, for a variety of reasons. First, in the presence of "fat tails" distributions, such as the distribution of wealth, a random sample may not be fully representative of all wealth groups, especially if the sampling frame of the survey does not allow for the oversampling of wealthy households, as it is the case for the SHIW. Second, even if very wealthy households were appropriately sampled, they might have a higher rate of nonresponse, as they may be harder to find or trace by interviewers (e.g., living in multiple residences, conducting busy working lives, and/or being more mobile), or they may be less willing to cooperate to reveal their complex asset portfolios. The compliance rate may well be lower at the top of the wealth distribution, distorting the estimation of inequality indicators (Kennickell, 2019, Korinek et al., 2007, Muñoz and Morelli, 2020). Indeed, the SHIW identifies fewer people and less wealth for the wealthiest ranges of the distribution compared to our multiplied-up estates from inheritance tax records. Total personal wealth recorded in the survey amounts to $60 \%$ to $70 \%$ of the balance sheets despite its implicit coverage of total population. Therefore, underreporting of different types of assets and liabilities, as well as coverage issues, may also apply to the middle and bottom ranges of the wealth distribution. 
Figure 7: Gini coefficient, Top 1\%, and Bottom 50\% shares in total wealth: comparing results with household survey data

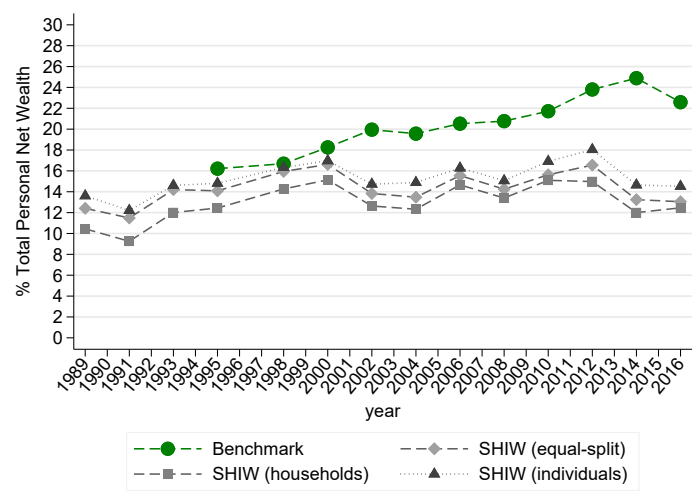

(a) Top $1 \%$

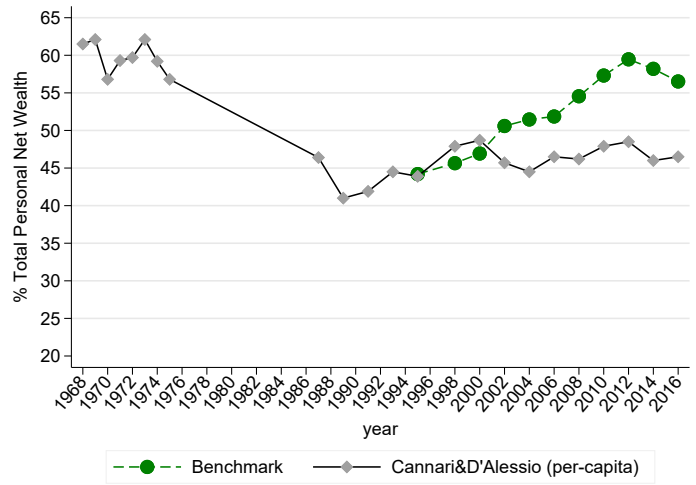

(c) Top $10 \%$ - in the long-run

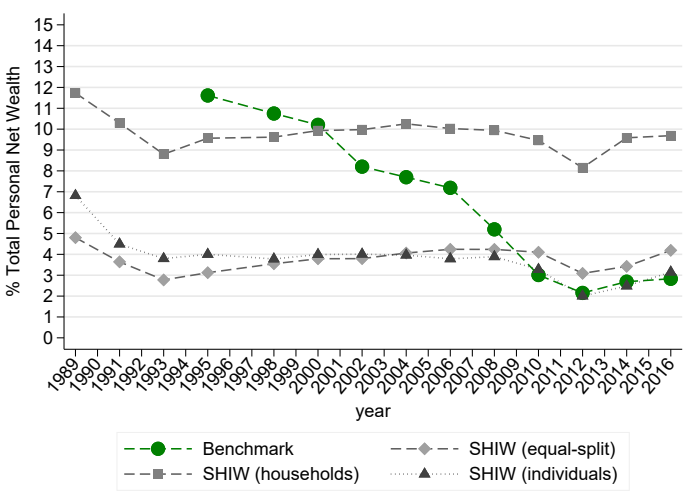

(b) Bottom $50 \%$

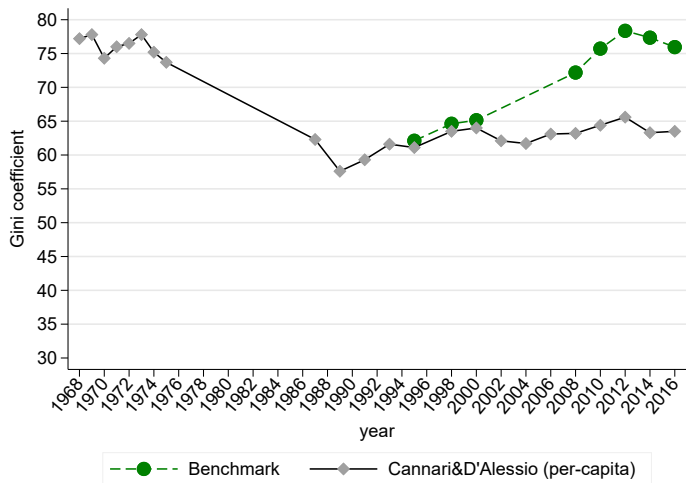

(d) Gini coefficient - in the long-run

Note: Panels (a) and (b) show the evolution of the top $1 \%$ and bottom $50 \%$ shares from household surveys (SHIW) compared to our benchmark series. The comparison requires adjusting the wealth concept and the unit of analysis (individuals). Panel (c) compares the evolution of our benchmark series of the top $10 \%$ with that from Cannari and D'Alessio (2018) based on the combination of the SHIW and historical surveys from 1968 to 1975 . 
Most notably, the share of the bottom $50 \%$ is almost identical in both sources since the mid-2000s. However, as shown in Figure 7(b), before 2004 the share held by the bottom $50 \%$ is substantially higher in our benchmark series as a result of the full imputation of net wealth reported in the balance sheet of the household sector. This stresses the need for better data to assess low-end segments of the wealth distribution, not just the high-end, as generally noted. The latter result could to be driven in part by the inability of the survey to appropriately account for the most important form of assets for the lower groups, namely currency, deposits, and valuables. In our derived benchmark series, they constituted more than $50 \%$ of the wealth of individuals with less than $€ 15,000$, that is, a substantial part of the bottom $50 \%$.

Rich lists and banking sector reports. Forbes magazine gives information on Italian billionaires; only 5 individuals were recorded in 1988, and 35 in 2019. It is not easy to assess the representativeness and reliability of these lists. The data are often based on journalistic estimates that can be subject to several types of errors, and the methodology cannot be evaluated. According to Vermeulen (2017), parametrically adjusting the SHIW with the extreme observations from the rich list increases the top $1 \%$ share by $6-7$ percentage points from a level of around $14 \%$ in 2010. Applying similar methods and data from the Forbes World's Billionaires, Davies et al. (2017) imputed the "missing" upper-end wealth tail to household survey data for many countries beginning in 2000. The exercise is also carried out, on an annual basis, for the Global Wealth Report by Credit Suisse; their estimates appear to be in line with our benchmark series, at least since the mid-2000s. Figure 8(a) shows this for the top $1 \%$.

We can track the share of total net wealth held by the Forbes richest 5 or 10 individuals, since 1988 and 2000 respectively. As shown in Figure 8(b), a group whose size is a thousand times bigger (the top $0.01 \%$ represents 5,000 individuals) holds a share ten times higher. The dynamics of the Forbes list broadly concurs with our benchmark series. The 5 wealthiest Italians almost tripled their share of total wealth from the mid-1990s to 2016, from approximately $0.2 \%$ to $0.7 \%$ (and the share remained at a similar level till 2019); the share of the top $0.01 \%$ went up too, from $\% 2$ to $7 \%$. 
Figure 8: Triangulation of the evidence with external data series

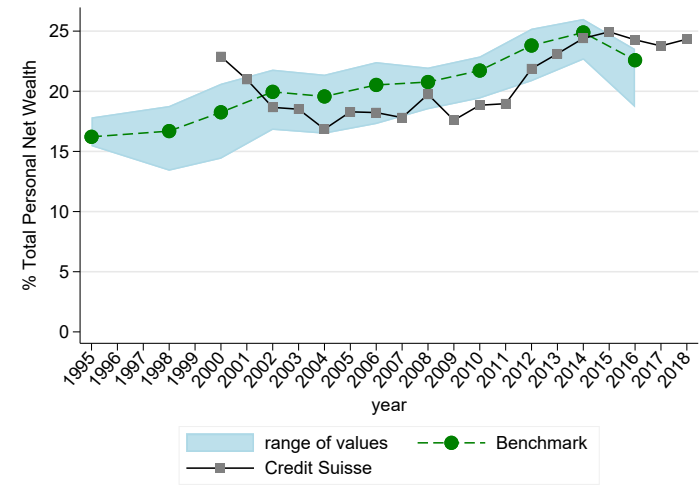

(a) Top $1 \%$ in Credit Suisse data

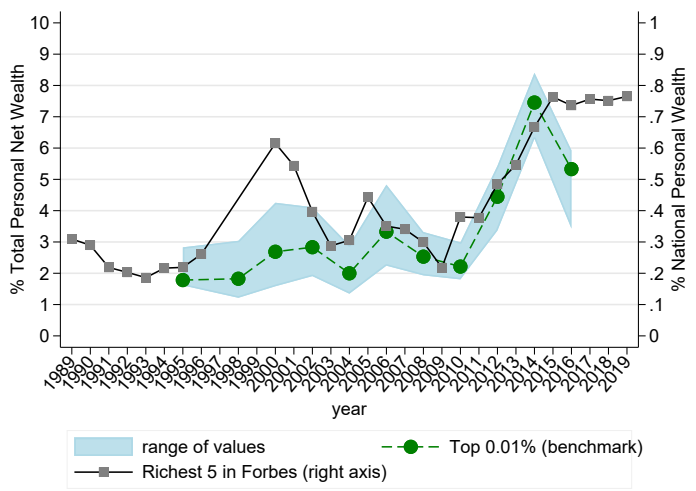

(b) The wealth share of 5 richest Forbes billionaires

Note: Panel (a) compares the top 1\% share of wealth from our benchmark series, from the Credit Suisse Report (combining SHIW data and Forbes rich list). Panel (b) compares the top 0.01\% share of wealth from our benchmark series with that of the 5 richest individuals listed in the USD global billionaires rich list by Forbes.

\section{Determinants of wealth concentration}

Identifying the precise channels affecting the evolution of wealth inequality is a fundamental question that has important implications for policy but remains broadly unanswered. Recent work in the U.S. has emphasized that wealth inequality can be fueled by differential saving rates coupled with a growing level of income inequality (Saez and Zucman, 2016). As discussed in Fagereng et al. (2019), richer households mostly "save by holding," "meaning that they tend to hold on to assets experiencing persistent capital gains." Indeed, a growing body of evidence stresses the importance of the heterogeneity of portfolio composition, asset prices, and rates of return across the wealth distribution (Advani et al., 2020, Alvaredo et al., 2018, Benhabib et al., 2017, Fagereng et al., 2020, Kuhn et al., 2020, Martínez-Toledano, 2020). Beyond these factors, individuals also differ in the extent of wealth transfers received via gifts and inheritances throughout their lifetimes, as stressed in Feiveson and Sabelhaus (2018). A growing amount of evidence suggests that the receipt of large inheritances may have a dis-equalizing effect on wealth distribution, especially in the long-run (Nekoei and Seim, 2018, Nolan et al., 2020). Reality is complex and certainly involves all the aforementioned elements, and others too. For instance, the recent work by Hubmer et al. (2020) highlights how the decline of the progressivity of income taxes could explain the most important part of the dynamics of US wealth concentration since 1980s. Other macroeconomic factors may well be very important too. Indeed, the period under analysis here, 1995-2016, is one of substantial economic turbulence, and structural reforms for the Italian economy. As remarked in Brandolini et al. (2018) "the currency crisis of 1992 is a watershed in Italy's economic development. It marks the start of a phase of weak economic performance and uncertain growth prospects." This section explores some of the potential determinants of the estimated trend of wealth concentration in Italy. 


\subsection{The portfolio composition across the wealth distribution}

Workers save out of earned incomes during their working lives in order to dis-save through retirement and to face any other expected or unexpected need throughout their life cycle. Moreover, for any given age, different people across the income and wealth distributions may have different saving rates. Beyond this (obvious) accumulation channel, the existing stock of real and financial assets tend to reproduce itself; financial and real estate wealth may be invested, generating income returns that can be saved in turn. Positive real interest rates may accrue on bank accounts, and assets may also appreciate or depreciate over time, implying changes in the valuation of the stock of wealth independent of individual decisions to save. Crucially, the strength of each of these channels may vary over time and may well apply differently to different segments of the distribution. For instance, households' savings rate out of disposable income has been steadily declining in Italy since the mid-1990s, dropping from $16 \%$ in 1995 to $3 \%$ in 2016. Over the same period, the harmonized interest rates on deposits (by the household and the non-financial corporate sectors) recorded by the Bank of Italy dropped from $5.6 \%$ to $0.4 \%$. As the weight of deposits in the wealth portfolio is particularly high at the bottom of the distribution (jointly with valuables, this class of assets is worth at least $50 \%$ of gross wealth for the bottom $50 \%$ group as shown in Figure 9), it is reasonable to expect a strong co-movement between the decline of saving rates (and of returns on savings) and the wealth share of the bottom 50\%. At the same time, we should expect the middle $40 \%$ group to be particularly sensitive to the dynamics of the real estate market as housing and lands constitute the biggest asset class for this group. House prices increased by $35 \%$ between 1995 and 2008, closely following the growth in the average net wealth held by the middle $40 \%$. Following the 2008/2009 global financial crisis, house prices stagnated and then started to decline; by 2016, the reduction in the average house price was $27 \%$, and the real average net wealth of middle $40 \%$ declined by $12 \%$ between 2008 and 2016 . Conversely, the reversal of house prices since the 2008 crisis, coupled with a fast rebound of stock prices, may have contributed to the substantial rise in wealth concentration that we observe since 2010. Indeed, the share price index declined by 59\% between 2007 and 2012 and rebounded by $50 \%$ by 2015 , before dropping again by $15 \%$ in 2016 . Financial securities (directly and indirectly held stocks and bonds) and corporate and non-corporate personal business assets are the dominant group of assets in the portfolios of the wealthy, especially in recent years. In 2016, individuals with more than $€ 20$ million (the top $0.01 \%$ ) held more than $80 \%$ of their wealth in the form of financial and business assets.

To further probe the role of heterogeneous portfolios and their returns, we use our data to show how different assets classes contributed to the rise in the concentration of wealth at the top. We divide wealth into net housing assets and net non-housing assets, and allocate both to different groups of the distribution (preserving the ranking of adults according to total net wealth). For each group $i$ we define the share in total net wealth as $S_{i}$, which in turn can be written as the weighted average of the housing $(H)$ wealth share and the non-housing $(\mathrm{NH})$ wealth share of the same group $i$ :

$$
S_{i}=\frac{W_{i}}{W}=\frac{H_{i}+N H_{i}}{W}=\frac{H_{i}}{H} \alpha_{H}+\frac{N H_{i}}{N H}\left(1-\alpha_{H}\right)=S_{i}^{H} \alpha_{H}+S_{i}^{N H}\left(1-\alpha_{H}\right),
$$

where $\alpha_{H}$ and $1-\alpha_{H}$ are the relative weights of net housing and net non-housing wealth 
Figure 9: The composition of wealth across the wealth distribution

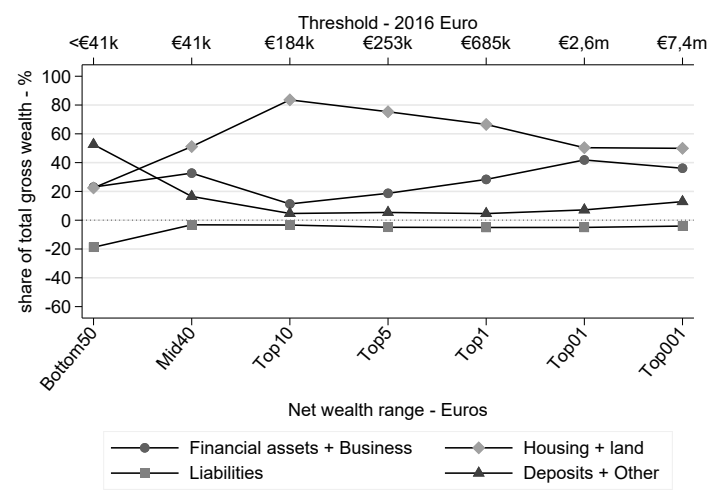

(a) 1995

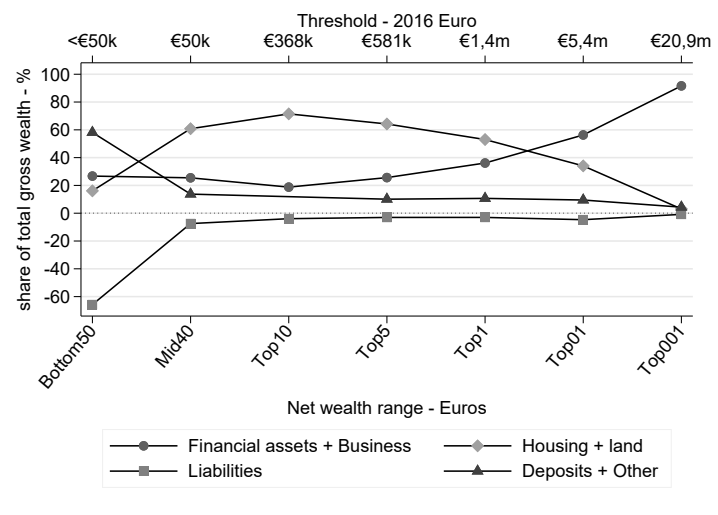

(b) 2016

Note: Adults are ranked by net wealth. Bottom, middle, and high-end groups are identified and total net wealth is decomposed into four classes: housing and land; business assets, equity, and debt securities; other assets (including current and saving deposits, valuables, etc.); and liabilities. The second $\mathrm{x}$-axis in each panel of the graph represents the monetary threshold (in 2016 Euros) to belong to each group.

in the total net wealth of the household sector. This simple exercise reveals that wealthy individuals have been capturing a growing share of non-housing wealth (e.g., financial and business assets). By contrast, the share of total housing stock captured at the very top of the net wealth distribution has remained relatively flat since 1995 (Figure 10, panels (c) to (e)). Upper end groups aside, the share of total non-housing wealth decreased visibly for the bottom $50 \%$ group, turning negative since early 2000s, and increased by 5 percentage points for the middle $40 \%$ group. The share of non-housing net wealth drives most of the negative trend for the bottom $90 \%$ and the positive trend for top groups, above the 90th percentile. For instance, the share of non-housing net wealth tripled between 1995 and 2016 for the top $0.1 \%$ group, growing from $5 \%$ to $15 \%$, approximately. This is in agreement with the findings described by (Alvaredo et al., 2018) for the UK, in the sense that housing wealth may have well "moderated the tendency for concentration to increase in other forms of wealth" ( p.37). However, this does not apply outside the top ranges of the wealth distribution. The pronounced downward trend in the share of the bottom $50 \%$ was driven by both net housing and net non-housing wealth (see Figure 10(a)); The magnitude of the decline in the relative share of middle $40 \%$ was reduced by a slight increase in the share of net housing assets (see Figure10(b)).

\subsection{The evolution of wealth over the life cycle}

The wealth concentration estimates discussed so far refer to snapshots of the wealth distribution in given years and include wealth and savings accumulated for life cycle purposes. As written in Cowell and Van Kerm (2015), "even if everyone had common wealth accumulation paths over the life cycle, wealth at any point in time would turn out to be unequally distributed when pooling observations of individuals of different age." Indeed, average wealth does vary considerably across the age distribution; older generations are much richer than 
Figure 10: The contribution of housing and non-housing wealth the the growing concentration of wealth

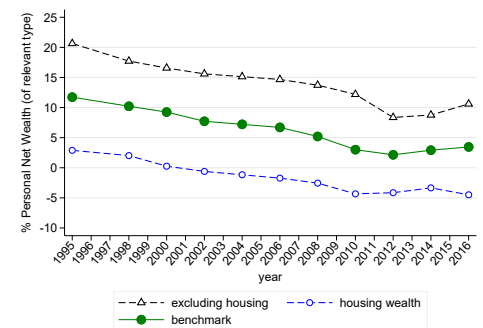

(a) Bottom 50\%

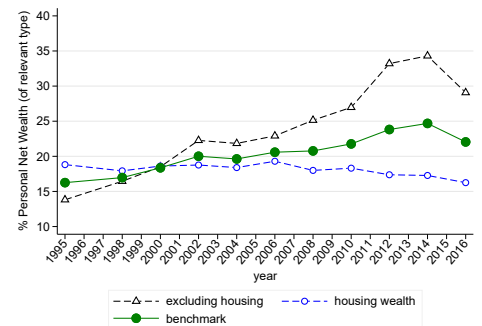

(d) Top 1\%

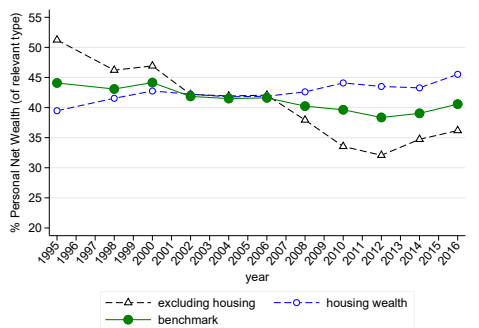

(b) Middle $40 \%$

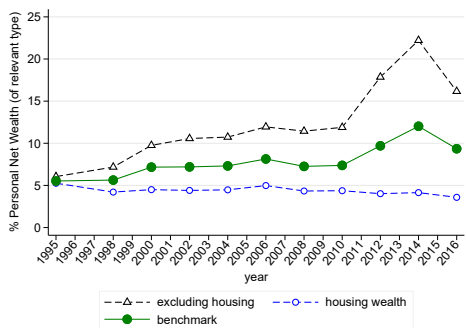

(e) Top $0.1 \%$

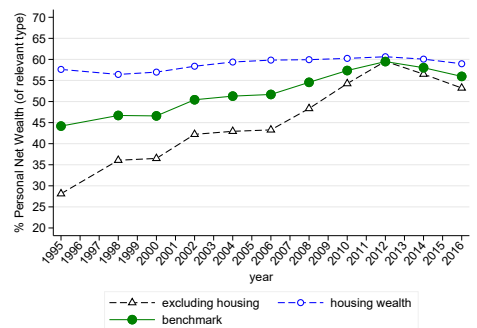

(c) Top $10 \%$

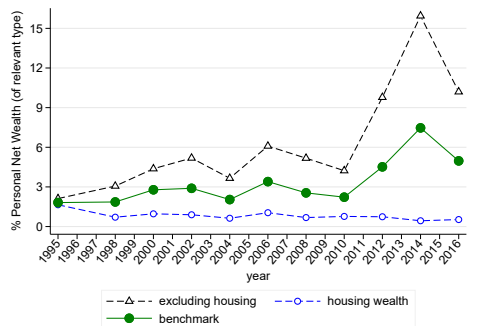

(f) Top $0.01 \%$

Note: We divide wealth into net housing assets and net non-housing assets, and allocate both to different groups of the distribution (preserving the ranking of adults according to total net wealth). For each group $i$ we define the share in total net wealth as $S_{i}$, which in turn can be written as the weighted average of the housing $(H)$ wealth share and the non-housing $(N H)$ wealth share of the same group $i$ can be defined as $S_{i}=\frac{W_{i}}{W}=S_{i}^{H} \alpha_{H}+S_{i}^{N H}\left(1-\alpha_{H}\right)$ where $\alpha_{H}$ and $1-\alpha_{H}$ are the relative weights of net housing and net non-housing wealth in the total net wealth of the household sector.

younger ones as one would expect. In 1995, average wealth peaked at 40-50 years old but was less than a third of this amount for the 20-40 year-old group. Average wealth increased for all ages until 2007 before receding following the Great Recession, in particular for younger groups (Figure 11(a)). However, assessing the average wealth holding between age groups does not sufficiently capture the role of age in determining the extent of wealth concentration.

To address this concern we take two steps, following Atkinson (1971). First, we assess the age distribution of wealth holding in the population as a whole and in the subgroup of wealthy individuals. If age were the most important factor driving wealth accumulation, we would find mostly older individuals populating the high end of the distribution. However, as shown in Figure 11(b), this is not the case: old, middle-aged, and sometimes young people alike can be found within the richest groups as well as in the overall population, albeit in different proportions. Second, we analyze the distribution of wealth holding within each age group and compare it to that of the overall population. Figures 11(c) and 11(d) display the high-end segment of the Lorenz curve corresponding to the richest $5 \%$ of adults (i.e., above the 95th percentile) for each independent age/gender group in comparison to that of the overall population. The vertical dotted lines identify the top $1 \%$ in each case. One 
Figure 11: The life-cycle dimension of wealth distribution and inequality

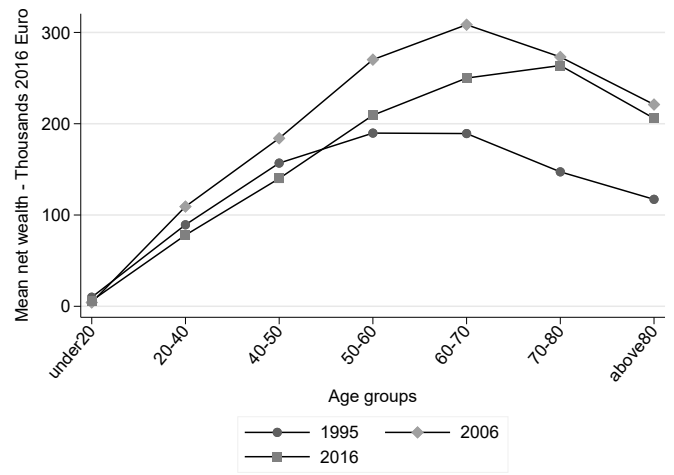

(a) Evolution of mean wealth across age groups

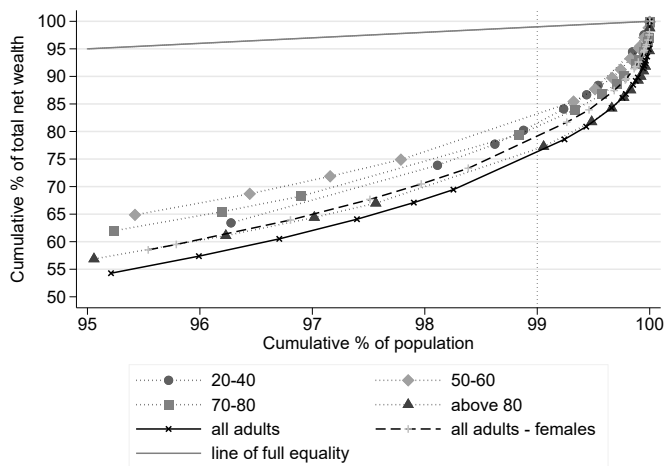

(c) Females 2016: The upper Lorenz curve by age groups:

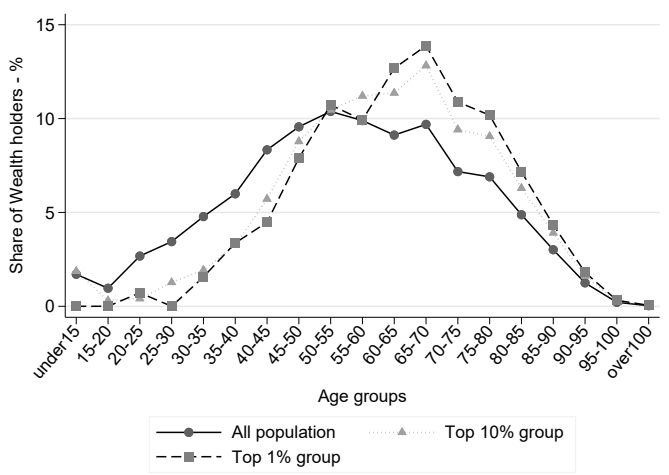

(b) The age distribution of wealth

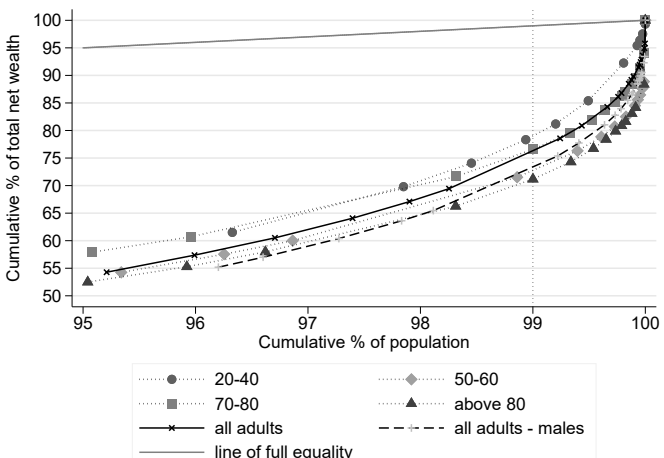

(d) Males 2016: The upper Lorenz curve by age groups

can derive the share of total wealth held by each top $1 \%$ group as $100 \%$ minus the cumulative percent of total wealth identified on the y-axis, where the vertical line meets each Lorenz curve. The result strongly suggests that wealth remains widely concentrated within all age/gender groups, with the shares of total wealth held by the top $1 \%$ being roughly similar, irrespective of age and gender. Most importantly, no group presents a degree of wealth concentration that is considerably lower than that of the overall population. The only exception appears to the younger group of males, for whom wealth appears relatively less concentrated than in the overall population.

The fact that wealth inequality is similar across age (and gender) groups is not a novel finding, but it has not been sufficiently stressed in the literature. Similar findings about considerable inequality even among people of the same age were already found in Cowell and Van Kerm (2015) and also in Atkinson (1971): "[I]f we standardize for age and sex, the degree of inequality is not substantially reduced" (p. 248). Atkinson concludes that "lifecycle factors cannot explain the upper tail of the current distribution of wealth in Britain, and there are good reasons for believing that there is a high degree of concentration in the 
distribution of wealth inherited by people over their lives." (pp. 251-252) The relevance of this statement about the residual role of inheritance in driving wealth concentration at the top can be explored with the existing data. We now turn to this important point.

\subsection{The growing role of inheritances and its dwindling taxation}

Wealth transfers, including inheritances and inter vivos gifts, are important economic resources for households. In rich countries, their scale relative to national income has increased substantially in recent decades (Piketty (2011); Atkinson (2018); Alvaredo et al. (2017)); Italy is no exception. As shown in figure 12(a), we estimate that from the mid-1990s to the mid-2010s the annual flow of total market value of inheritances and gifts almost doubled, from $8.44 \%$ to $15.18 \%$ of national income, and they grew from $1.71 \%$ to $2.45 \%$ of personal wealth. ${ }^{30}$ We also document a tendency of large bequests to concentrate over time in fewer hands. Figure 12(b) shows the evolution of the share of total estates held by the richest $1 \%$ of decedents. The latter increased by at least 4 percentage points from 1995 to 2016, from $18 \%$ to $22 \%$ approximately. The estimates reflect adjustment for under-reporting of wealth and allowance for the wealth of those individuals who are not represented on tax records. The results imply, indirectly, a potential concentration of inherited shares derived from total estate. The relevance of inheritance patterns for wealth accumulation may not be irrelevant at the very top of the wealth distribution. Data on Italian billionaires by Forbes indicate that the fortunes of 6 out of the top 10 richest individuals are recorded as "inherited" or "inherited and growing".

Despite the growing relevance of personal wealth and inheritance as proportion of national income, as well as their concentration, the receipts from the inheritance tax experienced a notable decrease from $0.14 \%$ to $0.06 \%$ of total tax revenues, from the end 1990 s to 2016 (Figure 12(a)). ${ }^{31}$ The dwindling role of inheritance and gift taxes is important to the extent that it enhances the share of the current wealth distribution and accumulation that is due to interpersonal wealth transfers. As argued in Cowell et al. (2018), wealth trans-

\footnotetext{
${ }^{30}$ These estimates are very closely aligned to those shown in Acciari and Morelli (2020) relying mostly on declared information on tax statistics, with aggregate and proportional corrections for under-reporting of wealth. Yet, the estimates presented in this paper rely on the benchmark wealth distribution of the entire population reconciled with the national household's balance sheet. Total wealth holdings are classified by gender, location, and age groups and each cell is multiplied with the relevant mortality rate (as estimated by the national statistical office - ISTAT). Such exercise represents a reverse engineering of the mortality multiplier method, estimating the entire deceased population and its wealth holdings every year. The advantage of this approach is the derivation of a full distribution of the estates at death, including implied adjustments to their wealth reported on the tax records as well as an allowance for the wealth of non-filers. A similar approach was applied in the work of Cannari and D'Alessio (2008) simulating inheritance receipts by applying mortality tables to the reported wealth in the Survey of Income and Wealth. In this case the total value of inheritance flows as a share of total net worth is substantially lower and it increased much more moderately over time, from $0.99 \%$ in 1995 to $1.52 \%$ in 2016 . The estimated series of total annual flows of gifts cannot be estimated with this method and is taken from Acciari and Morelli (2020).

${ }^{31}$ The total revenue generated from the inheritance tax associated with individuals who died in 2016 was worth approximately $€ 400$ million. The official figure of the Ministry of Economy and Finance for the inheritance tax revenue, measured at the year of account and not at year of death, is $€ 558$ million for 2016 . An additional $€ 183$ million came from the gift tax.
} 
fer taxes are very important for "the long-run distribution of wealth, reducing equilibrium inequality (the 'predistribution' effect) by a much larger amount than what is apparent in terms of the immediate impact of the tax (the 'redistribution' effect)." Along similar lines, the work by Nekoei and Seim (2018) argues that "inheritance taxation can reduce long-run wealth inequality", albeit, "solely through the taxation of very large inheritances."

The causes of the reduction in the tax revenue are found in the profound changes made to the structure of the estate, inheritance, and gift tax, including the marked decline of its progressivity over the last decades. A year before the inheritance tax was repealed (it was abolished in 2001 and reinstated in 2006), the estate tax with a progressive tax schedule was transformed into the current structure of a proportional inheritance tax (levied on the beneficiary). As described in Jappelli et al. (2014), the marginal rates of the estate tax ranged from $3 \%$ to $27 \%$ in the 1990 s. In 2000 , the inheritance tax was introduced with a unique, proportional tax rate at $4 \%$ for transfers received by a spouse or direct relative, which has remained unchanged even since the tax was reintroduced in 2006. The exemption threshold for similar transfers increased substantially from nearly $€ 125,000$ between 1995 and 1999, to nearly $€ 175,000$ until 2000, and then to $€ 1$ million from 2006 onward.

Approximately $70 \%$ of the estates above $€ 300,000$ were subject to taxation between 1995 and 1999. In the tax regime valid since October 2006, as highlighted in Figure 13(a), only $30 \%$ of estates valued between $€ 2.5$ million and $€ 6$ million and less than $80 \%$ of the richest estates (€10 million and above) were subject to taxation, on average. At the same time, the share of estates between zero and $€ 20,000$ subject to taxation increased from $1.6 \%$ in the pre-2000 tax regime to $14 \%$ on average in the current tax regime. Many small estates are now subject to taxation due to the fact that the exemption threshold was cancelled for wealth transfers occurring beyond the fourth degree of kinship. Even small inheritances are, therefore, subject to taxation if received from donors outside the more direct family sphere. As a result, the share of total estates that are now subject to taxation is just above $10 \%$, compared to approximately $8 \%$ in the 1990s. Furthermore, conditionally on being taxed, the richest estates now have a substantially lower tax bill. The richest estates (€10 million and above) paid the equivalent of $6.3 \%$ of the estate value in taxes on average before 2000 , with considerable variance around this average value. ${ }^{32}$

\footnotetext{
${ }^{32}$ As shown in the appendix, the average tax rate for estates above $€ 10$ million could be higher than $20 \%$ of the estate value or as low as zero. Given the existence of a large category of tax-exempt assets, the effective tax rates depend substantially on the composition of the estate.
} 
Figure 12: Inheritance and gifts as \% of national income vs. inheritance tax collection as $\%$ of total revenue

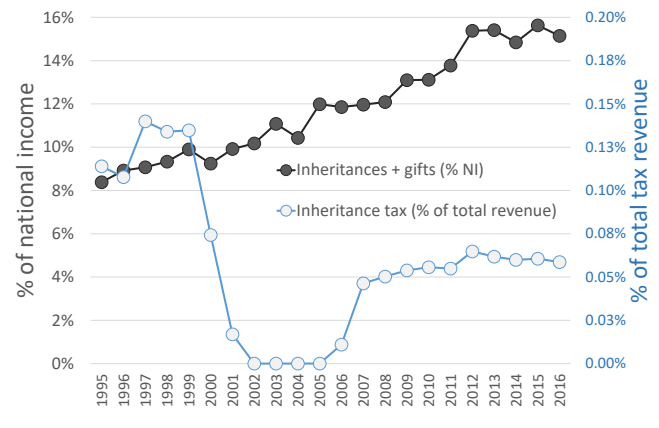

(a) Wealth transfers \& inheritance tax revenue

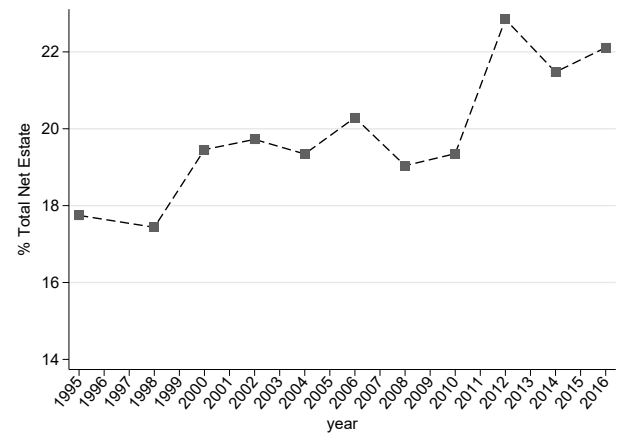

(b) Top1 \% - Estate concentration

Note: Panel a) shows the value of annual flows of inheritances and gifts inter vivos as share of national income and the value of inheritance tax paid (excluding gift tax) as a share of total annual tax revenue. The effective tax liabilities paid from the inheritance tax forms are reported at year of death. Total annual tax revenue is derived on a year of account basis from official statistics of the Ministry of Economics and Finance. Panel b) shows the share of total estate value held by the richest $1 \%$ of decedents. The value of the estates at death is adjusted for under-reporting, including allowances for the value of tax-exempt assets.

The value of total estate makes allowance for deceased individuals whose wealth is not reflected in the inheritance tax records (the missing population).

Figure 13: The decline of the tax burden on the wealthy

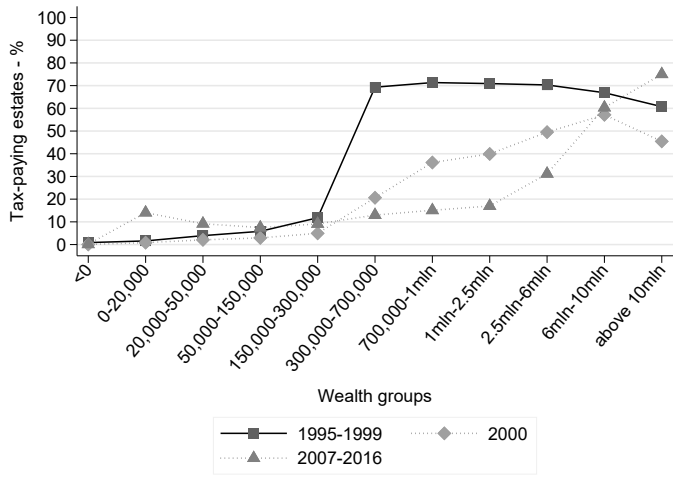

(a) Percent of estates taxed by net estate value

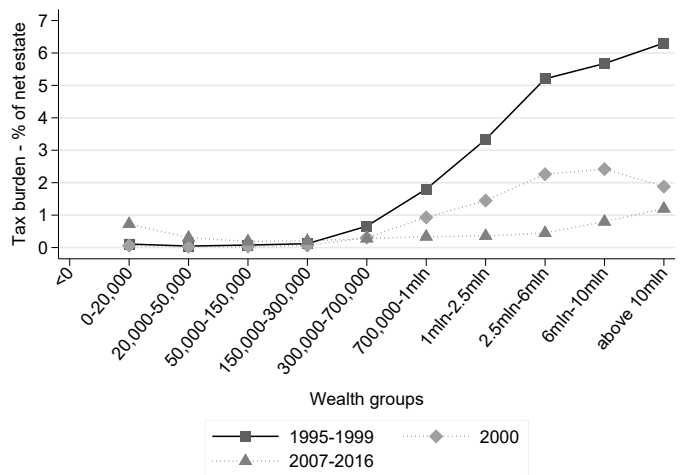

(b) average tax paid as percent of net estate value

Note: Panel (a) shows the \% of estates subject to inheritance tax. Panel (b) shows the average tax burden by net estate ranges. Following the evolution of major reforms in the tax structure in 2000 and 2006 , we compare the average values of the above-mentioned indicators in three main periods: 1995-1999, 2000, and 2007-2016. The 2001-2006 period is excluded as the inheritance tax was abolished in Italy during this period. The average tax burden is estimated based on the tax liability associated to each estate, computed as the sum of the tax applied on the global value of the estate, when applicable (i.e., before 2000), and on the share of the estate inherited by the heirs. 
As shown in Figure 13(b), the average tax bill on the same estate has, since 2006, dropped to $1.2 \%$ of the estate value. This is not too dissimilar from the average tax bill of $0.7 \%$ associated with very small estates (between zero and $€ 20,000$ ). Therefore, under the current regime, a much smaller share of large estates are subject to taxation, the average tax rate for the largest estates has dropped by $80 \%$, and the progressive structure of the inheritance tax - relative to the estate value - no longer exists. This does not necessarily mean that the major changes to the inheritance tax observed in Italy since year 2000 has directly determined the increase in wealth concentration in the same period; nevertheless, it can play a more substantial role for its long-run trend.

\section{Robustness analysis}

\subsection{Alternative mortality rates}

Older people, as expected, do have higher mortality rates than younger ones. Similarly, males tend to have a shorter life span than females. However, demographic factors are not the only ones influencing mortality. Socio-economic conditions such as marital status, geographical location, education, and income or wealth levels matter too. Indeed, rich people tend to live longer, other things being equal. Chetty et al. (2016) highlighted that being at the top of the income distribution provides individuals with a substantial longevity advantage; people aged 40-60 years old in the top $1 \%$ of the U.S. income distribution have a mortality rate that is $30 \%$ of the rate for the overall population of the same age group. This could be relevant for the estate multiplier method, as a failure to appropriately account for mortality heterogeneity may result in biased estimates of the distribution of wealth, a point already highlighted in earlier work (Atkinson and Harrison, 1978); nevertheless, the underlying distribution of estates also plays a role, as explained in Alvaredo et al. (2018).

For a robustness analysis, we make use of the most updated recent estimates from the Italian National Statistics Office, which account for the socio-economic gradient of mortality by linking the mortality records to the education levels for 2012, and for age groups between 25 and 90 years old. A distinction is drawn between four education groups: no education or elementary school; middle school; high school; and college degree or higher. ${ }^{33}$ Controlling for education has an important effect on mortality risk. The life expectancy of a 25 year-old with no education or with elementary school is 4 years lower, on average, than that of an individual holding a college degree or higher. The difference in life expectancy is 5 years higher for males alone. Table Q.1 shows that, in 2012, the mortality rate for 40 year-old males was $0.16 \%$ on average. The mortality rate drops by more than half for a male in the same age group but with a college degree or higher. By contrast, the mortality rate is more than twice the average $(206 \%)$ in the case of an elementary school education at most. ${ }^{34}$

\footnotetext{
${ }^{33}$ The ISTAT original classification is the following: "Nessun titolo o Licenza elementare"; "Licenza media inferiore"; "Licenza media superiore"; and "Laurea o titolo superiore". Two additional categories are dropped as redundant: "Nessun titolo o licenza elementare o licenza media inferiore; and "Licenza elementare o licenza media inferiore."

${ }^{34}$ This mortality rate gradient by education groups is similar to what used by Kopczuk and Saez (2004) for the U.S.
} 
In seeking to establish whether and how steeper mortality multipliers change wealth concentration estimates, we assume that individuals with assets above $€ 1$ million have a relative longevity advantage - in relation to the overall population with the same demographic characteristics - equal to those in the highest education class. Individuals with wealth below $€ 50,000$ have been assumed to have the mortality rate of the group with primary education at most. Finally, individuals in intermediate wealth ranges, namely between $€ 50,000$ and $€ 300,000$ and up to $€ 1$ million, are assumed to have mortality patterns similar to those with middle school and high school, respectively. This type of adjustment is clearly imperfect and the information about mortality rates adjusted by education is only available for 2012; the same relative adjustments have been applied to the remaining years in our sample. The direction of the change is as expected (an increase in top shares), but the difference with the benchmark series at the top is small (for a more detailed discussion about the nature of these adjustments and their implications for top wealth shares see Alvaredo et al., 2018, Berman and Morelli, 2021).

A further confirmation that the results are robust to the use of more refined mortality multipliers is the use of tabulations containing finer disaggregation by age bracket and geographical location. Multipliers in 1995 were lower in the north of the country compared to the south and the islands. By 2016 it was the opposite. Theoretically, not accounting for such heterogeneity may bias downward the increasing trend in wealth concentration, given that the northern areas are the wealthiest. The benchmark series are robust in the presence of such refinements.

\subsection{The inclusion of durables}

The benchmark estimates discussed in Section 3.1 are based on distributing the entirety of the national balance sheets to the adult population. As mentioned, NA figures are not necessarily the ideal point of reference. We have discussed that some assets are missing from the official records, despite their relevance for households, such as vehicles and other durable goods (accounting for approximately $8 \%$ of total wealth identified in the 2016 SHIW data). The exclusion of such assets would likely be felt more strongly in the bottom parts of the distribution. Hence, the exclusion of durables can have different implications for inequality estimates than the exclusion of financial assets stashed in off-shore accounts. As shown in Figure 14, including durables would, in fact, reduce the top shares marginally, but would increase the share of the bottom $50 \%$ by a non-trivial amount of $1-2$ percentage points.

\subsection{The role of imputations}

Imputations are always surrounded with considerable uncertainty. In this paper we rely on a number of assumptions based on the observed wealth holdings aggregated by the four large macro-categories of assets available in the digitized tax records. These imputations could not be carried out asset by asset based on micro-level evidence and can appear controversial. For the benchmark series, recall that we make the following imputations: (i) we first multiply up the estate distribution using mortality multipliers; (ii) we then append 
Figure 14: Top 10\% and Bottom 50\% shares in total wealth: including and excluding durables

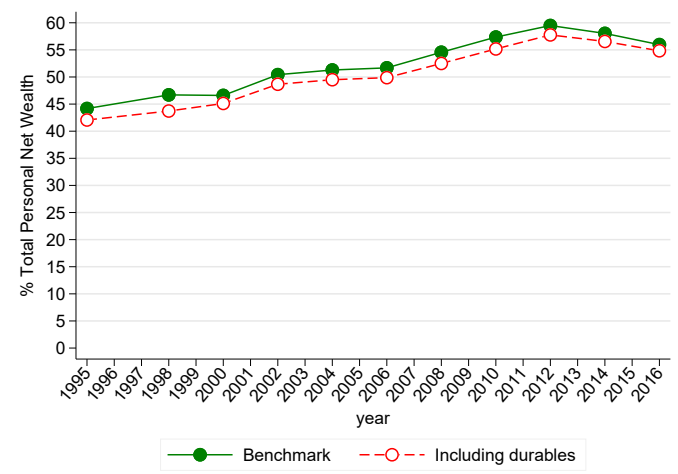

(a) Top $10 \%$

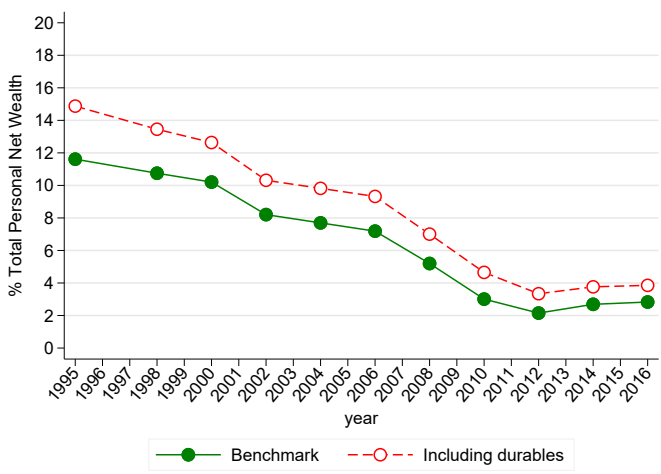

(b) Bottom 50\%

Note: The value of durables is imputed to the gender, age, location, and wealth levels as reported in the survey data. .

an estimate of the wealth of the missing population based on household survey data; and finally (iii) we distribute the remaining wealth gap with respect to the NA according to the relative distribution of asset classes in the identified wealth from tax records complemented with that of the missing population from survey data.

One must wonder to what extent the benchmark estimates are driven by specific imputation choices in steps (ii) and (iii). To address this concern we discuss two alternative imputation scenarios in the Appendix. First, we derive a series that imputes the wealth gap by relying exclusively on the identified asset distribution based on tax records; second, we derive a series where step (ii) is based exclusively on values reported in the household survey data, rather than relying on adjusted values to account for underreporting. ${ }^{35}$ Both approaches attach more weight to wealth reported in the tax records, which is on average more concentrated than what would appear if one takes into consideration smaller wealth holdings that cannot come to the notice of the tax authority. Hence, the alternative set of imputations, when compared to our benchmark series, generally suggest higher wealth concentration at the top and a lower share for the bottom $50 \%$ of the population (see Figures O.1(a)- O.1(d) in the Appendix O). In this respect, our benchmark series is likely to provide conservative estimates of wealth concentration at the top.

Wealth concentration with no imputations. Most importantly, we also estimate wealth concentration at the top without resorting to imputations of any kind, that is, by applying the mortality method to the reported estates on the inheritance tax records (i.e., entirely bypassing step (iii) above). Estimates for the UK in Atkinson and Harrison (1978) and

\footnotetext{
${ }^{35}$ As mentioned earlier in the paper, to account for underreporting of assets in the household survey data, we proportionally adjust non-housing asset values using the ratio of total value between the National Accounts and the SHIW, asset class by asset class.
} 
Alvaredo et al. (2018), for instance, followed this path. ${ }^{36}$ The derivation of such a variety of wealth concentration statistics enhances our understanding of the series and their comparability across countries, given this was the dominant procedure in the literature until recently. Figures 15(a) and 15(b) give the results. The series for the top 1\% share based on internal totals and no imputations point to a more moderate increase of inequality over the past decades. Importantly, and reasonably, the role of imputations appears stronger only in those years where the underlying inheritance tax data are much less complete (i.e., between 2001 and 2006). ${ }^{37}$ The evolution of the top $1 \%$ share based on internal totals and no imputations is also compared to that of other countries as available from existing literature. Both levels of wealth concentration in Italy as well as its trends appear very much in line with available comparable estimates for the UK, Norway, Finland, Sweden, Spain, and the Netherlands.

This may be suggestive of the fact that the imputation procedures of the unobserved wealth can play an important role in generating cross-country heterogeneity in the levels and trends of wealth concentration and should be carefully assessed and understood.

Finally, the evidence provided by our unadjusted series shows that the level of wealth concentration is more aligned with that obtained using comparable estimates derived from the SHIW. Yet, the level of wealth concentration remains higher with a more pronounced positive trend (see Figure P.2 in the appendix).

\footnotetext{
${ }^{36}$ Importantly, this was done using both internal and external wealth totals. Typically, researchers use external data (e.g., the National Accounts) on total wealth that bear no relation to tax data. However, when the population coverage of inheritance tax records is particularly high (like in the case of Italy or the UK), one can also rely on the multiplied-up estates as well as the estimated wealth of the missing population to derive an internal measure for total wealth (as in Alvaredo et al., 2018, Atkinson and Harrison, 1978).

${ }^{37}$ See Appendix $\mathrm{P}$ for more evidence on additional wealth groups. Notice, also, that the external total series with no imputation can be derived on a yearly basis, as it does not require any information from household survey data to be estimated.
} 
Figure 15: Top 1\% without imputations

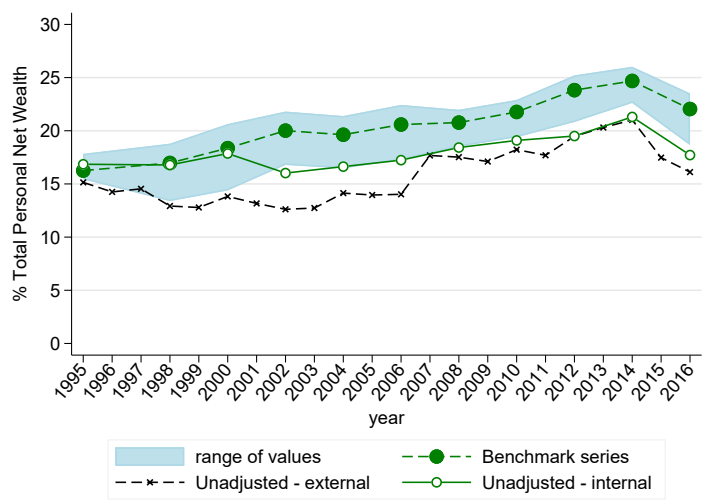

(a) No imputations

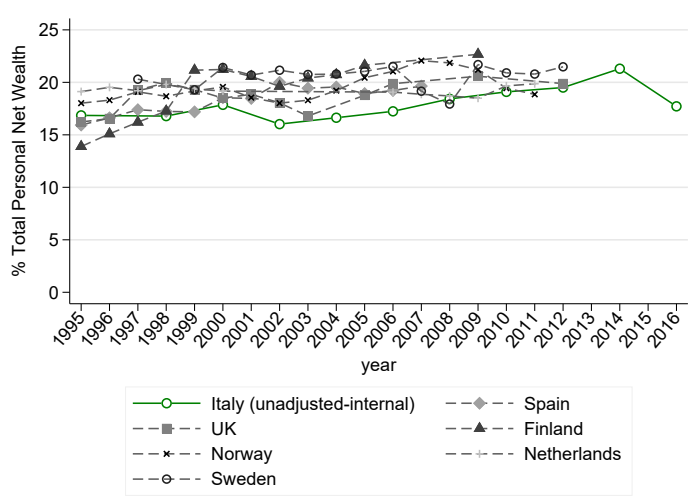

(b) No imputations - other countries

Note: Panel a compares the benchmark series of top $1 \%$ wealth share, consistent with the NA, to two series derived without resorting to any imputations of missing wealth. The two series reflect different strategies to estimate an appropriate wealth total (i.e. the denominator). On the one hand, we subtract tax-exempt assets from the NA total (external total). On the other hand, we estimate the wealth of the missing population and add it to the identified wealth obtained through the re-scaling the inheritance tax records with mortality multipliers (internal total). Panel b compares the 'internal total' series to the evolution of wealth concentration in other countries. The UK series is taken from Alvaredo et al. (2018) and it is directly comparable to the Italian one (e.g. derived from the inheritance tax data using an internal total and no imputations). Figures for Finland, Netherlands, Norway, Sweden estimated by Roine and Waldenström (2015) from wealth tax tabulations. Data for Spain are taken from Alvaredo and Saez (2009) from wealth tax data.

\section{Final remarks}

"Statistics on wealth distribution," writes Atkinson (1978), "play 'a key political role' and they are as sensitive an issue as the balance of payments or unemployment figures. This means that it is all the more important that they should be firmly based. We should examine critically the evidence and the assumptions underlying it." With these principles in mind, this paper makes contributions along three dimensions: methodological, empirical, and on implications for future research.

This paper estimates new series of wealth inequality in Italy over 1995-2016, a period of substantial economic turbulence and structural reforms for the national economy. Methodologically, the work uses, for the first time, the full set of inheritance tax returns. In line with similar works for other countries, we show that the administration of the inheritance tax generates high-quality data with substantial coverage of the population. The use of these data provides more convincing coverage of the upper end of the wealth distribution compared to the household survey data. Particular attention has been given to the critical analysis of the assumptions required to go from the tax records to the distribution of the wealth of the household sector in the National Accounts. As this involves a number of controversial decisions, we have adopted a multi-series approach, that is, one that allows for the possibility of comparing the pieces of information given by different and competing data 
sources. A series without imputations is also estimated. We firmly believe that, given the current, imperfect state of data on the distribution of assets and liabilities, such an approach is preferable to the alternative option of looking at one and only one series resulting from a single source, or from a particular combination of sources. The data currently available to study the personal distribution of wealth in Italy are not ideal. As a consequence, many decisions based on judgment had to be made. We have sought to be as explicit about the adjustments as space and readability permit. Other scholars may opt to apply different assumptions.

Concerning findings, our main results suggest a substantial increase in wealth concentration and wealth inequality, and a dramatic decline of wealth shares held by the bottom groups of the adult population. Over the past two decades, Italian wealth distribution became substantially more unequal. The 2008/2009 financial crisis, as well as the ensuing double-dip economic recession and European debt crisis, which peaked between 2010 and 2012, appear to have markedly accelerated the process, with the bottom $50 \%$ of the adult population now holding only $3 \%$ of total wealth, while the richest $0.01 \%$ hold more than $10 \%$. In the 2000s, these two groups held a similar share of total wealth, approximately $7 \%$, before starting to diverge. These trends occurred in tandem with a decreasing household saving rate, shrinking availability of liquid financial resources for the bottom half of the adult population, a doubling of the weight of aggregate flow of wealth transfers, rising concentration of bequests in the hands of few, and a substantial reduction of the tax burden on wealthy inheritors. In probing the evidence about potential determinants of wealth concentration, the evidence collected suggests that large net-of-tax wealth transfers, together with the heterogeneous effect of asset price changes across the distribution, may have played a non-negligible role in explaining the rising wealth concentration at the top. At the same time, changes in the demographic structure of the population may not help explain the trend in wealth concentration at the top.

Growing wealth disparities in this scenario appear concerning on several grounds. First, rising wealth inequality may be coupled with growing financial vulnerability and insecurity for a vast number of adult individuals who have limited private financial resources to cushion adverse circumstances. Second, growing inequalities of wealth holdings can have corrosive effects on equality of opportunity, as well as on intergenerational mobility when they crystallize over time and turn into persistent disparities across generations. Available, comparable cross-country measures suggest that Italy (as well as the U.S.) is one of the countries where offspring's earnings are the most dependent on those of their parents, implying low intergenerational mobility across generations (for a discussion see Acciari et al., 2019, Bloise, 2018, Cannari and D'Alessio, 2018, Corak, 2013).

Although the paper expands the available windows of observation on the Italian wealth pyramid, many data limitations remain, and it is imperative to invest heavily in official statistics to measure, directly and indirectly, net wealth holdings. Three main steps can be taken to improve data on wealth distribution in Italy. First, the stock of asset holdings may be indirectly estimated through the observation of their resulting yields via capitalization methods. Such flows of income, the asset returns, can be partly observed in income tax data. 
A large fraction of investment incomes are not always taxable, and therefore not necessarily observable on tax returns. In Italy, most capital incomes are taxed at the source and are not reported in the tax files, making the application of the capitalization method unfeasible at present, but this administrative feature of the income tax should not be understood as an absolute impediment to the production of information for statistical purposes. Second, a detailed census on real and financial assets would be an excellent source for estimating the distribution of wealth holdings. The gathering of such information is already a common practice for real estate assets through the cadastre, although it is usually difficult to access for research purposes. Moreover, the actual cadastral values of real estate need updating to be brought in line with market valuations. A comprehensive registry of financial assets, accessible for research analysis, would prove very helpful. Since 2011, Italian law made such a register a concrete reality as financial institutions are obliged to share data concerning financial wealth holdings of their individual customers with the tax agency. ${ }^{38}$ Third, a renovated survey on households wealth holdings could be partially linked to some of the administrative registers listed above (e.g., by pre-filling some of the questions on real estate and financial holdings) and could be endowed with a new sampling design, one that over-samples wealthy households. These changes could go long way toward expanding our knowledge of the wealth holdings of both the low end and the high end of the wealth distribution. Preserving a focus on the households as the main unit of analysis would also be very important to better understand the welfare implications of a changing wealth distribution (e.g., many assets are shared within households irrespective of their individual ownership). Likewise, the use of household survey data remains a fundamental anchor to adopt a complementary definition of wealth which does not neglect the complex interactions between the need to accumulate private wealth and the provision of public goods and services, and social security benefits.

Improving our knowledge of the size distribution of income and wealth is a realistic goal with important implications for policy interventions. Likewise, it is also essential that future research sheds further light on the main determinants of large fortunes and wealth concentration, including the role of different tax policies as well as monetary policy intervention. Better data on the poorer segments of the wealth distribution are also needed to gain a more complete view of the relevance of financial vulnerability and insecurity conditions for households. The recent COVID-19 pandemic has highlighted the importance of available personal liquid assets to accommodate large and widespread income shocks for a sustained period of time.

\section{References}

Paolo Acciari and Salvatore Morelli. Wealth Transfers and Net Wealth at Death: Evidence from the Italian Inheritance Tax Records 1995-2016. NBER Working Paper 27899, National Bureau of Economic Research, October 2020.

Paolo Acciari, Alberto Polo, and Giovanni L Violante. "And Yet it Moves": Intergener-

\footnotetext{
${ }^{38}$ According to Decree Law 06/12/2011, n. 201, article 11, such data can only be used for tax evasion risk analysis and for other institutional activities of the public authorities.
} 
ational Mobility in Italy. NBER Working Paper 25732, National Bureau of Economic Research, April 2019.

Arun Advani, George Bangham, and Jack Leslie. The UK's Wealth Distribution and Characteristics of High-wealth Households. Wealth Tax Commission Evidence Paper no. 1, 2020 .

Thilo N. H. Albers, Charlotte Bartels, and Moritz Schularick. The Distribution of Wealth in Germany, 1895-2018. ECONtribute Policy Brief No. 001, 2020.

Annette Alstadsæter, Niels Johannesen, and Gabriel Zucman. Who Owns the Wealth in Tax Havens? Macro Evidence and Implications for Global Inequality. Journal of Public Economics, 162:89-100, 2018.

Annette Alstadsæter, Niels Johannesen, and Gabriel Zucman. Tax Evasion and Inequality. American Economic Review, 109(6):2073-2103, June 2019.

Facundo Alvaredo and Emmanuel Saez. Income and Wealth Concentration in Spain from a Historical and Fiscal Perspective. Journal of the European Economic Association, 7(5): 1140-1167, 2009.

Facundo Alvaredo, Anthony Barnes Atkinson, Lucas Chancel, Thomas Piketty, Emmanuel Saez, and Gabriel Zucman. Distributional National Accounts ( DINA) Guidelines : Concepts and Methods used in WID.world. WID.world Working Paper Series N 2016/1, 2016 .

Facundo Alvaredo, Bertrand Garbinti, and Thomas Piketty. On the Share of Inheritance in Aggregate Wealth : Europe and the USA , 1900 - 2010. Economica, 84:239-260, 2017.

Facundo Alvaredo, Anthony B Atkinson, and Salvatore Morelli. Top Wealth Shares in the UK Over More than a Century. Journal of Public Economics, 162(March):26-47, 2018.

Facundo Alvaredo, Anthony Barnes Atkinson, Thomas Blanchet, Lucas Chancel, Luis Bauluz, Ignacio Flores, Matthew Fisher-Post, Bertrand Garbinti, Goupille-Lebret Jonathan, Clara Martínez-Toledano, Marc Morgan, Theresa Neef, Thomas Piketty, AnneSophie Robilliard, Emmanuel Saez, Li Yang, and Gabriel Zucman. Distributional National Accounts ( DINA ) Guidelines : Concepts and Methods Used in World Inequality Database. WID.world. WID.world working document, 2020.

Anthony B Atkinson et al. On the Measurement of Inequality. Journal of Economic Theory, $2(3): 244-263,1970$.

Anthony Barnes Atkinson. The Distribution of Wealth and the Individual Life-Cycle. Oxford Economic Papers, 23(2):239-254, 1971.

Anthony Barnes Atkinson. Wealth and Inheritance in Britain from 1896 to the Present. Journal of Economic Inequality, 16:137-169, 2018.

Anthony Barnes Atkinson and Allan James Harrison. Distribution of Personal Wealth in Britain. Cambridge Univ Press, 1978. ISBN 0521217350. 
Banca d'Italia. Household Wealth in Italy 2013. Supplements to the Statistical Bulletin Monetary and Financial Indicators 69, December 2014.

Michael Batty, Jesse Bricker, Joseph Briggs, Elizabeth Holmquist, Susan McIntosh, Kevin Moore, Eric Nielsen, Sarah Reber, Molly Shatto, Kamila Sommer, Tom Sweeney, and Alice Henriques Volz. Introducing the Distributional Financial Accounts of the United States. Finance and Economics Discussion Series - Board of Governors of the Federal Reserve System 2019-017, March 2019.

Jess Benhabib, Alberto Bisin, and Mi Luo. Earnings Inequality and Other Determinants of Wealth Inequality. American Economic Review, 107(5):593-97, May 2017.

Yonatan Berman and Salvatore Morelli. On the Distribution of Estates and the Distribution of Wealth: Evidence from the Dead. NBER Working Paper 28546, National Bureau of Economic Research, March 2021.

Francesco Bloise. The Poor Stay Poor, the Rich Get Rich: Wealth Mobility Across Two Generations in Italy. CIRET Working paper 4, 2018.

Andrea Brandolini, Luigi Cannari, Giovanni D'Alessio, and Ivan Faiella. Household Wealth Distribution in Italy in the 1990s. Temi di discussione del Servizio Studi - Banca D'Italia $530,2004$.

Andrea Brandolini, Luigi Cannari, Giovanni D'Alessio, and Ivan Faiella. Inequality Amid Income Stagnation: Italy Over the Last Quarter of a Century. Questioni di Economia e Finanza - Occasional papers - Banca d'Italia 442, 2018.

Luigi Cannari and Giovanni D'Alessio. La Trasmissione Intergenerazionale di Reddito e Ricchezza. La Rivista delle Politiche Sociali - Italian Journal of Social Policy, (3):105$127,2008$.

Luigi Cannari and Giovanni D'Alessio. Education, Income and Wealth:Persistence Across Generations in Italy. Questioni di Economia e Finanza - Occasional papers - Banca d' Italia 476, 2018.

Luigi Cannari and Giovanni D'Alessio. Wealth Inequality in Italy: A Reconstruction of 1968-75 Data and a Comparison with Recent Estimates. Questioni di Economia e Finanza - Occasional papers - Banca d'Italia 428, Banca d'Italia, 2018.

Raj Chetty, Michael Stepner, Sarah Abraham, Shelby Lin, Benjamin Scuderi, Nicholas Turner, Augustin Bergeron, and David Cutler. The Association Between Income and Life Expectancy in the United States, 2001-2014. JAMA, 315(16):1750-1766, 042016.

Miles Corak. Income Inequality, Equality of Opportunity, and Intergenerational Mobility. Journal of Economic Perspectives, 27(3):79-102, September 2013.

Frank Cowell, Van de gaer Dirk, and He Chang. Inheritance Taxation: Redistribution and Predistribution. In John A Bishop and Juan Gabriel Rodríguez, editors, Inequality, Taxation and Intergenerational Transmission, volume 26 of Research on Economic Inequality, pages 1-13. Emerald Publishing Limited, jan 2018. 
Frank A Cowell and Philippe Van Kerm. Wealth Inequality: A Survey. Journal of Economic Surveys, 29(4):671-710, 2015.

Giovanni D'Alessio. Gender Wealth Gap in Italy. Questioni di Economia e Finanza Occasional Papers - Banca d' Italia 433, 2018.

James B. Davies, Rodrigo Lluberas, and Anthony F. Shorrocks. Estimating the Level and Distribution of Global Wealth, 2000-2014. Review of Income and Wealth, 63(4):731-759, 2017.

Mario Draghi. Household wealth in central bank policy analysis - Remarks by Mario Draghi Governor of the Bank of Italy. In The Luxembourg Wealth Study: Enhancing Comparative Research on Household Finance, pages 0-12. Bank of Italy, 2007.

Andreas Fagereng, Martin Blomhoff Holm, Benjamin Moll, and Gisle Natvik. Saving behavior across the wealth distribution: The importance of capital gains. Working Paper 26588, National Bureau of Economic Research, December 2019. URL http://www .nber.org/papers/w26588.

Andreas Fagereng, Luigi Guiso, Davide Malacrino, and Luigi Pistaferri. Heterogeneity and Persistence in Returns to Wealth. Econometrica, 88(1):115-170, 2020.

Laura Feiveson and John Sabelhaus. How Does Intergenerational Wealth Transmission Affect Wealth Concentration? FED Notes - Board of Governors of the Federal Reserve System 2018-06-01, Board of Governors of the Federal Reserve System (US), 2018.

Martin Feldstein. Social Security, Induced Retirement, and Aggregate Capital Accumulation. The Journal of Political Economy, 82(5):905-926, 1974.

Giacomo Gabbuti and Salvatore Morelli. Inheritances, Wealth Concentration and Regional Divides in Italy during the First Globalisation. Unpublished manuscript, 2020.

Bertrand Garbinti, Jonathan Goupille-lebret, and Thomas Piketty. Accounting for Wealth Inequality Dynamics : Methods, Estimates and Simulations for France ( 1800-2014 ). WID.world Working Paper Series N 2016/5, 2016.

Pablo García Luna and Bryan Hardy. Non-bank counterparties in international banking. Bis quarterly revier, Bank of International Settlements, September 2019.

Joachim Hubmer, Per Krusell, and Anthony A. Jr. Smith. Sources of U.S. Wealth Inequality: Past, Present, and Future. Unpublished manuscript, May 2020.

Tullio Jappelli, Mario Padula, and Giovanni Pica. Do Transfer Taxes Reduce Intergenerational Transfers? Journal of the European Economic Association, 12(1), 2014.

Niels Johannesen and Gabriel Zucman. The End of Bank Secrecy? An Evaluation of the G20 Tax Haven Crackdown. American Economic Journal: Economic Policy, 6(1):65-91, 2014. 
Arthur B. Kennickell. The Tail that Wags: Differences in Effective Right Tail Coverage and Estimates of Wealth Inequality. The Journal of Economic Inequality, 17(4):443-459, 2019 .

Wojciech Kopczuk and Emmanuel Saez. Top Wealth Shares in the United States, 1916-2000: Evidence from Estate Tax Returns. National Tax Journal, LVII(2):445-486, 2004.

Anton Korinek, Johan A. Mistiaen, and Martin Ravallion. An Econometric Method of Correcting for Unit Nonresponse Bias in Surveys". Journal of Econometrics, 136(1):213 $-235,2007$.

Moritz Kuhn, Moritz Schularick, and Ulrike I. Steins. Income and wealth inequality in america, 1949-2016. Journal of Political Economy, 128(9):3469-3519, 2020. doi: $10.1086 / 708815$.

Clara Martínez-Toledano. Housing Bubbles, Offshore Assets and Wealth Inequality in Spain. WID.world Working Paper Series N 2017/19, 2017.

Clara Martínez-Toledano. House Price Cycles, Wealth Inequality and Portfolio Reshuffling. Unpublished manuscript, 2020.

Ercio Muñoz and Salvatore Morelli. kmr: A STATA Command to Correct Survey Weights for Unit Nonresponse using Group's Response Rates. Stone Center on Socio-Economic Inequality Working Paper Series N 02, 2020.

Arash Nekoei and David Seim. How Do Inheritances Shape Wealth Inequality? Theory and Evidence from Sweden. CEPR Discussion Paper No. DP13199, 2018.

Brian Nolan, Juan Palomino, Philippe Van Kerm, and Salvatore Morelli. Intergenerational Transfers by Size and Wealth Inequality in Rich Countries. Stone Center on SocioEconomic Inequality Working Paper Series N 21, 2020.

Pierce O'Oreilly, Parra Ramirez Kevin, and Stemmer Michael A. Exchange of Information and Bank Deposits in International Financial Centres. OECD Taxation Working Papers 46, OECD, September 2019.

Valeria Pellegrini, Alessandra Sanelli, and Enrico Tosti. What Do External Statistics Tell Us About Undeclared Assets Held Abroad and Tax Evasion? Bank of Italy Occational Paper N 367, 2016.

Thomas Piketty. On the Long-run Evolution of Inheritance: France 1820-2050. Quarterly Journal of Economics, 126(3):1071-1131, 2011.

Thomas Piketty, Gilles Postel-Vinay, and Jean-Laurent Rosenthal. Wealth concentration in a developing economy: Paris and france, 1807-1994. The American Economic Review, 96 (1):236-256, 2006.

Jesper Roine and Daniel Waldenström. Handbook of Income Distribution, volume 2, chapter Long-Run Trends in the Distribution of Income and Wealth, pages 469-592. Elsevier, 2015 . 
Emmanuel Saez and Gabriel Zucman. Wealth Inequality in the United States Since 1913: Evidence From Capitalized Income Tax Data. Quarterly Journal of Economics, 2016.

Matthew Smith, Owen Zidar, and Eric Zwick. Top Wealth in the United States: New Estimates and Implications for Taxing the Rich. Unpublished manuscript, 2019.

Philip Vermeulen. How Fat is the Top Tail of the Wealth Distribution? Review of Income and Wealth, 64(2):357-387, 2017.

Gabriel Zucman. The Missing Wealth of Nations: Are Europe and the U.S. Net Debtors or Net Creditors? The Quarterly Journal of Economics, 128(3):1321-1364, August 2013. 


\section{Appendices}

\section{A Wealth totals: households sector balance sheet}

For our benchmark series, the total net wealth of the household sector (excluding the nonprofit sector serving households - NPSH) are reconstructed based on the Bank of Italy estimates of the households balance sheet available for the years 1995 to 2013. The Bank of Italy publication of the households balance sheet was discontinued in 2015. The exercise was resumed in 2019, in collaboration with the national statistics office - ISTAT - covering a shorter time horizon (from 2005) and aggregating the household sector and the NPSH. The latter estimates are used to extrapolated the balance sheet of the household sector from 2013 to 2016. The series for 1995-2016 are then linked proportionally in 1995 to the earlier series beginning in 1966, published by the World Inequality Database (WID.world).

\section{B Data sources on reported wealth at death in Italy}

Data used in this paper come from the full inheritance tax returns, referred to as "successions," opened between 1995 and 2016. The tax return is filed by the estate executor (one of the heir, or a legal representative) within twelve months of death and is then submitted to the office of the revenue agency (Agenzia delle Entrate) in the province where the deceased had residence. The time limit was set to 6 months up to 2003. Our data are evaluated at year of death. The data are considered to be consolidated after two years following the year of death. ${ }^{39}$ The information contained in the first page of the paper tax form (the so-called "Modello 4.") are digitized by the Ministry of Economy and Finance (see figure B.1). The last data update in this paper was obtained in May 2020. A set of 19,200 tax returns presented in 2017 and 2018 with the new electronic form, but related to deaths that occurred in 2016, were included in the data. Microdata are transformed into detailed tabular form by the statistical office of the Ministry of Economics and Finance and shared.

The main tabulations provided have 34 net wealth ranges, from negative values to the highest range worth $€ 20$ million or more. The demographic information is provided by seven age groups (i.e., under 20, 20 to 40, 40 to 50, 50 to 60,60 to 70,70 to 80 , and over 80), two gender groups (i.e., males, females), and three Italian macro areas (i.e., south and islands, north, and center). A gender not stated and age not stated groups also appear when needed. Tabulations by more refined age classes (every 5 years, from under 5 to 100 years old and above) were also provided with for a subset of years, namely for 1995 and for the post-2012 period. Four asset classes are identified in the tabulations: Housing and land; business assets, equity, and debt securities; other assets (including current and saving deposits, valuables, etc.); and liabilities and deductible expenses. Similarly, the tabulations identify the taxes paid (on the global value of the estate as well as on the inherited shares), the value of assets sold within six months from death (reported between 1990 and 2000), and the capitalized value of all gifts and donations done in life.

\footnotetext{
${ }^{39}$ This is done because the heirs might miss the 12 -month deadline, or the assessing procedure by the Revenue Agency might last several months for the most complex inheritances.
} 
Figure B.1: The first page of the Modello 4 - Inheritance tax form

Sintrate

MOD. 4

\section{DICHIARAZIONE DI SUCCESSIONE}

Direzione Provinciale di

Ufficio Territoriale di

O ESTREMI DELLA PRESENTAZIONE (barrare la casella che interessa)

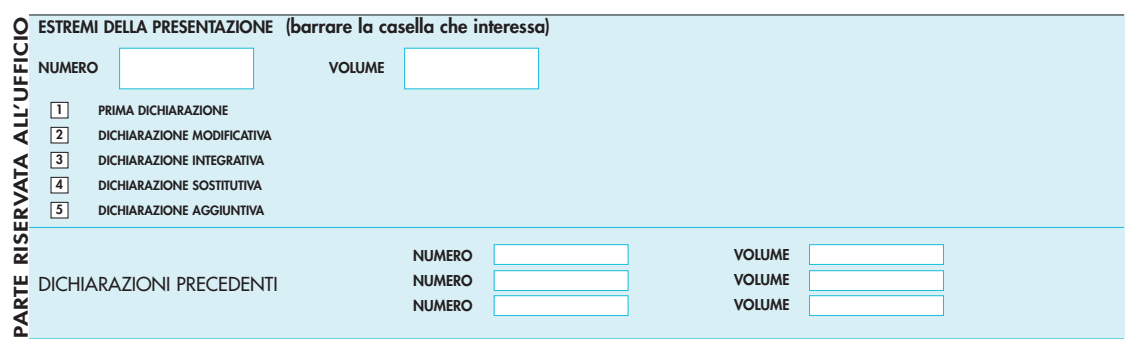

DATI ANAGRAFICI DEL DEFUNTO

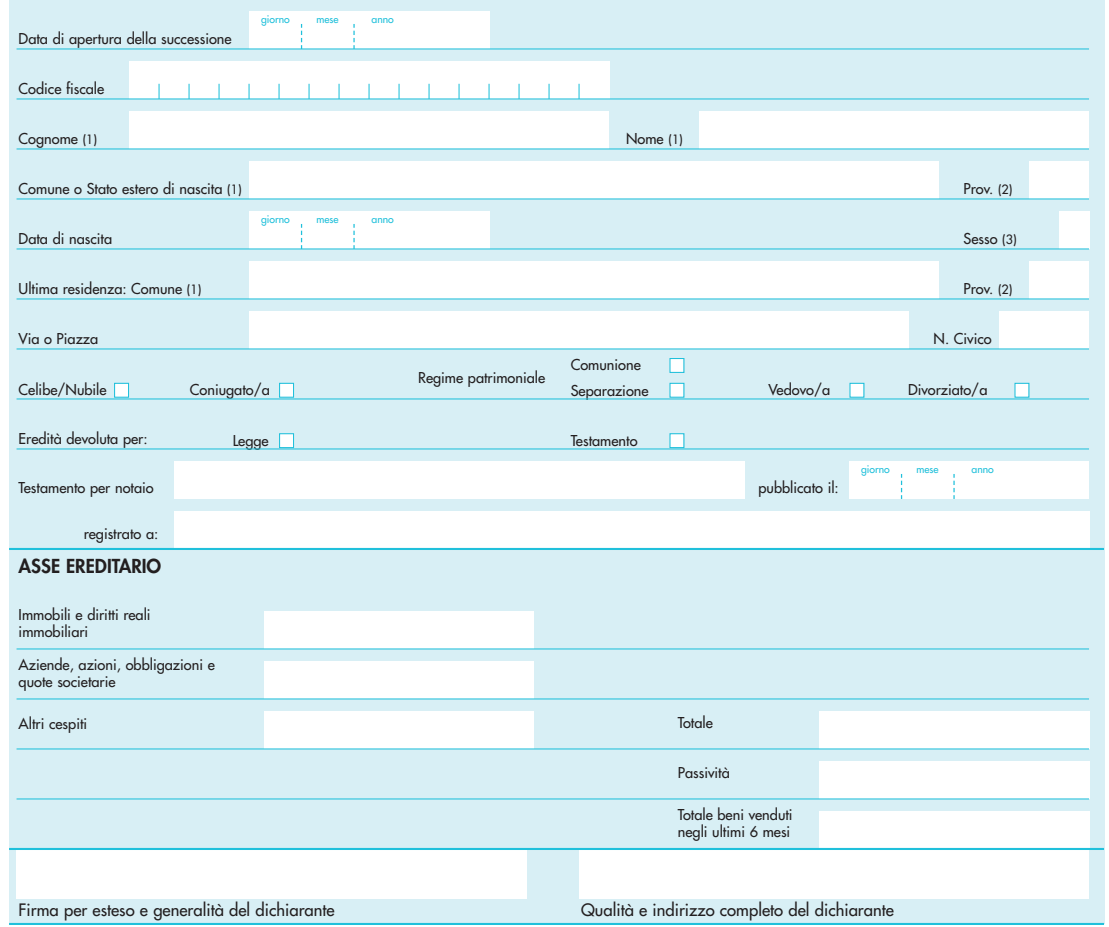

(1) Senza abbreviazioni

(1)

- Le parti evidenziate con tondino colorato sono riservate all'Uficio
AWEERTENA : Ove $i$ quadri isultino insufficienti compilare quadri aggiuntivi.

Note: document retrieved from https://www.agenziaentrate.gov.it 


\section{Re-weighting the population of the deceased using the mortality multiplier method}

We make use of the information reported to the tax authorities for the administration of inheritance or estate taxes as well as detailed mortality rates by a set of socio-demographic characteristics. The inverse of the mortality rate of each decent group $i$ (e.g. multiplier

is defined as $m_{i} \equiv \frac{1}{p_{i}}$, where $p_{i}$ is the mortality rate of group $i$ ) represents the number of living individuals with similar socio-demographic characteristics. In this paper we multiply the number of decedents and their reported wealth value by the relevant mortality multiplier $m_{i}$ for each specific socio-demographic group $i$. This procedure reshapes the decedent population, creating a representation of the living population to estimate its distribution of wealth.

We define the estate value of each decedent as $w_{E, i}$ and arranged them in descending order, so that $w_{E, i} \geq w_{E, j}$, if $i<j$. The population of decedents is $N_{E}$ and the total value of their estates is defined as $W_{E}$ and takes the following form:

$$
W_{E}=\sum_{i=1}^{N_{E}} w_{E, i} .
$$

The application of the mortality multiplier provides the following result:

$$
W=\sum_{i=1}^{N_{E}} m_{i} w_{E, i} .
$$

where $W$ is the total wealth among the living population of the group $i$.

Figure C.1, illustrates how the age distribution of wealth holdings is affected by the application of mortality multipliers, shifting from the population of decedents (panels (a) and $(\mathrm{d})$ ) to the population of the living (panels (b) and (e)). Figure C.1 also illustrates, in the panels (c) and (f), how the share of prevalent age groups differs across the wealth distribution by zooming into the richest $1 \%$. The population of decedents is clearly skewed towards the individuals aged 80 and above, whereas the application of mortality multipliers rescales the population in favour of middle-aged groups. Yet, on average, wealthy individuals belonging to the top $1 \%$ tend to be older than the overall population. 
Figure C.1: From the population of decedent to that of living wealth holders using mortality multipliers: distribution by age groups over time

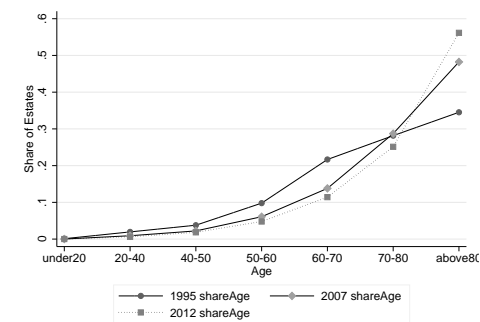

(a) Decedent wealth holders filing inheritance tax returns
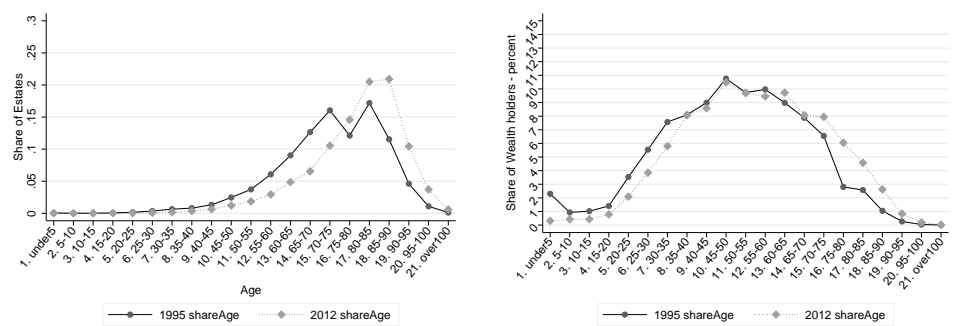

(d) Decedent wealth holders filing (e) Identified wealth holders-5 inheritance tax returns-5 year age year age classes classes

Source: Panels a) and d) represent the age distribution of decedents whose wealth is represented on MEF micro data on inheritance tax returns. Panels b) and e) represent the age distribution of living wealth holders derived by multiplying the inheritance tax returns by mortality rates (obtained from ISTAT mortality tables) Panels c) and f) are similar to b) and e) conditioned on having a net wealth value higher than the 99th percentile.

\section{Mortality rates}

\section{D.1 Data source}

The main source of information for mortality rates in Italy is the database assembled by ISTAT and publicly released online at demo.istat.it. The information on mortality is provided on a yearly basis. It includes age, gender, and geographical location up to the level of province of residence. We use the information at the level of the given five macro-areas of residence (north-est, north-west, center, south, and islands) and consolidate this into three macro-areas: south (including islands), center, and north. The database includes, for each age, gender, year, and location, biometric variables such as the number of deaths, life expectation, survival probability, and the probability of death. These biometric details are estimated out of a synthetic population of 100,000 individuals.

Once the database of mortality rates is structured, we invert the rates to obtain mortality multipliers. The heterogeneous pattern of mortality rates and multipliers by age can be observed in figure D.1 comparing the evidence in 1995 and 2016 for Italian men. As seen 
in panels (a) and (b), the probability of death raises exponentially above the 70 year-old threshold, and the average reduction of mortality rates occurred between 1995 and 2016 can be visibly observed as the 2016 line lies below the 1995 one especially for older groups. The mortality multipliers, by construction, show large heterogeneity for younger groups, especially below 30 years old. Panels (c) and (d) of figure D.1, also reveals that imperceptible changes in mortality rates for younger cohorts would generate substantial variation in multipliers. Equally, more substantial changes in mortality rates for older cohorts is not necessarily reflected in substantial changes in mortality multipliers.

We further group age information to mimic the structure of tax tabulated information on estate left at death. Tax tabulations are structured in 7 age groups : under 20, between 20 and 40, between 40 and 50, between 50 and 60, between 60 and 70, between 70 and 80 , and above 80 years old. We discard mortality observations below 10 years old and above 103 years old to avoid outliers. We also create 20 age groups, in 5-year ranges, to mimic the set of more detailed tax tabulations available in 1995 and yearly between 2012 and 2016. In this case, no age information is discarded.

The average mortality rate, as computed for individuals between 10 and 103 years old, was 1.27 percent in 1995 and declined slightly to 1.20 in 2016. The resulting mortality multipliers range from 78 in 1995 to 83 in 2016. These trends can be seen in figure D.2. The number of deaths are close to 600,000 individuals per annum in the most recent years, up by approximately 50,000 units from 1995 . 
Figure D.1: The mortality rate and multiplier across the age distribution: 1995 vs 2016

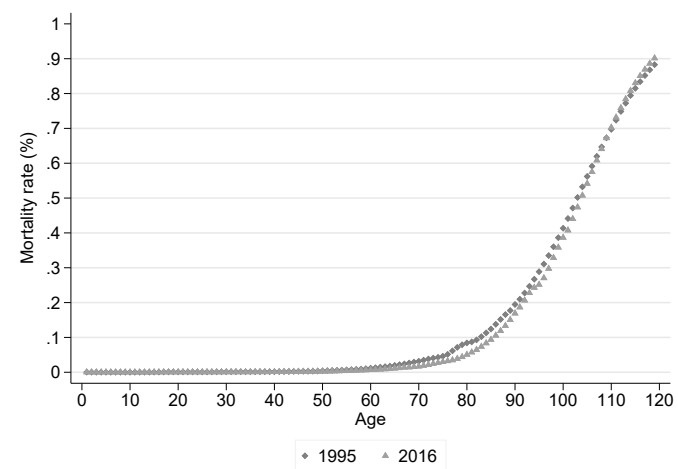

(a) Mortality rates - Males

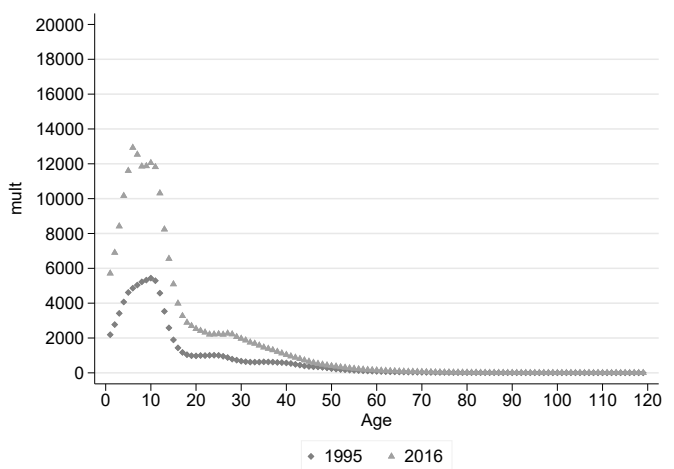

(c) Mortality multipliers - Males

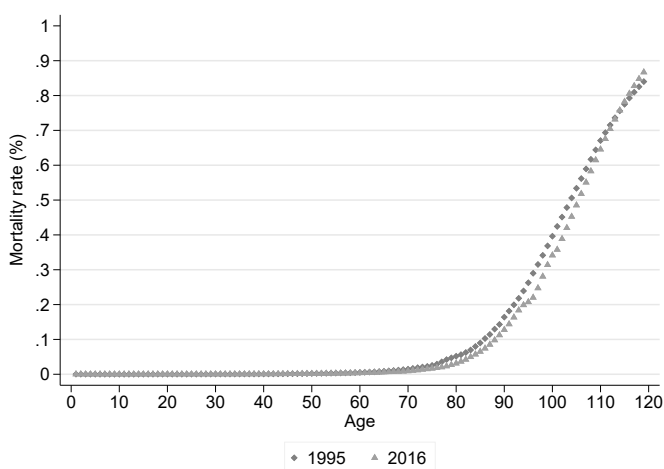

(b) Mortality rates - Females

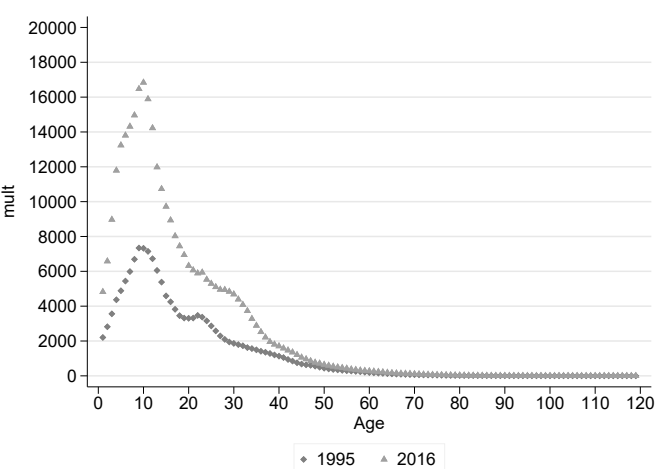

(d) Mortality multipliers - Females

Source: Own computation from ISTAT mortality tables. Mortality multiplier is defined as the inverse of the mortality rate.

Figure D.2: The evolution of average mortality rates and multipliers: 1995-2016

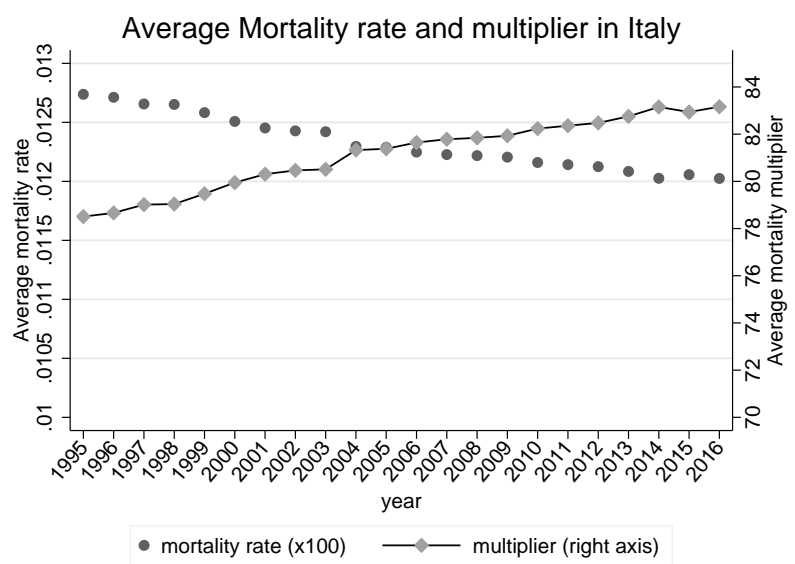

Source: Own computation from ISTAT mortality tables. Mortality multiplier is defined as the inverse of the mortality rate. 


\section{E Adjusting the value of real estate in the inheritance tax records}

Real estate assets are declared using a notional valuation (i.e. cadastral value) for inheritance tax purposes, rather the current market value. As Italian real estate cadastral values are typically well below market values, the use of unadjusted amounts declared in the inheritance tax returns will lead to distorted distributional information as well as an underestimation of the value of personal wealth. Ideally, one would want to substitute the cadastral value for its equivalent market price for every building recorded within tax data. However, this would require an extremely refined and sophisticated set of data which is not possible to access. To overcome this problem, instead, we multiply the cadastral values by an annual adjustment factor derived as the share of average national nominal house price and cadastral value.

The derived ratio of average market price to cadastral value of housing is observed to be constant over the years 2009-2012 and equal to 3.3. In the following years, and following the reduction of housing prices, the ratio declined to 3.2 in 2013, 3.0 in 2014-2015 and 2.9 in 2016. The detailed time series of adjustment factors applied to our data for 2009-2012 is shown in table E.1.

Table E.1: The evolution of average cadastral and market values for housing

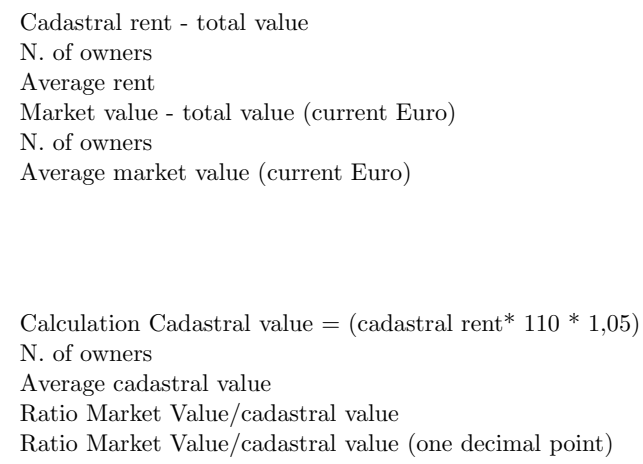

$\begin{array}{llll}2009 & 2010 & 2011 & 2012 \\ 13,060,818,875 & 13,354,007,469 & 13,824,649,519 & 14,047,787,404 \\ 26,742,044 & 27,058,332 & 28,269,412 & 28,502,721 \\ 488 & 494 & 489 & 493 \\ 4,983,370,521,246 & 5,107,630,342,488 & 5,319,036,384,226 & 5,294,979,063,776 \\ 26,757,715 & 27,063,237 & 28,278,342 & 28,511,215 \\ 186,241 & 188,729 & 188,096 & 185,716 \\ & 1.010496435 & 0.990893001 & 1.007822964 \\ 488 & 494 & 489 & 493 \\ & & & \\ 2009 & 2010 & 2011 & 2012 \\ 1,508,524,580,063 & 1,542,387,862,670 & 1,596,747,019,445 & 1,622,519,445,162 \\ 26,742,044 & 27,058,332 & 28,269,412 & 28,502,721 \\ 56,410 & 57,002 & 56,483 & 56,925 \\ 3.30 & 3.31 & 3.33 & 3.26 \\ 3.3 & 3.3 & 3.3 & 3.3\end{array}$

Average annual market value of properties for the years 2009-2016 is obtained from the "Osservatorio del Mercato Immobiliare - OMI", published by the Revenue Agency/Nomisma. Similarly, data on the average annual cadastral rent of houses owned by physical persons are derived from the internal data of the Revenue Agency and the Ministry of Economics and Finance, "Analisi Patrimonio Immobiliare - API", used for the annual publication by the Ministry of Economy and Finance, "Gli immobili in Italia."

The average cadastral values are then derived multiplying average cadastral rents by tax coefficients used for the inheritance tax base. For owner-occupying houses the coefficient equals 100 up to 2003 and 110 since 2004, and since 1997 an additional flat re-valuation of cadastral value of 5 percent is applied for tax purposes. ${ }^{40}$

\footnotetext{
${ }^{40}$ The cadastral value for year 2013 , as an example, would therefore be derived as the cadastral rent in
} 
Table E.2: Adjustment coefficient for cadastral value of real estates

\begin{tabular}{|c|c|c|c|c|c|c|}
\hline & year & $\begin{array}{l}\text { annual percentage } \\
\text { change house } \\
\text { nominal price (BIS) }\end{array}$ & $\begin{array}{l}\text { annual percentage } \\
\text { increase cadastral } \\
\text { rents (MEF) }\end{array}$ & $\begin{array}{c}\text { Inheritance tax } \\
\text { coefficients on } \\
\text { cadastral rent } \\
\text { (owner occupied houses) }\end{array}$ & $\begin{array}{l}\text { Inheritance tax } \\
\text { revaluation } \\
\text { coefficient of } \\
\text { cadastral rent }\end{array}$ & $\begin{array}{l}\text { Market value/ } \\
\text { cadastral value }\end{array}$ \\
\hline \multirow{14}{*}{$\begin{array}{c}\text { Estimates based on } \\
14^{*} \quad \text { cadastral rend and } \\
\text { market price evolution }\end{array}$} & 1995 & 0.01 & 0.004 & 100 & 1 & 2.2 \\
\hline & 1996 & 0.04 & 0.004 & 100 & 1 & 2.3 \\
\hline & 1997 & 0.03 & 0.004 & 100 & 1.05 & 2.2 \\
\hline & 1998 & 0.00 & 0.004 & 100 & 1.05 & 2.2 \\
\hline & 1999 & 0.01 & 0.004 & 100 & 1.05 & 2.2 \\
\hline & 2000 & 0.04 & 0.004 & 100 & 1.05 & 2.3 \\
\hline & 2001 & 0.06 & 0.004 & 100 & 1.05 & 2.4 \\
\hline & 2002 & 0.12 & 0.004 & 100 & 1.05 & 2.7 \\
\hline & 2003 & 0.06 & 0.004 & 100 & 1.05 & 2.8 \\
\hline & 2004 & 0.06 & 0.004 & 110 & 1.05 & 2.7 \\
\hline & 2005 & 0.08 & 0.004 & 110 & 1.05 & 2.9 \\
\hline & 2006 & 0.06 & 0.004 & 110 & 1.05 & 3.1 \\
\hline & 2007 & 0.05 & 0.004 & 110 & 1.05 & 3.2 \\
\hline & 2008 & 0.03 & 0.004 & 110 & 1.05 & 3.3 \\
\hline \multirow[t]{8}{*}{$8^{*} \mathrm{MEF}$ - Official estimates } & 2009 & & & 110 & 1.05 & 3.3 \\
\hline & 2010 & & & 110 & 1.05 & 3.3 \\
\hline & 2011 & & & 110 & 1.05 & 3.3 \\
\hline & 2012 & & & 110 & 1.05 & 3.3 \\
\hline & 2013 & & & 110 & 1.05 & 3.2 \\
\hline & 2014 & & & 110 & 1.05 & 3.0 \\
\hline & 2015 & & & 110 & 1.05 & 3.0 \\
\hline & 2016 & & & 110 & 1.05 & 2.9 \\
\hline
\end{tabular}

Average cadastral value was relatively stable at around $€ 56$ thousand between 2009 and 2016, whereas the average marked value declined, over the same period, from $€ 186$ thousand to $€ 162$ thousand.

Unfortunately, for the years before 2009 we could not resort to the publication "Gli immobili in Italia" and we had to estimate the ratio of market price to cadastral value. To do so, we estimated the average market value by using the observed yearly variation of housing prices (using the Bank of International Settlements - BIS - estimates of nominal growth rate of house price index based on the published figures by the Bank of Italy for more recent years). Similarly, we made use of the average yearly percentage change of average cadastral rent over the period 2007-2013, to estimate the average cadastral value between 1995 and 2009. Cadastral rents increased, on average, by 0.4 percent every year. As explained above, allowance for changes in the tax legislation affecting the cadastral values should also be made. As detailed in table E.2, the derived yearly adjustment factors applied to the cadastral values range between 1.9 in 1995 to 3.3 in 2013.

The use of a yearly national adjustment factor for cadastral values may have a series of shortcomings. First, the use of a national multiplier ignores disaggregated geographical heterogeneity. This may affect estimates of wealth concentration as long as such unobserved geographical heterogeneity correlates with wealth rankings. Similarly, we adopted a unique adjustment factor across cadastral classes. However, different cadastral classes has different cadastral adjustment coefficients to be applied to the cadastral rent for tax purposes. As

2013 times 110 times 1.05 . 
written above, as of January 2004, 110 is the multiplier applied to the main owner-occupied housing (the so called 'prima casa', falling within the cadastral classes A/1 to A/11 with the exception of A/10). The coefficient, as of mid 2004, is 120 if the house is not the main residence. These coefficients apply to regular dwellings, to castles, villas, and historical building alike. If most secondary houses were concentrated only in the hands of wealthy individuals, the use of a constant adjustment factor to house cadastral rents, may create a bias. Other things being equal, this may result in a upward bias for our estimates of wealth concentration, as the reported value of a secondary house in the inheritance tax return is $9 \%$ higher than the owner occupied house (120/110). However, the final effect on the wealth shares cannot be entirely known in advance as second homes may also have a larger systematic undervaluation of market value. Cadastral multiplier vary according to the type of real estate, 120 also applies to many buildings in the $\mathrm{C}$ cadastral categories such as covered car parks, cellars, stores, laboratories and small businesses, with the exception of shops (cadastral category $\mathrm{C} 1$ ), in this case the coefficient is 40.8. On land rents the coefficient is 90 and on offices rent (cadastral category A10) the coefficient is 60. Other cadastral categories mainly apply to public spaces and buildings and may not be relevant for personal ownership of real estates. As a systematic assessment of the market value of all different cadastral categories is not available, it is not possible to assess how the adjustment factor based on the owner-occupied houses we used fits with the degree of underestimation of cadastral values of other real estate categories. Unfortunately, we could not obtain the information about cadastral types from our individual data but we could observe the share composition of different types of buildings owned by different individuals across the income distribution. Although not precise this exercise provides informative results. Indeed, real estate different from housing represent less than $10 \%$ of household real estate wealth and is distributed quite evenly across income classes. Despite some existing heterogeneity, the share of houses and apartment structure remains quite high even for the highest income class $(86 \%)$. Therefore, unless the cadastral heterogeneity is systematically correlated to unobserved geographical variations, allowing for different adjustment factors should not produce large biases in our estimates. 


\section{F The identified population using inheritance tax records}

Figure F.1: The coverage of decedents people and total adult population using inheritance tax records

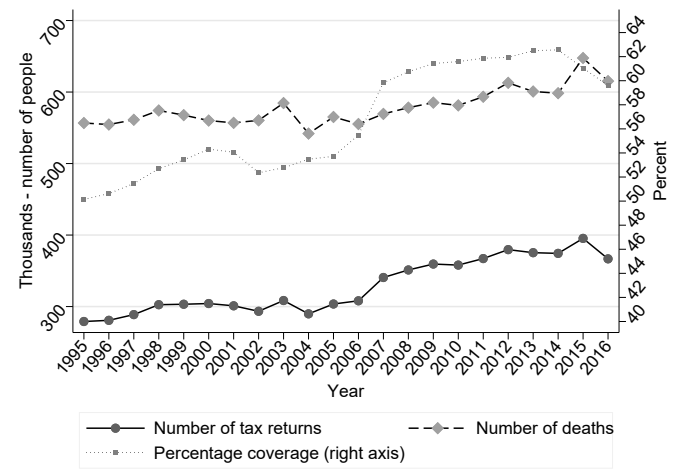

(a) $\mathrm{N}$ of decedents and filers

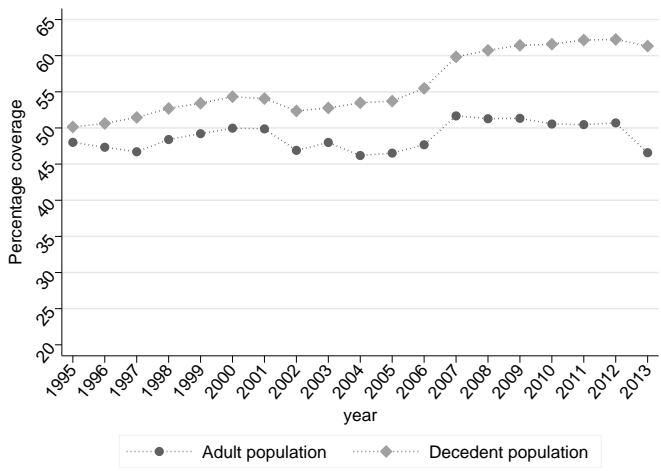

(b) $\%$ of dead and living adults covered

Note: Panel a) shows the number of inheritance tax returns compared to the number of dead person every year. Panel b) shows the coverage rate of the decedent people through the inheritance tax returns (i.g. the ratio between the number of tax returns and the number of deceased) as well as the coverage rate of the total adult population (i.e. the ratio between the number of identified adults via the mortality multiplier method and the actual number of adults). Population and mortality statistics are obtained from ISTAT. 
Figure F.2: Coverage of total population by age groups: multiplied-up inheritance tax records vs. SHIW

Total individuals by Age: SHIW vs tax data - 2006

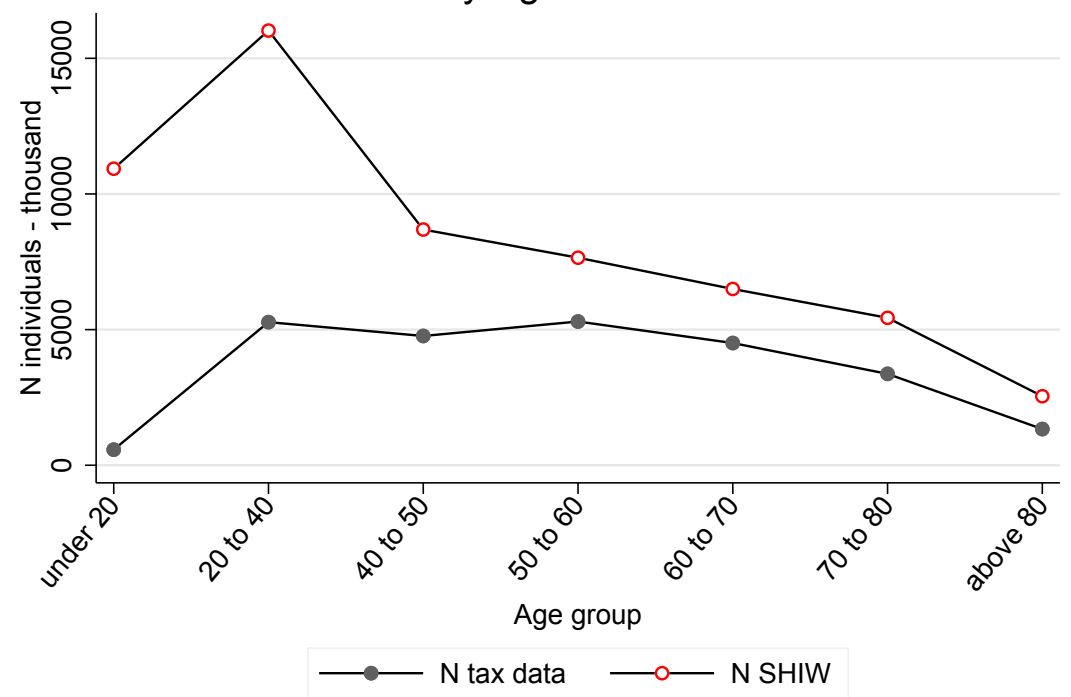

Figure F.3: Frequency of adults across the wealth distribution: 2010 tax-based identified wealth vs. SHIW

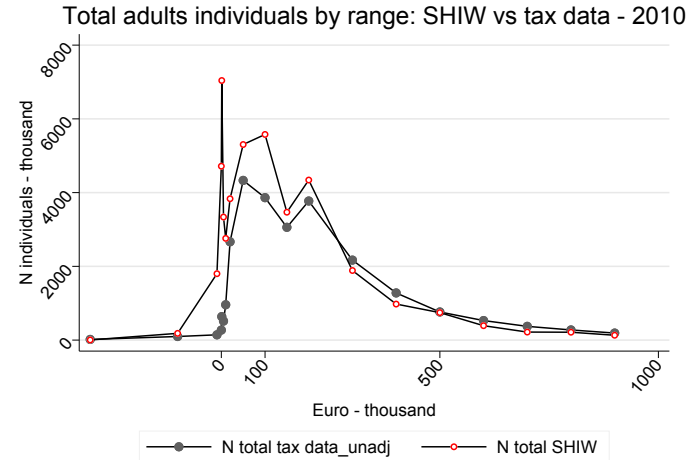

(a) adults with less than $€ 1$ million

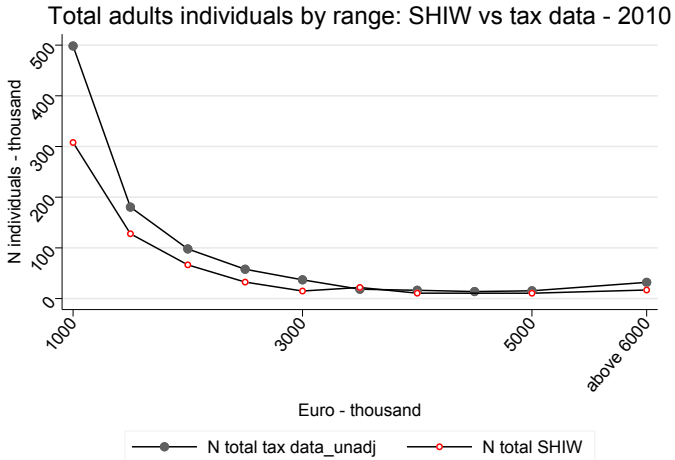

(b) adults with at least $€ 1$ million

Source: The graphs compare, for each wealth range, the number of adults (aged 20 or more) identified from multiplied-up inheritance tax records (i.e. figures re-scaled using mortality multipliers) to that estimated from the SHIW data. Panel a) shows the trimmed distribution below 1 milion Euro. Panel b) shows data above the 1 milion Euro range. Wealth holdings of the households in the SHIW data are allocated to individual adults before comparing it to the tax-based information. The Tax-based information presented here does not allow for the wealth of the missing population or for underreporting of wealth. 


\section{G Total estates and total identified wealth using inheritance tax records}

Figure G.1: Total estates and total identified wealth by asset classes

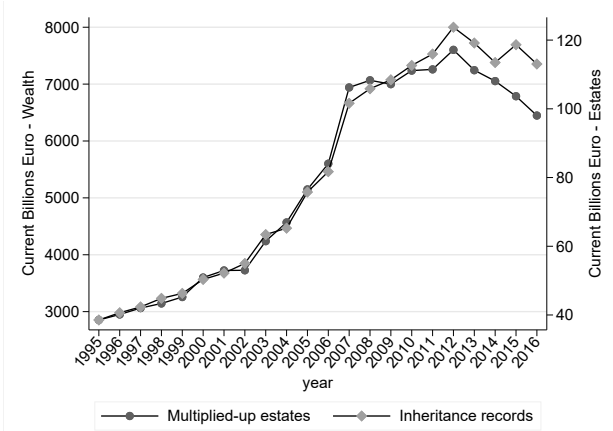

(a) Total gross wealth

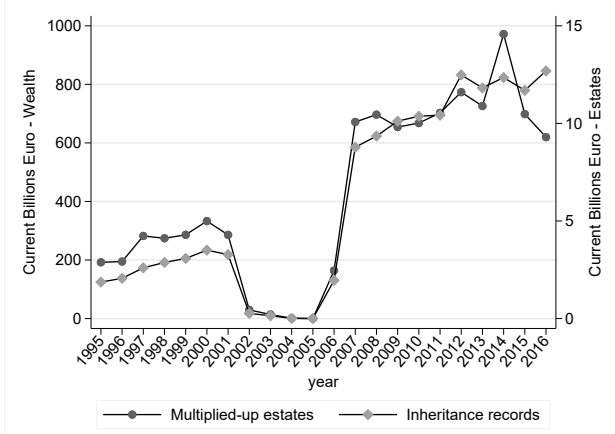

(c) Total financial and private business wealth

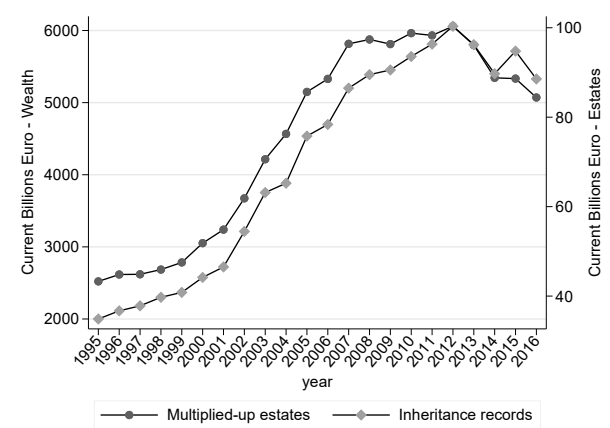

(b) Total housing and land wealth

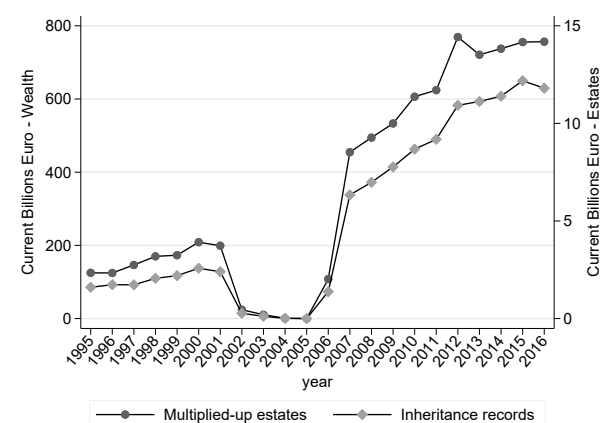

(d) Total deposits, valuables, and other wealth

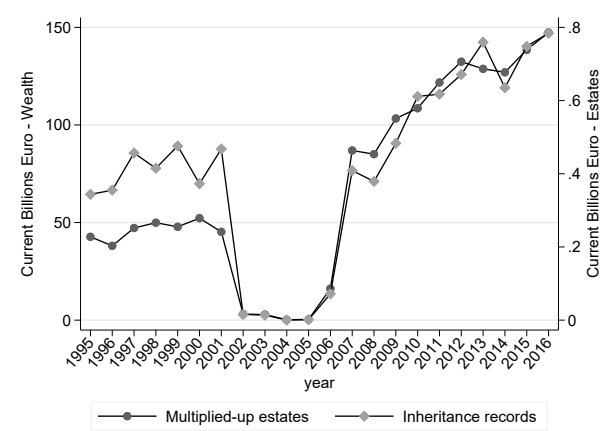

(e) Total liabilities

Note: The figure compares the total value reported on inheritance tax records to the total net wealth identified by multiplying-up the reported net estates with the inverse of mortality rates. The comparison is carried out for total gross wealth (panel a), total market value of land and housing wealth (panel b), total value of financial and private business assets (panel c), total value of deposits, valuables, and other wealth (panel d), and total liabilities (panel e). Note that the inheritance and gift tax was repealed between 2001 and 2006, causing reported values, other than housing and land, to plummet. 
Figure G.2: Total estates, total wealth and total housing and land wealth: household's sector balance sheet, SHIW, and multiplied-up estates data
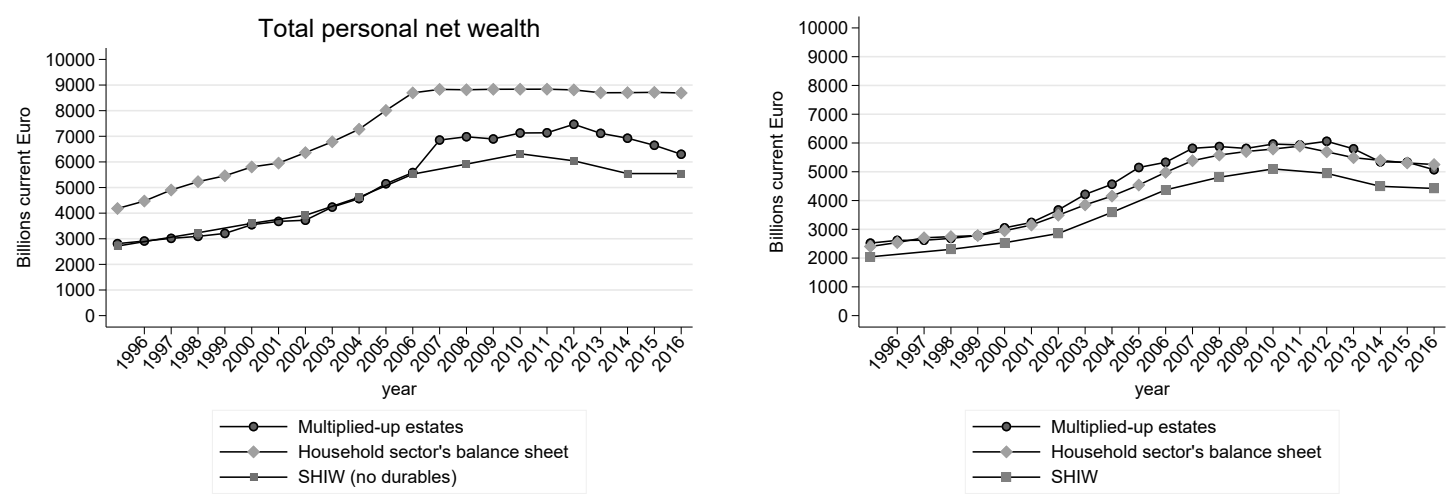

(a) Total wealth: NA, SHIW, and multiplied-up es- (b) Total housing and land wealth: NA, SHIW, and tates multiplied-up estates
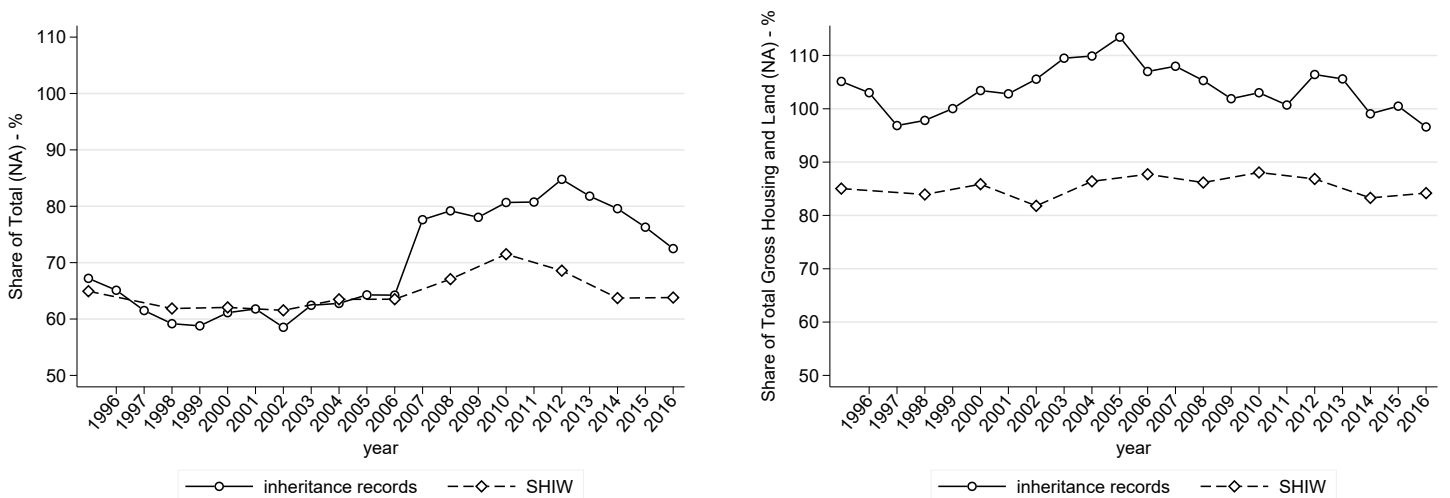

(c) Total wealth: SHIW, and multiplied-up estates - (d) Total housing and land wealth: SHIW, and coverage rate ( $\%$ of NA figures) multiplied-up estates - coverage rate (\% of NA figures)

Note: Panels a) and b) show values of total households net wealth and total gross value of housing and land using three different independent sources: the household's sector balance sheet (estimated using data from ISTAT and Bank of Italy); the household survey - SHIW (with full coverage of the population), and the total value of wealth reported on inheritance tax records multiplied-up with the inverse of mortality rates (with partial coverage of the population). Note that, at this stage, the only adjustments applied to

the inheritance tax data are the transformation of real estate cadastral values into market values.

\section{H Imputation of missing wealth}

\section{H.1 Estimation and imputation of the wealth of the missing population}

The inheritance tax return filing is necessary to legally transfer real estate property rights to the heirs. In the absence of real estate, tax returns should be filed if the total estate (net of liabilities) is above 35.000 Euro. In 2014, the latter threshold was raised to 100.000 Euro. Hence, any individual decedent who has relatively little accumulated financial wealth and no real estate is in principle not be represented in the tax records. 
Using the SHIW, we identified the so called 'missing population'. To do so, we first allocate household wealth to each single adult composing the households. Following the work by D'Alessio (2018), we make use of information about individual asset holding to allocate each specific asset to different individuals. ${ }^{41}$ Alternatively, we split equally the total household specific asset value between the head of the household and her partner. In the absence of a partner all household wealth is allocated to the head.

Based on information about pension and insurance contributions, we also estimated the outstanding accumulated reserves available in these funds and allocated them to individuals. $^{42}$ Once individual asset holding is estimated we identify every head of household or partner who is not in possession of housing and who is below the reporting threshold as required by the inheritance tax legislation: approximately 25.000 Euro, increased to 100.000 Euro from 2014 onward. Everyone who is below this threshold and is not a homeowner is considered to belong to the missing population. This also includes every adult, different than the head of the household or her partner, with wealth below the specified thresholds. In 1995, there were approximately 21 million adults not homeowners and whose wealth is below the specified threshold. This number declined gradually by 1 million till 2010 before starting to raise back again to 1995 levels in 2016.

The identified missing population and its net wealth is appended to the tax-based information.

Figure H.1: Number of missing adults and their wealth by asset type

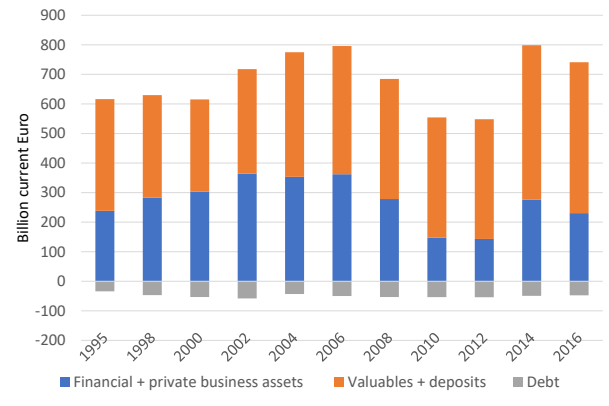

(a) Wealth of the missing population

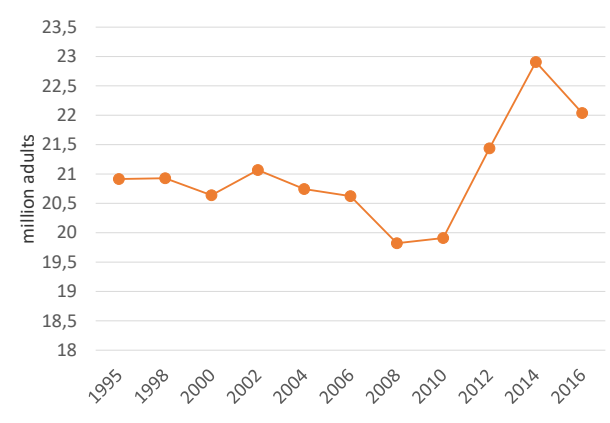

(b) Missing population (number of adults)

Source: Estimates from SHIW data

\footnotetext{
${ }^{41}$ The final exercise slightly differs from D'Alessio (2018) as the information needed to split asset holding is not always readily available in the household survey public use file. The exact procedure used in this paper is explained in the AppendixK and differences in the procedure used by D'Alessio (2018) will be pointed out.

${ }^{42}$ This exercise is explained within the Appendix L.
} 
Figure H.2: The identified number and wealth of the missing population by age group, macro area, and wealth range

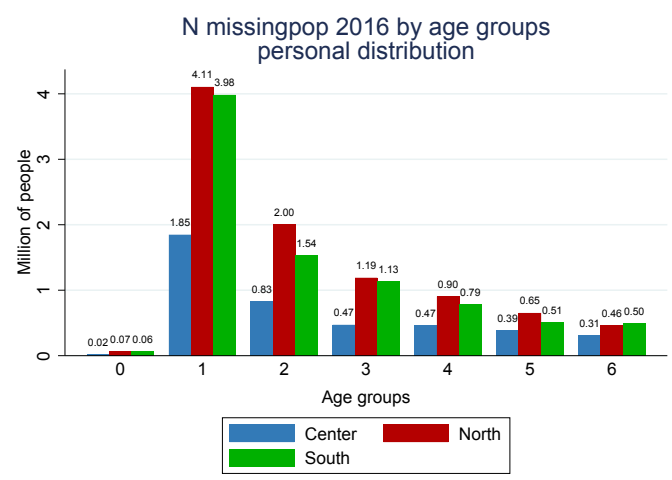

(a) $\mathrm{N}$ by age group and macro area

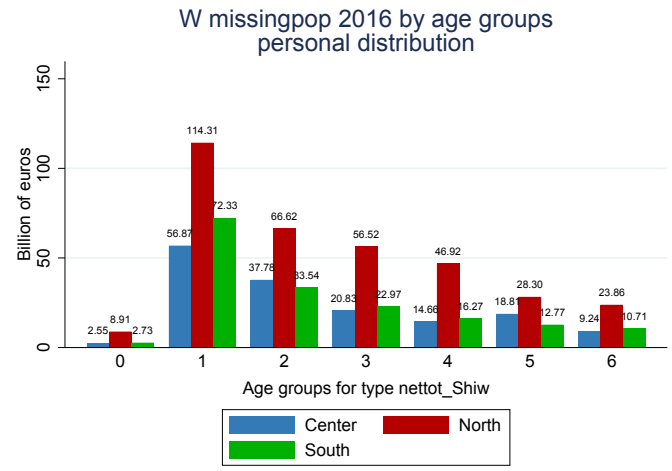

(c) Net wealth by age group and macro area

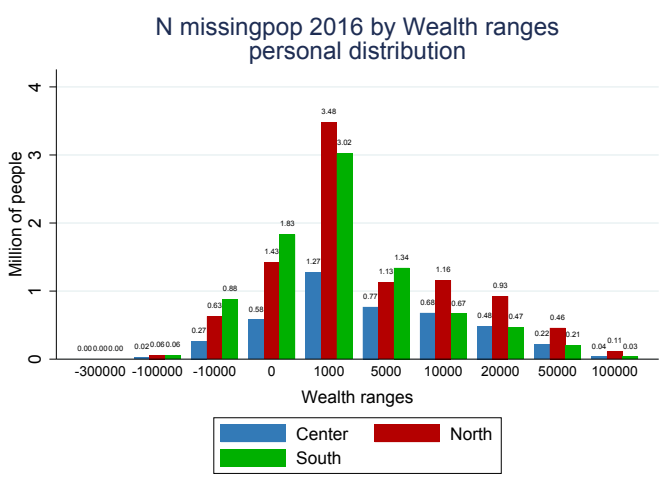

(b) $\mathrm{N}$ by wealth range and macro area

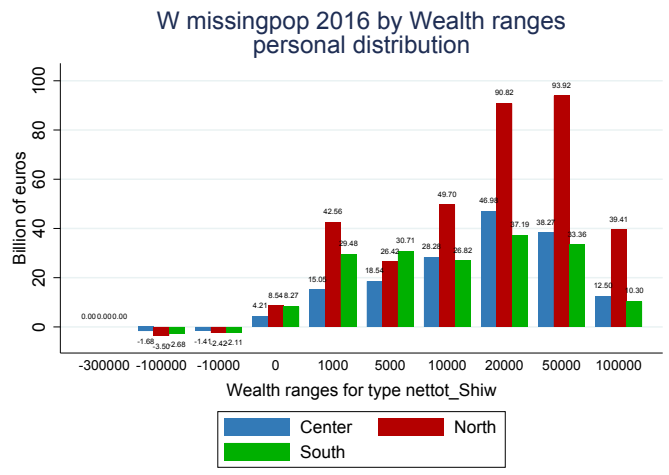

(d) Net wealth by wealth range and macro area

Source: Own computation from based on SHIW data. Adults without real estate ownership and with a level of net wealth below the reporting threshold for inheritance tax purposes (e.g. below 100 thousands Euro after 2014) are considered to be part of the missing population.

\section{H.2 Imputation of tax-exempt assets}

To derive a measure of unreported tax-exempt assets we use the tax code and practice in filing. The value of these assets are then imputed. The imputation is based on the observed proportional distribution of joint financial and business assets (observed from the tax data adjusted for the missing population). ${ }^{43}$ In particular, we impute the total value of insurance technical reserves net of liabilities (the total value of assets accumulated in pension, life insurance, and severance payment funds), and $50 \%$ of Italian government securities. Indeed, the reporting of government bonds is often recommended by tax accountants and most certainly happens in those cases where securities are bundled with other assets in investment funds, as officially documented by banks and other financial intermediaries following death of a legal owner. Such investment bundles can be fully reported on the

\footnotetext{
${ }^{43}$ The value of the shares in unquoted companies is taken at the book value for tax purposes and it is not modified for our distributional exercise.
} 
inheritance tax form, and the tax authority would then compute the relevant tax deductions.We impute $100 \%$ of government securities during the years where the estate, gift, and inheritance tax was not in place (e.g. the period included between October 2001 to October 2006 ). We also include $90 \%$ of notes and coins (100\% in years where the tax was abolished) in our definition of unreported tax exempted assets, although this is not technically the case. The contribution of this asset is very marginal and makes this choice practically irrelevant. ${ }^{44}$

The total net value of financial tax-exempt assets which are likely to be reported in the inheritance tax records was worth $€ 320$ billion in 1995 and $€ 940$ billion in 2016, just above $10 \%$ of total personal net wealth in the country (cfr. Figure H.3).

Figure H.3: Total net value of financial assets exempted from inheritance tax and likely to be unreported on inheritance tax forms

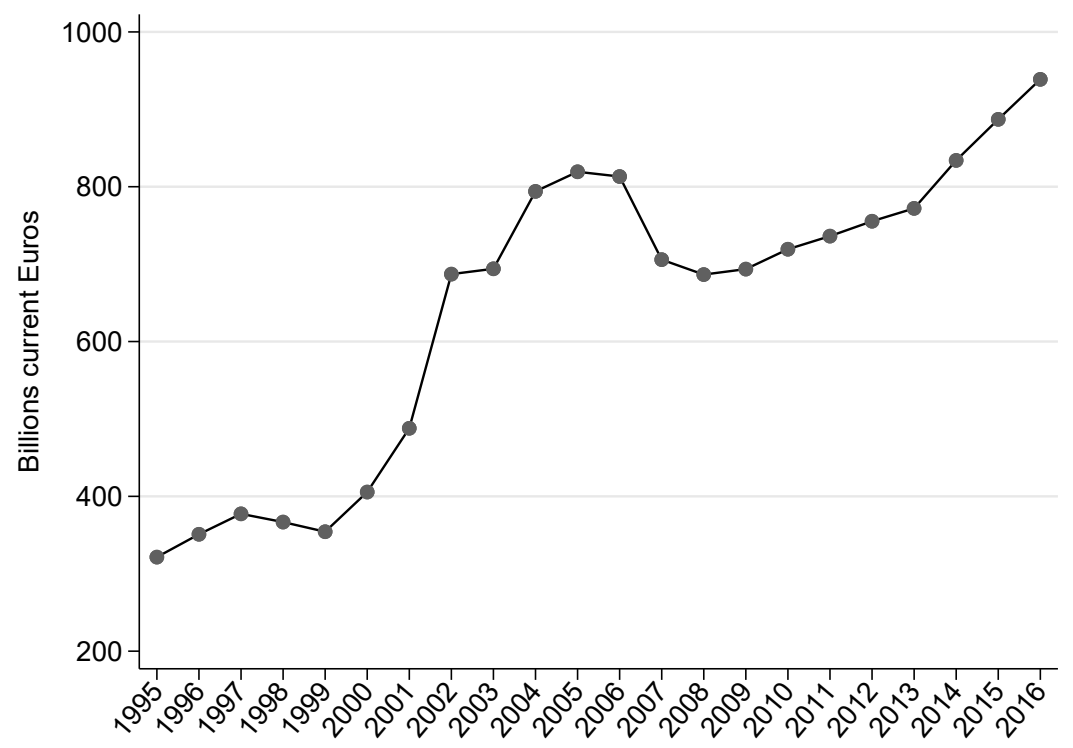

\section{H.3 Matching NA aggregates: imputing the remaining wealth gaps}

The derivation of our benchmark series of wealth distribution and concentration requires, by construction, the alignment of our aggregates with those based on the National Accounts household's balance sheet. The imputation of the wealth of the missing population and the unreported tax exempt assets are complemented with the imputation procedure of any remaining discrepancies (positive or negative) between the national accounts aggregates and our data (see Figure H.4). The imputation is based on four macro wealth categories: Financial plus private business assets; valuables, deposits, and others; housing and land assets;

\footnotetext{
${ }^{44}$ Unless specifically inventoried, cash money is considered to be evaded by the tax authority (a general rule of thumb is applied to compute tax liabilities, considering notes and coins to amount to $10 \%$ of the value of the declared estate).
} 
and liabilities.

As described above for the imputation of tax exempt assets, the imputation is based on the observed proportional distribution of these assets macro categories (observed from the tax data adjusted for the missing population). Such proportional distributions are visually represented in Figure H.5.

Figure H.4: Adjusted identified wealth, SHIW, and the national balance sheet

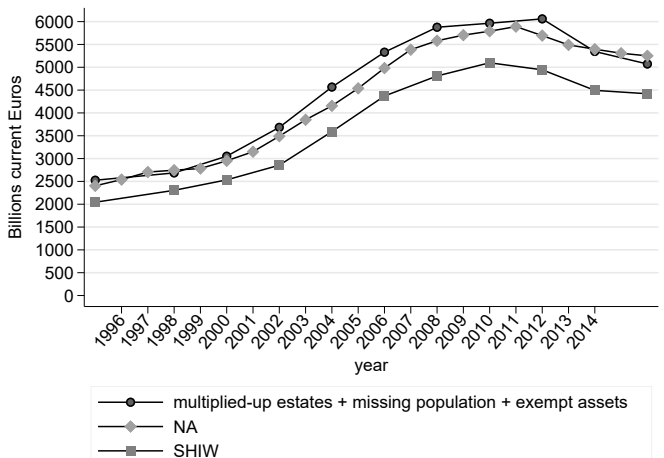

(a) Housing and land assets

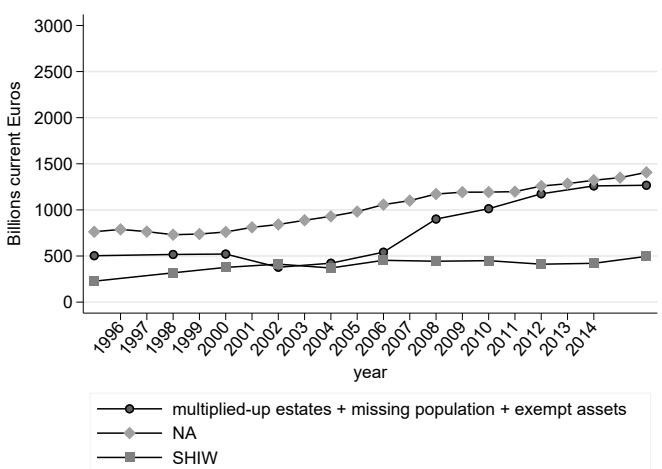

(c) Valuables and deposits

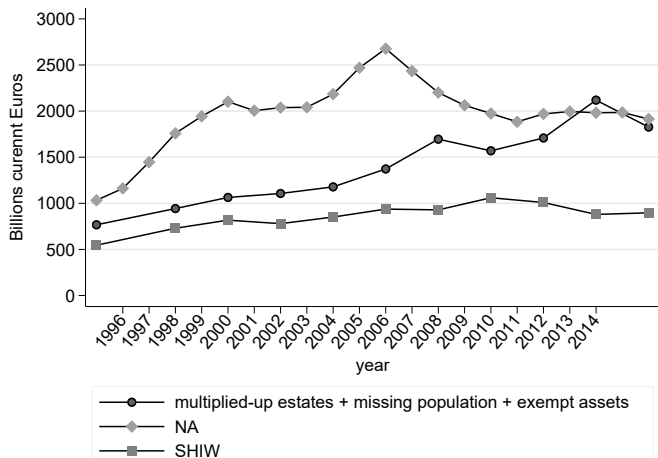

(b) Financial and private business assets

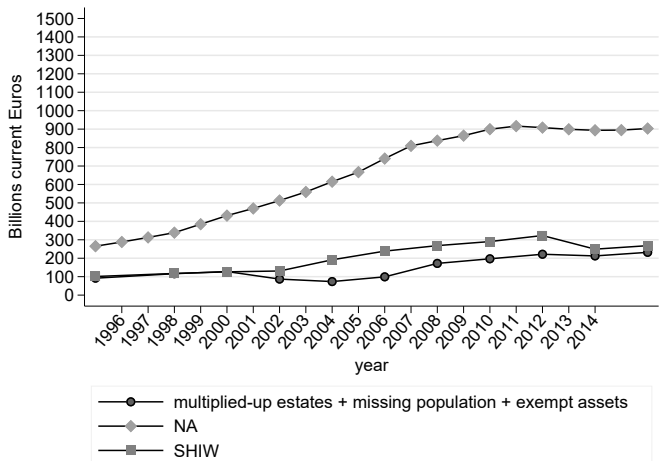

(d) Liabilities

Note: The figures show values of total reported wealth, by asset classes, using three different independent sources: the household's sector balance sheet (estimated using data from ISTAT and Bank of Italy); the household survey - SHIW (with full coverage of the population), and the total adjusted value of wealth reported on inheritance tax records multiplied-up with the inverse of mortality rates. The adjustments to the reported wealth make allowances for the unobserved wealth held by the non-filers (missing population) and for the unreported tax exempt assets. Hence the adjusted values reported here refer to the full population as in SHIW. 
Figure H.5: Proportional distribution of assets by types and wealth ranges

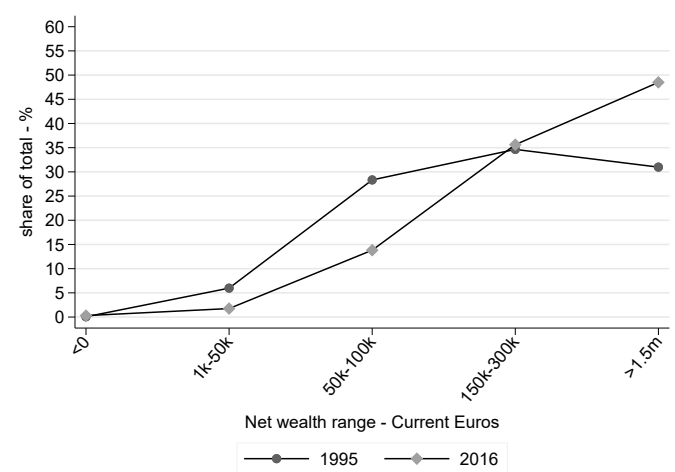

(a) Housing and land assets

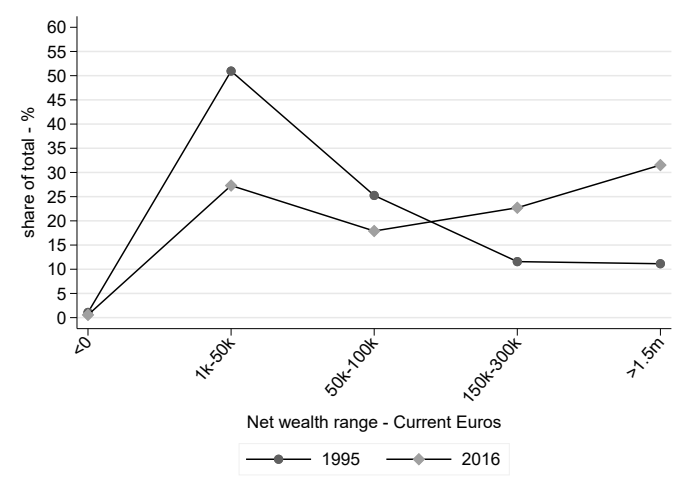

(c) Valuables and deposits

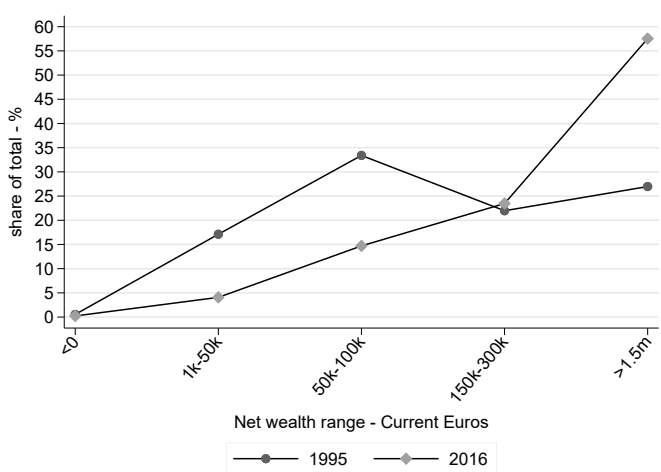

(b) Financial and private business assets

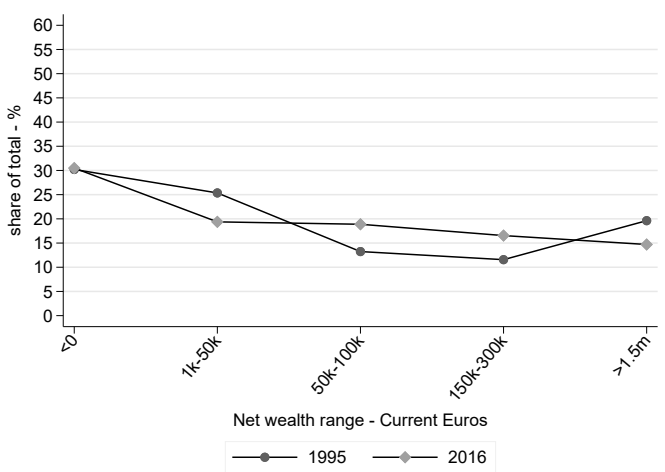

(d) Liabilities

Note: The graph shows a simplified representation, for each class of assets, of the proportions of total assets held across the wealth groups (ranked across total net wealth). These proportional factors are used to impute missing assets and liabilities and matching aggregates with the relevant series of the household's sector balance sheets. 
I The inheritance tax revenue, coverage, and its progressivity structure

Figure I.1: The share of total estates subject to taxation

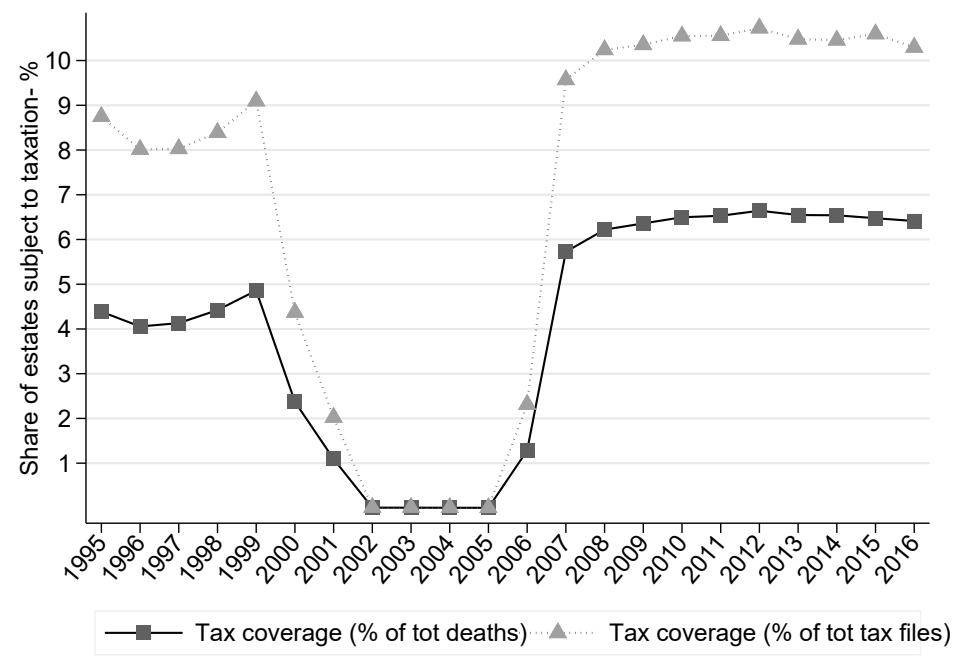


Figure I.2: Average tax paid and inheritance tax revenue: 1995-2016
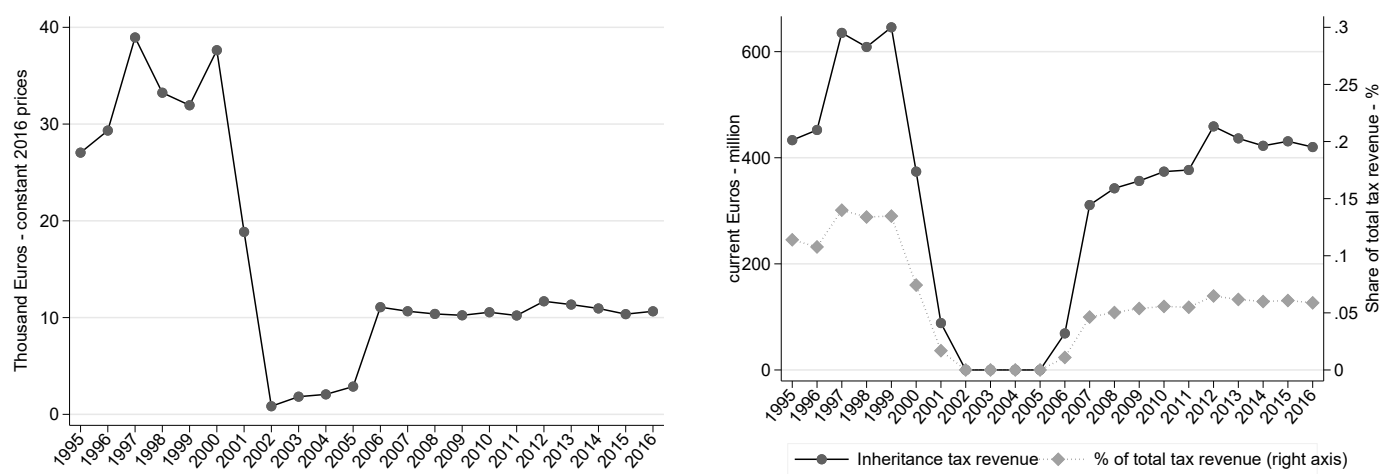

(a) Real average tax paid

(b) Inheritance tax revenue (\% total revenue)
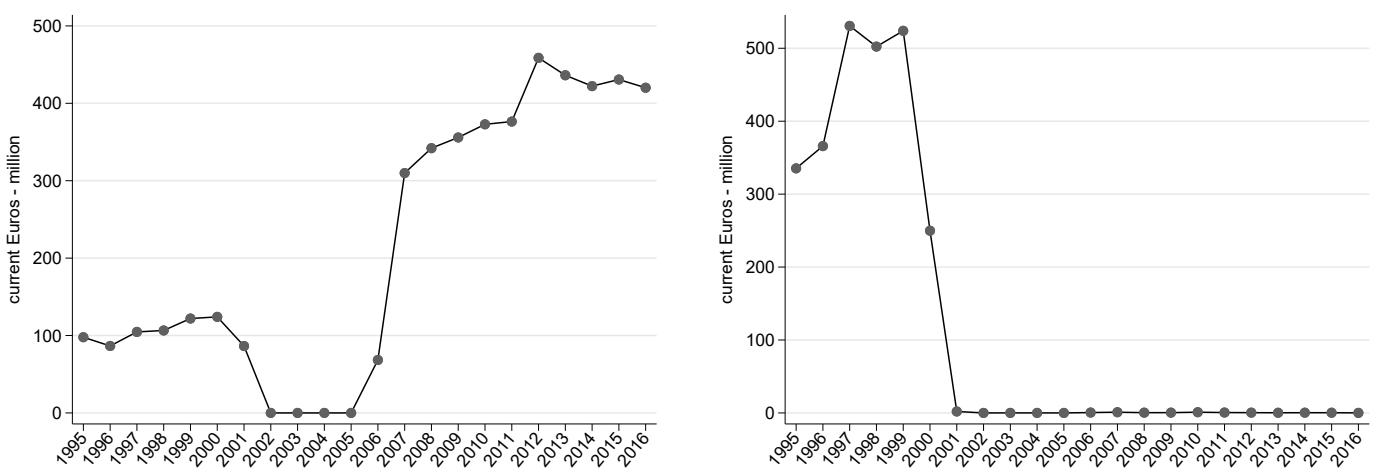

(c) Revenue from inheritance tax only

(d) Revenue from the estate tax only 
Figure I.3: The heterogeneity of the share of estates subject to taxation and the effective tax burden burden: a comparison across three tax regimes (1995-199, 2000, and 2007-2016)

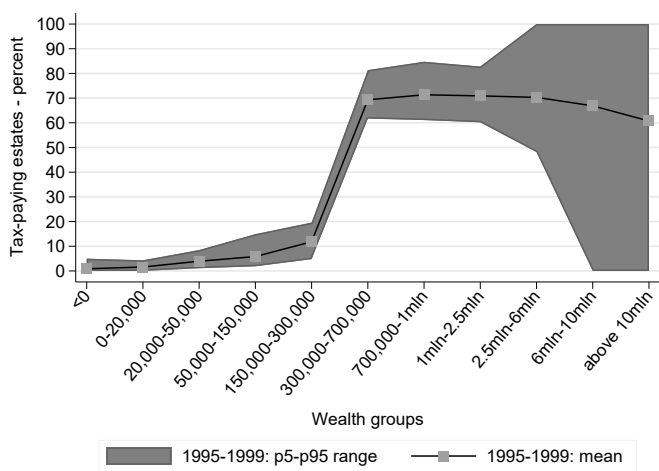

(a) \% of estates taxed: 1995-1999

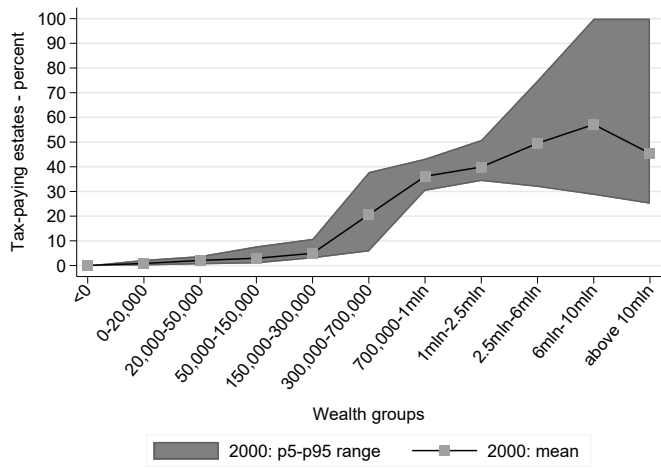

(c) \% of estates taxed: 2000

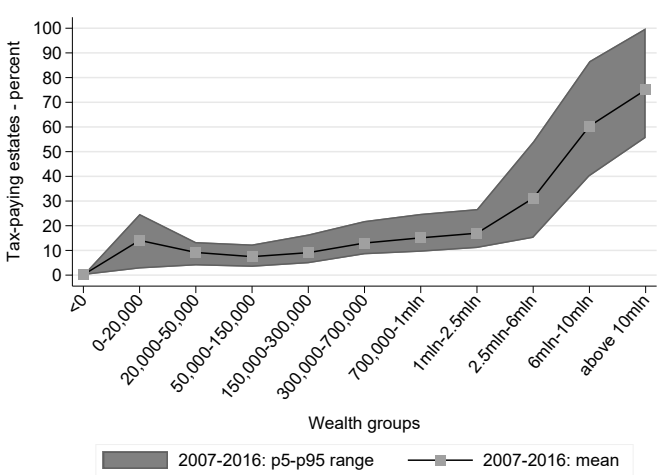

(e) \% of estates taxed: $2007-2016$

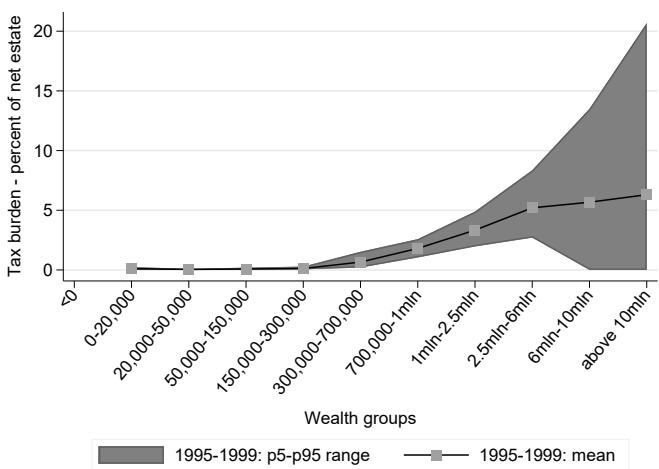

(b) Average tax burden:1995-1999

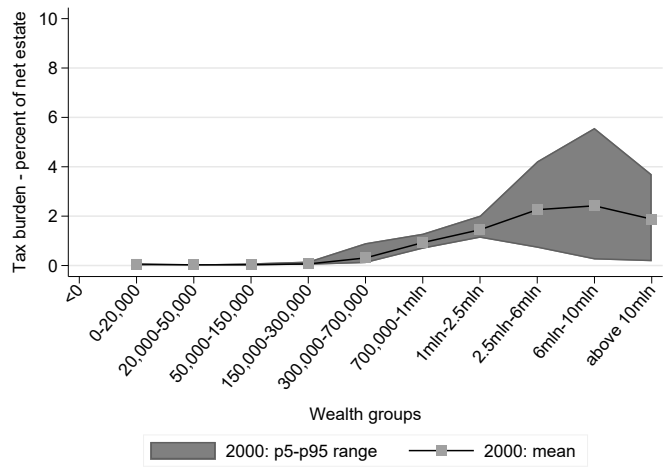

(d) Average tax burden:2000

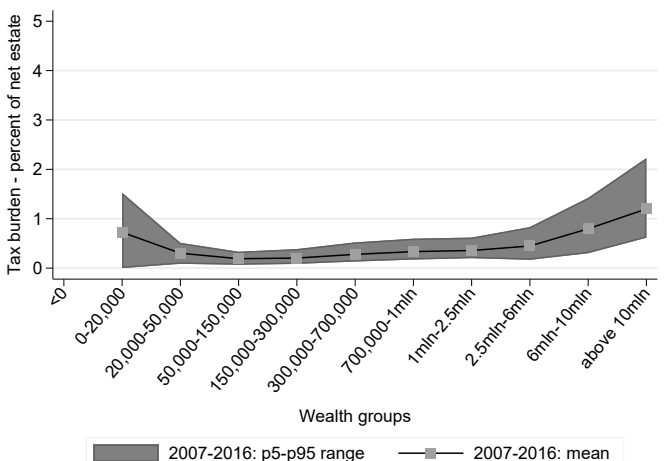

(f) Average tax burden:2007-2016 


\section{J Total inheritances and gifts}

Figure J.1: Growing wealth transfers as \% of total income

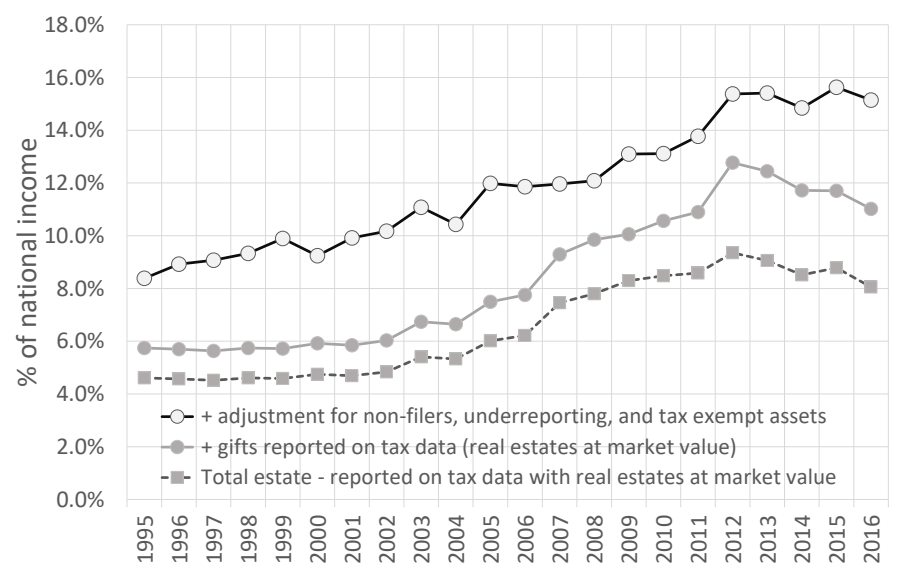

(a) Annual flows of inheritances (and gifts) over national income

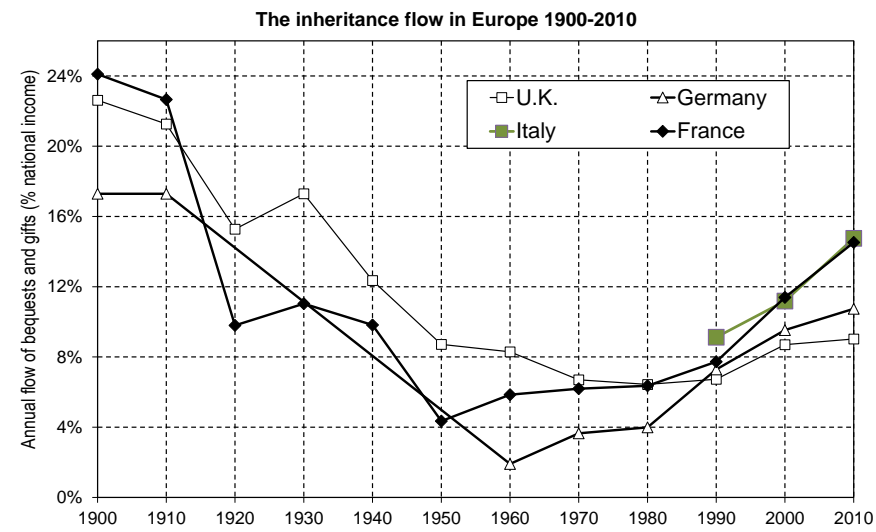

(b) Decennial averages: comparison with other countries

Note: Panel a) estimates the annual flows of inheritances and gifts starting from the information reported on the inheritance tax records and the gift tax records. The reported values of housing and land are adjusted to reflect market value. The final estimate makes allowances for the wealth of non-filers as well as additional underreporting of assets. Panel

b) replicates Figure 4. "The inheritance flow in Europe 1900-2010" from the work of Alvaredo et al. (2017), adding the decennial average series for Italy. 


\section{K Allocating household wealth to individuals using the Sur- vey on Household Income and Wealth}

The derivation of the personal distribution of assets from the observations available at the household level can be approximated thanks to information about asset holdings available within the household survey responses to a variety of questions. In doing so, we follow the exercise carried out by D'Alessio 2018. Two main caveat apply. First, as we use the public available survey data, subject to a more restricted set of information, our results slightly differ from D'Alessio 2018. Second, whenever possible, we distribute each asset to the adult members of the household. However, the sum of the components of each asset subgroup is generally slightly different than the aggregate subgroup available in the survey. In fact, the imputations of missing assets carried out by the statistical office of the Bank of Italy are only distributed at a higher level of aggregation and not asset by asset. The observed discrepancy for each subgroup of assets is then distributed to individuals within the households (without changing the derived individual distributional of each asset subgroup). There are ten main asset subgroups relating to different subcategories of real and financial assets and liabilities. Net wealth in the Survey of Household Income and Wealth is defined as total real assets (AR) plus total financial assets (AF) minus total financial liabilities (PF). In turn, AR has three main subgroups (AR1= housing, land and other buildings, AR2 = businesses, AR3 $=$ valuables $), \mathrm{AF}$ has four subgroups $(\mathrm{AF} 1=$ Deposits, CDs, repos, postal savings certificates, AF2 = Government securities, AF3= bonds, mutual funds, equity, shares in private limited companies and partnerships, foreign securities, loans to cooperatives, AF4 = Credit due from other households), and PF has three subgroups (PF1= Liabilities to banks and financial companies, PF2= Trade debt, PF3= Liabilities to other households).

The details of the exercise are the following. AR1 is the result of the property value (VALABIT) times the household's ownership share (QPRO). The number of adult owners can also be identified. Each adult owner is given an equal share of the real estate. The amount of advance payments on property that household does not yet own (ANTIC) are also added to the variable AR1 and equally allocated to the adult members of the households.

AR2 is composed of the business equity value, excluding the value of properties. This information is contained in one variable (VALAZ) that can be extracted from three different datasets within the Self-employment income section of the survey: LINB - Selfemployment income: until 1989 members of the professions, the self-employed, sole proprietors and entrepreneurs with fewer than 20 employees; LINC - Self-employment income: entrepreneurs with 20 or more employees, after 1989 active shareholder/partner; and LIND - Self-employment income: family businesses. In the first two datasets the personal ownership share of business equity can be directly identified. In the case of family business, we

allocate the ownership share proportionally to the number of hours worked in the business (D'Alessio, 2018).

AR3 value is allocated to the households and there is no usable information within the survey that can be used to infer a distribution to individual members of the household. The reported value is equally split among each adult members of the household. 
The value of AF1 (e.g. Deposits, CDs, repos, postal savings certificates) can in principle be allocated within the family after "according to the number of owners, selecting the components ordered by age (adults/non-adults), status in household (head of household, spouse, other member) and income" as described in D'Alessio (2018). However, the variable identify the number of owners within the households is not available in the public database. Hence, we only divide AF1 equally among all adult members of the households, similarly to what D'Alessio in doing for years preceding 2008.

Variables AF2 and AF3 (e.g. Government securities, bonds, mutual funds, equity, shares in private limited companies and partnerships, foreign securities, loans to cooperatives) can also be allocated to members of the households after 2008 by using the variable ICTIT containing information about the number of owners of investment and government securities within the households. Differently from the variable AF1, this can also be done using the public use files, although the information is only available in the annual wave files of the survey and not in the historically harmonized dataset. Following D'Alessio (2018) we distribute the value of AF2+AF3 to the members of the household by sorting them by age, status in household, and income. For year preceding 2008, the total value is divided equally among household adult members.

The variable AF4 is composed of business credits (CREC12d) from two datasets LINB e LIND, plus credits from other households (TCREDIT), which is only available in the annual wave files of the survey and not in the historically harmonized dataset. Hence, we derive the variable TCREDIT in the historically harmonized SHIW dataset as a residual from the difference between AF4 and the sum of the CREC12d from both LIND and LINB databases. The exact individual share of CREC12d can be computed directly from LINB whereas the value of CREC12d from LIND is allocated to individual members of the household based on the number of yearly hours worked in the family business. The variable PF1 is composed of business debts (i.e. DEBC12AB and DEBC12C from LINB and LIND databases) as well as all debts not linked to business activities (i.e. DEB12A; DEB12B; DEB12C; DEB12D; DEB12E; DEB12F; DEB12P from the FAMI database). The individual share of business debts from LINB are directly allocated to household members whereas they are estimated from LIND based on estimated yearly worked hours within the family business. The sum of DEBC12AB from LIND and LINB should match the aggregate DEB12O reported in the FAMI database. This is not the case as imputation procedures are only reported at the higher aggregation level (e.g. DEB12O). The observed discrepancy for each households is distributed to its members using the observed number of yearly hours worked in the family business. The same applies to DEBC12C. The variable DEB12A, linked to housing ownership are allocated to individuals following the same criteria used to allocate housing assets within the household (e.g. method used to allocate AR1). The remaining debts, in the absence of more detailed information, are allocated equally to each adult member of the households. The sum of total sub-components would still be smaller than the estimated value of PF1 for each household as reported in the FAMI database. To match precisely the aggregates, we distribute the observed discrepancy to each household and keep the observed proportions of PF1 across household adult members. The variable PF2 is composed of self- 
employment and family business debts, DEBC12D from both databases LINB and LIND. As above, the exact individual share of DEBC12D can be identified from LINB whereas we estimate it in LIND by looking at the individual reported yearly hours worked in the family business. Similarly, to what was done for PF1, we distribute within each household, the difference between the household aggregate value of PF2 and the total PF2 derived as the sum of each sub-components. The variable PF3 (Liabilities to other households) was distributed equally among all adult members of the household.

\section{Estimating private pension and life insurance accumulated assets using the Survey on Household Income and Wealth}

The SHIW asks households about the value of their accumulated capital private pension and life insurance funds. However, this information is not available in every year and contains lots of missing values. In order to estimate the accumulated reserves into pension and life insurance funds we also resort to additional information about the value of annual payments and contributions into pension funds and life insurance as well as the beginning year of contribution. The information is available at the household level and the information available within annual waves matches precisely the historically harmonized database. The accumulated capital in year $t$ is then computed as the reported or estimated accumulated capital at time t-1 capitalized to time t using a constant 3\% return plus the new contributions done between $\mathrm{t}-1$ and $\mathrm{t}$.

For the panel sample of the survey we can compare the reported year when contributions to pension or life insurance funds begins. When the answers are not consistent we consider the first answer available as the 'true' beginning year. If such information is not available or if the information is not consistent with the first reported payment contribution, we consider as the official beginning year of the accumulation, the first year of reported contribution into life insurance (e.g. variable assvita) or pension fund (e.g. variable pensint). If the contributions is reported to begin before the first wave of the survey, we used the year of the first reported contribution as the beginning of the accumulation process (e.g. this would presumably under-estimate the potential asset accumulation of older households).

In some years the variables assvita and pensint do not report any value. However, if any information is reported in both earlier and later years we compute the average between the two values and impute it to the missing observation. In 2016, the survey asks what is the initial contribution to the insurance or the pension fund. If this information is reported we consider this as the correct information to compute accumulated capital.

\section{Accounting for the wealth hidden in offshore accounts}

A fraction, perhaps substantial, of financial wealth remains hidden from official statistics and tax agencies. With the help of the wealth management industry and a growing freedom of capital movements, this could generate growing tax revenue losses. Zucman (2013) estimates that the hidden wealth held offshore accounts to $\$ 5.6$ trillion, or $10 \%$ of the world 
GDP. The global estimates of portfolio securities held offshore can be derived using two main sources, as described by Zucman (2013). First, one can estimate the total amount of financial wealth managed by Swiss banks on behalf of foreigners (approximately $\$ 2.3$ trillion in 2017) using data from the central bank of Switzerland. This is sizeable and the authors suggest this 'data source alone captures a large fraction of the world's total offshore wealth (30-50\% in recent years)'. Moreover, to estimate the global amount of offshore portfolio securities, beyond what is held in Switzerland banks, one could track anomalies in global investment statistics, namely the positive discrepancy between global portfolio liabilities and assets, indicating to what extent the portfolio securities are less likely to be reported as assets on the international investment positions of countries.

Until very recently, the information publicly available was not sufficient to reconstruct how the global offshore wealth was distributed across countries and whom this wealth belongs to. The distributional implication of unreported offshoring of wealth was, therefore, difficult to be precisely investigated (see Roine and Waldenstrom, 2008 for a previous attempt to investigate this important issue). A series of recent works, helped to shed light on these important issues.

First, Alstadsæter et al. (2018) approximated the relative distribution of world offshore wealth across countries around 2007. The authors unveil the cross-sectional heterogeneity of the incidence of offshore wealth across different countries in the world. In the abstract of their work the authors write that 'The equivalent of $10 \%$ of world GDP is held in tax havens globally, but this average masks a great deal of heterogeneity from a few percent of GDP in Scandinavia, to about 15\% in Continental Europe, and $60 \%$ in Gulf countries and some Latin American economies'. According to this estimates, Italians held approximately $12 \%$ of GDP of financial wealth in offshore accounts in 2007, equivalent to approximately 190 billion of Euro.

This estimate is obtained in two main steps. The most important country-specific information is derived from the Bank for International Settlements who recently disclosed bilateral deposits holdings by foreigners in the most significant offshore financial centers in the world (Switzerland, Hong Kong, Singapore, Cayman Island etc.). In doing so, Alstadsæter et al. (2018) compute the share of total deposits held in most offshore financial centers held by Italians. Bank deposits, however, only account for a small share of total financial wealth held offshore as it excludes portfolios of equities, bonds and mutual fund shares and other securities. In order to overcome this limitation, Alstadsæter et al. (2018) assume the remaining global financial wealth (portfolio securities) held offshore, as estimated in Zucman (2013), is distributed across countries in the same way as offshore bank deposits are. This is clearly an imperfect adjustment although the only feasible one with the current data availability. The authors suggest that "the correlation between the two distributions is likely to be high but imperfect."

To provide an external validation of this tentative estimate an alternative series based on the estimates provided by Pellegrini et al. (2016) who independently attempted to estimate securities financial assets held in offshore centers by investors resident in Italy, Germany, 
France, the Netherlands, and Spain between 2001 and 2013. In this paper the authors, similarly to what done in Zucman (2013), made use of global discrepancy between the stock of financial assets and liabilities to derive the global stock of financial assets held in offshore centers. The global undeclared amount of undeclared assets was then allocated to different investor countries based on two approaches. The baseline approach distributed undeclared assets according to the official derived liabilities share of each issuing country as declared in the CPIS data (Coordinated Portfolio Investment Survey ), implicitly assuming that "investors resident in any given country allocate the unreported foreign wealth to the same portfolio of assets used for the investment of declared wealth" (p.16). This procedure results into an estimated total value of undeclared debt and equity securities of approximately 140 billion Euro in 2007.

In order to compare these figures directly with those provided in Alstadsæter et al. (2018) we further need to estimate the value of undeclared bank deposits held by individual investors in offshore centers. The work by Pellegrini et al. (2016) only derive the global amount of undeclared bank deposits held by non-banking sector in offshore centers as obtained from the cross-border banking statistics released by the Bank of International Settlements. In order to derive the share of offshore bank deposits held by Italians, we first assume that $1 / 2$ of the undeclared bank deposits are allocated to individuals ${ }^{45}$. We then distribute a share of the global amount of individual bank deposits held offshore according the country's relative share of global GDP. The resulting estimated value of total financial wealth held offshore by Italian investors is approximately 187 billion Euro in 2007 . Incidentally this a very similar value to what independently derived by Alstadsæter et al. (2018).

This exercise is carried out also for the remaining years from 2001 to 2013 to derive a time series evolution of Italian financial wealth held in offshore accounts. In order to derive the evolution of offshore wealth for a longer period of time, between 1995 and 2016, we anchor the level of financial wealth held offshore in 2007 as reported in Alstadsæter et al. (2018) and we assume that the time series evolution follows the relative evolution of European offshore wealth. The results indicate that Italian financial wealth held offshore went from $5 \%$ of GDP in 1970 to approximately $18 \%$ in 2016 . We will use the absolute values of this series between 1995 and 2001 and its relative evolution between 2013 and 2016, when no time series and country-specific information can be estimated from Pellegrini et al. (2016).

One important feature to highlight of latter work is the allowance made in their statistics for the voluntary declaration of financial assets held abroad to the Italian tax authority thanks to the Voluntary Disclosure (VD) agreement scheme put in place by the Italian government in 2009/2010. Under very favorable tax and legal conditions, thousands of taxpayers decided to declare approximately 100 billion of financial assets under this VD scheme, leading to subsequent revisions of the official statistics on the international investment po-

\footnotetext{
${ }^{45}$ The same share was assumed in Johannesen and Zucman (2014) and appears consistent with more recent works by García Luna and Hardy (2019) who found that at end-March 2019, households (including non-profit institutions serving households) accounted for $51 \%$ of Switzerland banks' cross-border liabilities. In the same work, if considering all the countries in the sample, households accounts for only $14 \%$ of banks' cross-border liabilities.
} 
Figure M.1: The share of financial wealth held offshore as \% of GDP, total financial wealth, and total personal net wealth

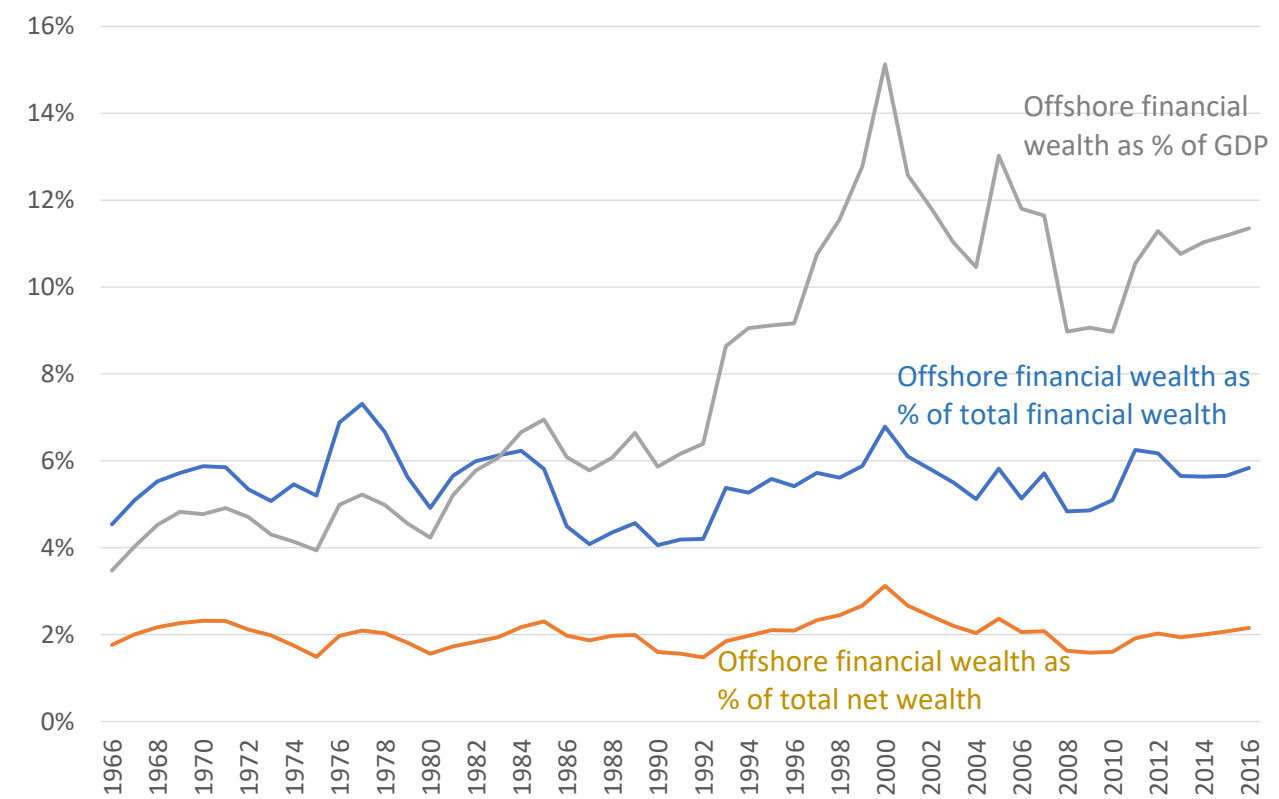

sitions and the Italian balance of payments.

The resulting final series suggests that Italian financial wealth held in offshore accounts went from 5\% of GDP in 1970 to approximately $11 \%$ of GDP in 2016. Given the strong relative rise in household wealth over the same period, the choice of the comparator clearly matters. Offshore wealth as a share of total net personal wealth appears to be more stable and oscillating around $2 \%$ between 1970 and 2015. The estimation of the time series of financial wealth held offshore by Italian households it is only the first step to investigate its distributional implications. The second step involves the estimation of the share of the financial wealth held offshore that remains undeclared and therefore unaccounted in tax administrative data and the national accounts. The third step requires the estimation of how undeclared financial wealth held offshore is distributed among wealth holders.

Alstadsæter et al. (2019) matched individual tax records on income and wealth to records obtained from tax amnesties in Denmark and Norway as well as recent random leaks from offshore financial institutions (e.g. Panama Papers in 2016 and the "Swiss Leaks" from HSBC Switzerland). The investigation suggests that the 90 to $95 \%$ of total wealth held offshore is evading taxes as it goes unreported to tax authorities. Moreover, their findings suggest that offshore wealth is highly skewed at the top of the wealth distribution being 
concentrated almost entirely (up to $95 \%$ ) to the top 1 percent (50\% of which being allocated to the richest top $0.01 \%$ group alone).

We consequently assume that $95 \%$ of offshore wealth is undeclared, this high share is also consistent with data of financial wealth abroad declared to Italian tax authorities in the context of the stamp duty (IVAFE - Imposta sul Valore delle Attività Finanziare all'Estero): reported financial wealth held in "black listed" countries in tax year 2016 was only 2.9 billion euros over a total of 114 billion euros of financial wealth held in all foreign countries (source: Italian Ministry of Economy and Finance). Applying the same distribution described above to the Italian data reveals that wealth concentration is even more concentrated than what tax data alone imply. The level of the share of total net wealth held by the richest one percent of the adult population increases by approximately 2 percentage points throughout. This is a sizeable effect that becomes even more visible at the very top of the distribution. The richest one in one thousand individuals saw its share of total net personal wealth increasing by $65 \%$ in 1995 (from 1.9 to 3.2 percent) and by $15 \%$ in 2016 (from 7.3 to 8.4 percent). The inclusion of unreported offshore financial wealth, however, does not appear to substantially affect the trend of the wealth concentration over the period of investigation.

It would be interesting to observe the future trends of wealth hidden in offshore accounts in the light of the recent achievements in terms of new standards of global exchange of information among tax authorities. While Johannesen and Zucman (2014) find that total bank accounts in International Financial Centers (IFCs) had not declined significantly since the expansion of exchange of information in 2008, more recent OECD work (O'Oreilly et al., 2019) show a significant decline associated to exchange of information on request, automatic exchange of information and FATCA (the US Foreign Account Tax Compliance Act). In particular, automatic exchange of information commencement in 2017 and 2018 is associated with a reduction in IFC bank deposits of $22 \%$. This virtuous process of exchange of information at the international level in the near future might render wealth declared on inheritance tax returns closer to the actual wealth. Further information on this domain can be found on the OECD website ${ }^{46}$.

\footnotetext{
${ }^{46}$ www.oecd.com/tax/exchange-of-tax-information/
} 


\section{$\mathrm{N}$ Wealth shares and asset price changes}

Figure N.1: The role of asset prices and the households saving rate

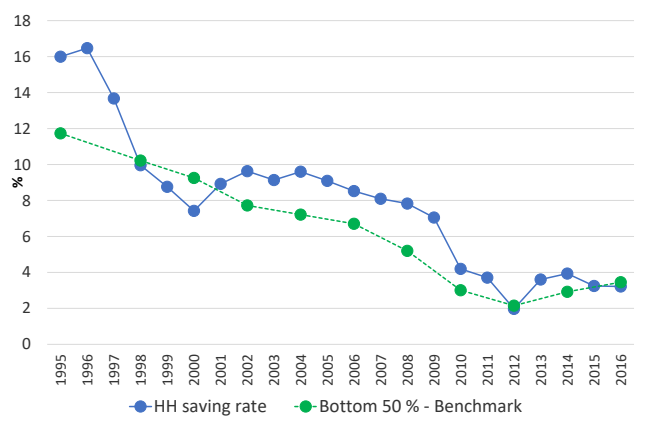

(a) Bottom $50 \%$ and the household saving rate

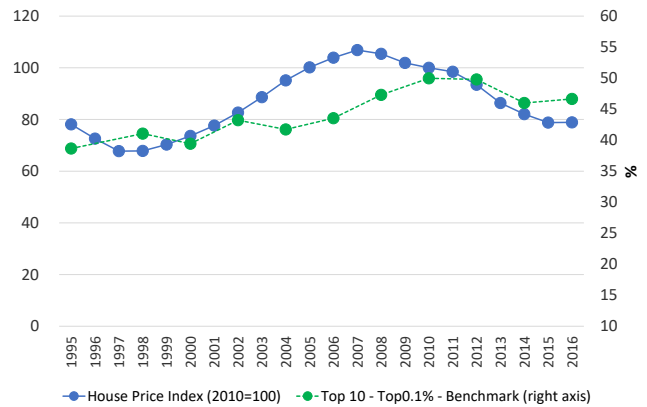

(c) Top 10 - Top $0.1 \%$ and the house price index

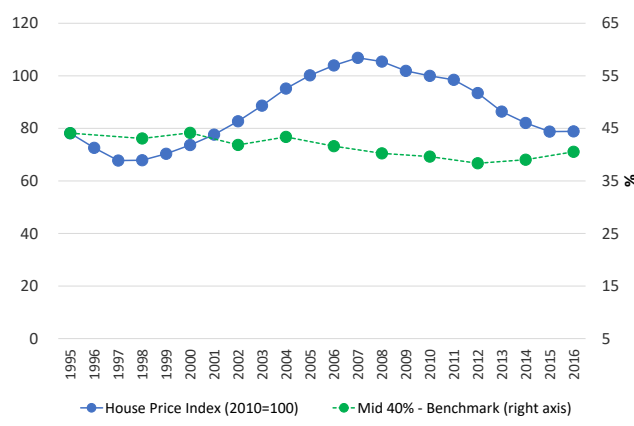

(b) Mid $40 \%$ and the house price index

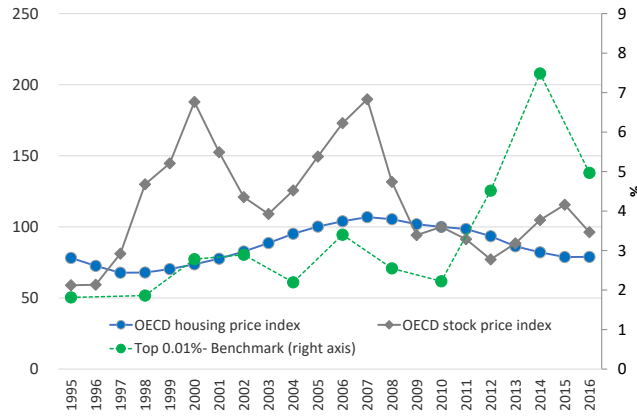

(d) Top $0.01 \%$, the house price and the stock price indexes

\section{O Wealth concentration with alternative imputation deci- sions}

In this paper we rely on a number of assumptions based on the observed wealth holdings aggregated by the four large macro-categories of assets available in the digitized tax records. These imputations could not be carried out asset by asset based on micro-level evidence and can appear controversial. For the benchmark series, we recall, (i) we first multiply-up the estates distribution using mortality multipliers; (ii) we then append an estimate of the wealth of the missing population based on the households' survey; and finally (iii) we distribute the remaining wealth gap with respect to the NA according to the relative distribution of asset classes in the identified wealth from tax records complemented with that of the missing 
population from survey data.

One must wonder to what extent the benchmark results are driven by specific imputation choices in steps (ii) and (iii). To address this concern we discuss here two alternative imputation scenarios, doing as in the benchmark case but making changes in the second (ii) and third (iii) steps.

In the first alternative approach, the relative distribution of each asset class, used for imputing the unobserved wealth from the national accounts, are derived from the estimated distribution of wealth of the living without allowing for the wealth of the missing population. In the second alternative approach, instead, we impute the wealth gap using the relative distribution derived from the estimated distribution of wealth of the living allowing for the wealth of the missing population. In doing so, we follow very closely the approach used for the benchmark series. However, we use slightly different estimates of the wealth of the missing population. Rather than adjusting the information reported on the survey data regarding the non-housing assets as done in our benchmark approach, we take the reported values of asset holding as it is.

Essentially, both approaches attach more weight to wealth reported in the tax records, which is on average more concentrated than what would appear if one takes into consideration smaller wealth holdings that cannot come to notice to the tax authority. Hence, the alternative set of imputations, when compared to our benchmark series, generally imply higher wealth concentration at the top and a lower share for the bottom $50 \%$ of the population (figures O.1(a)- O.1(d)). In this respect, our benchmark series is likely to provide conservative estimates of wealth concentration at the top. 
Figure O.1: Wealth shares with alternative imputation procedures

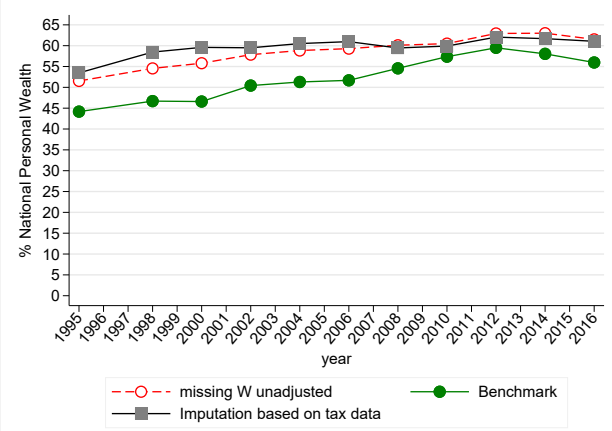

(a) Top $10 \%$

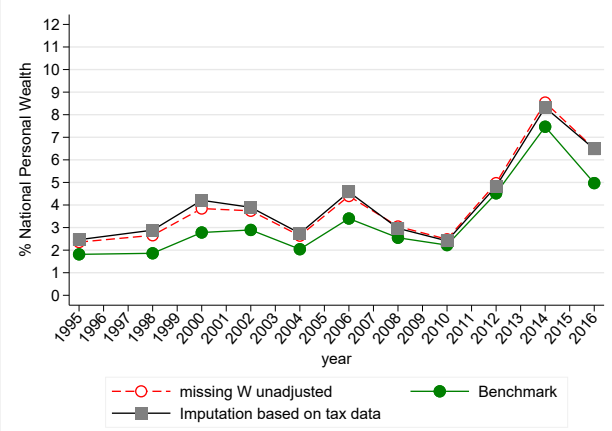

(c) Top $0.01 \%$

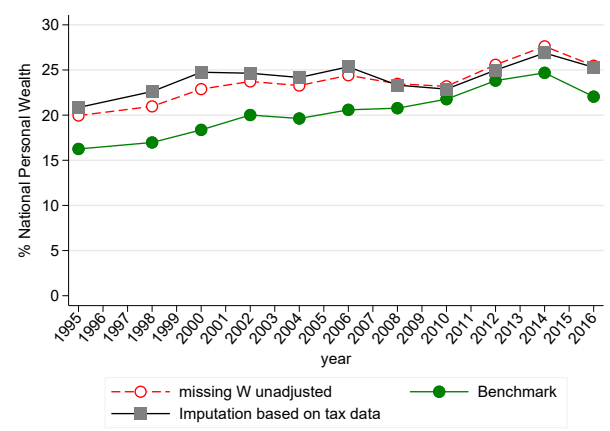

(b) Top $1 \%$

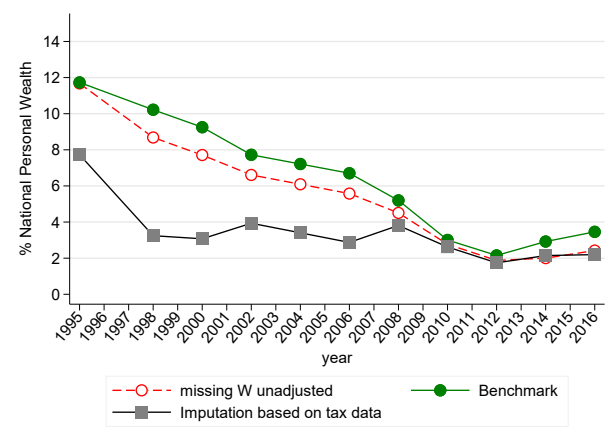

(d) Bottom 50\% 
Figure O.2: Proportional distribution of assets by types and wealth ranges: benchmark approaches compared to alternative assumptions in 2016

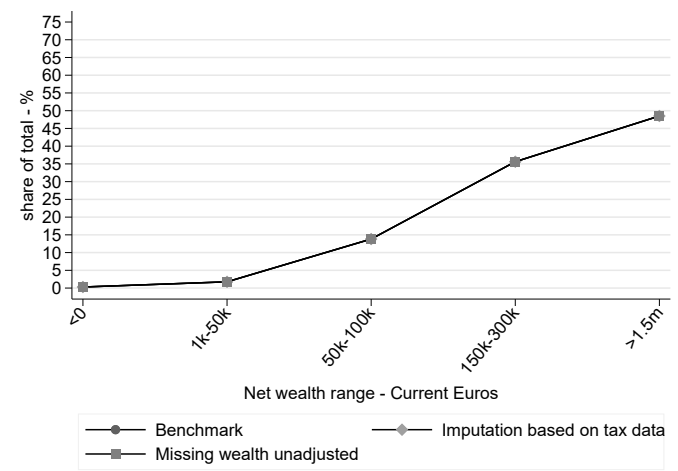

(a) Housing and land assets

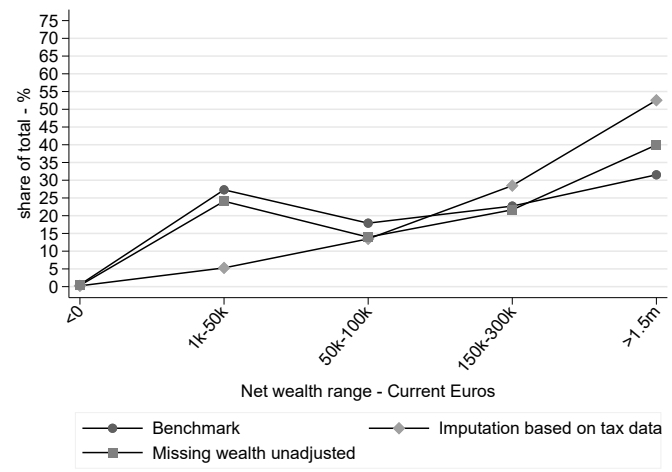

(c) Valuables and deposits

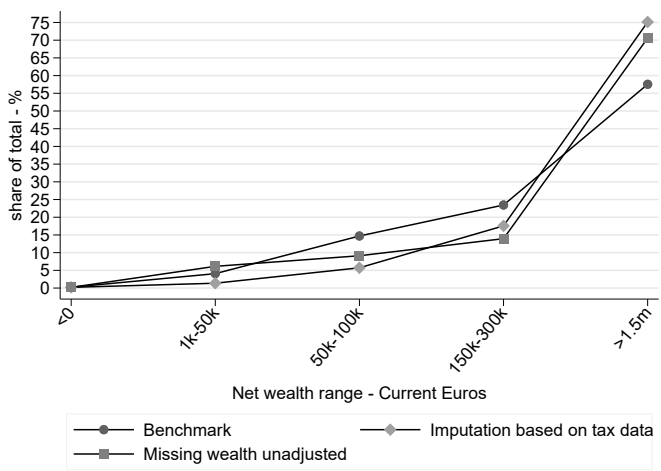

(b) Financial and private business assets

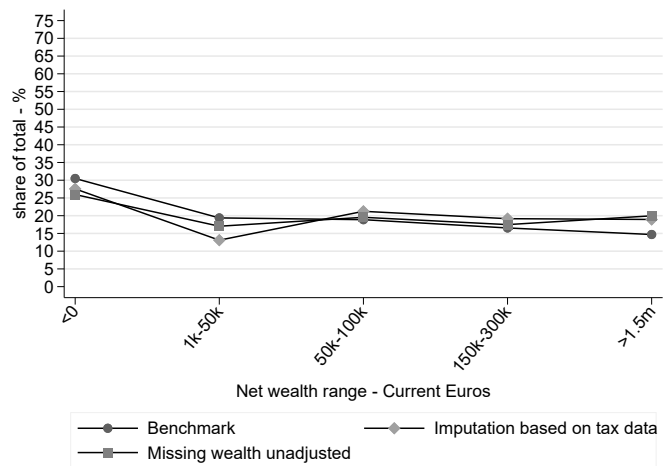

(d) Liabilities

Note: The graph shows a simplified representation, for each class of assets, of the proportions of total assets held across the wealth groups (ranked across total net wealth). These proportional factors are used to impute missing assets and liabilities and matching aggregates with the relevant series of the household's sector balance sheets. The figure presents, for the year 2016, three alternative imputation factors. In the

benchmark approach we impute wealth using the relative distribution derived from the estimated distribution of wealth of the living allowing for the wealth of the missing population from the SHIW, adjusted for potential underreporting. In an alternative approach we allow for the wealth of the missing population from the SHIW taking the information on the SHIW as given, making no adjustments. In the third alternative approach, the relative distribution of each asset class, are derived from the estimated distribution of wealth of the living, directly from inheritance tax data without allowing for the wealth of the missing population. 


\section{P Estimates with no imputations}

We derive estimates of wealth shares without resorting to imputations of any kind, that is, by applying the mortality method to the reported estates on the inheritance tax records. As mentioned in the main text of the paper, estimates for the UK in Atkinson and Harrison (1978) and Alvaredo et al. (2018), for instance, followed this path. Importantly, this can be done using both internal and external wealth totals. Typically, researchers use external data (e.g., the National Accounts) on total wealth that bear no relation to tax data. However, when the population coverage of inheritance tax records is particularly high (like in the case of Italy or the UK), one can also rely on the multiplied-up estates as well as the estimated wealth of the missing population to derive an internal measure for total wealth (as in Alvaredo et al., 2018, Atkinson and Harrison, 1978).

In the main text we presented the results for the top $1 \%$ share. Here, additional wealth shares are reported in Figures P.1(a)-P.1(d). The role of imputations appears stronger when the external total is used, especially in those years where the underlying inheritance tax data are much less complete (i.e., between 2001 and 2006). The derivation of the bottom 50\% share appears to be particularly sensitive to imputations and the use of an external total.

Figure P.1: Wealth shares without imputations vs. benchmark series

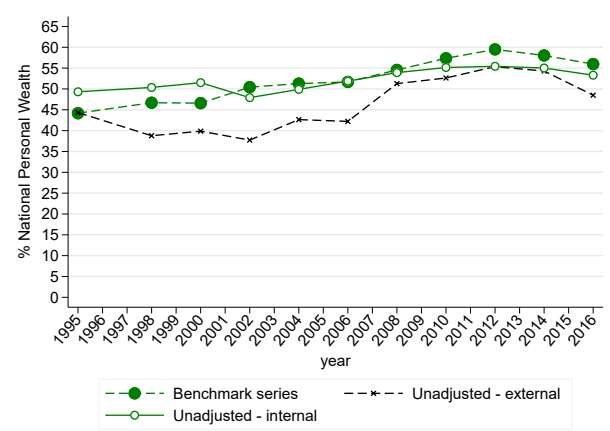

(a) Top $10 \%$

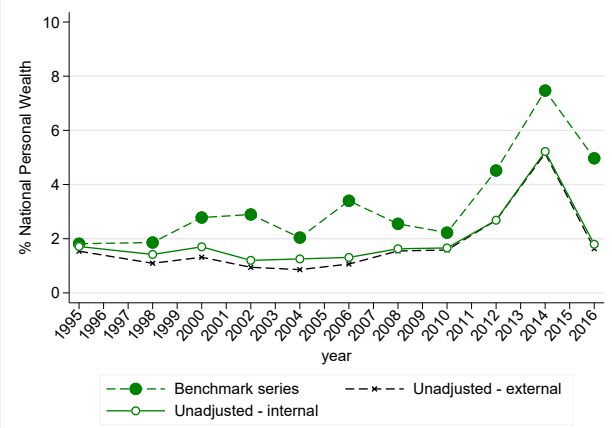

(c) Top $0.01 \%$

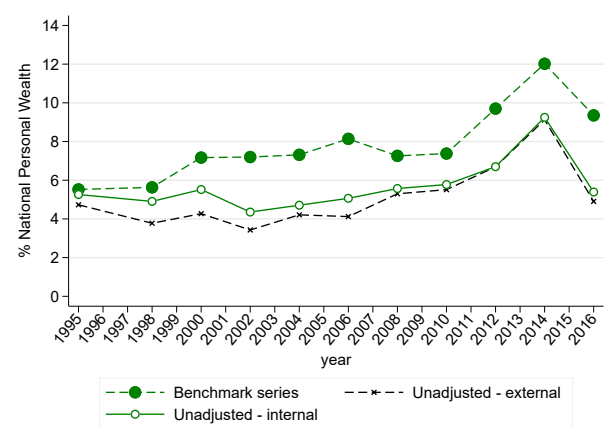

(b) Top $0.1 \%$

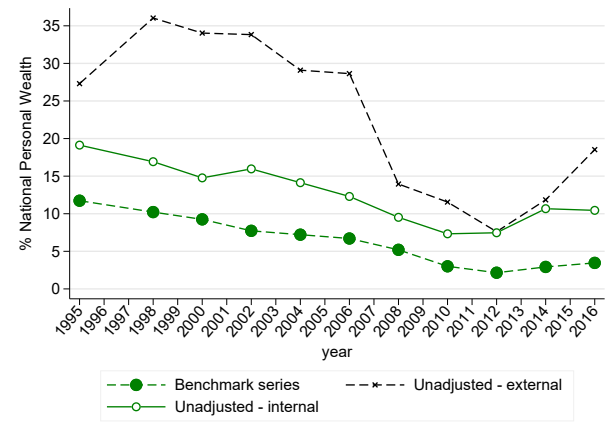

(d) Bottom 50\% 
Figure P.2: The Top 1\% without imputations vs. SHIW

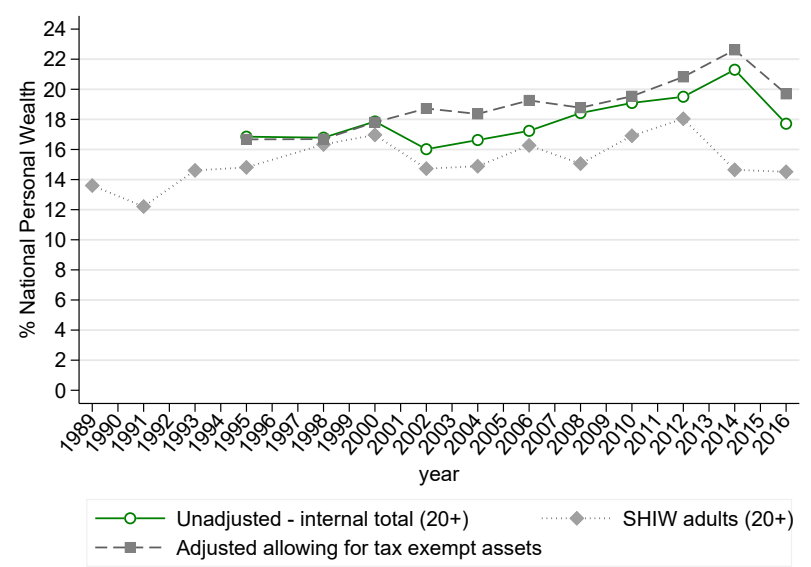

\section{P.1 External total: Total net wealth excluding likely unreported tax ex- empt assets}

This is obtained by subtracting an estimate of unreported tax-exempt assets from the total net wealth from the households sector. To derive a measure of unreported tax-exempt assets we use the tax code and practice in filing. In particular, the missing tax-exempt financial assets are derived as follows: $100 \%$ of insurance technical reserves value (e.g. private pensions, life insurance and accumulated reserves for severance payments are non-taxable assets according to the inheritance and gift tax legislation), 50\% of Italian government securities (e.g. the government bonds are tax exempt and the tax authority suggest to include them in the tax form, and they are typically reported if bonds are included within an investment fund together with other securities), $90 \%$ of notes and coins (e.g. we assume that most of cash holding is not reported, as generally done by the tax authority who assumes that $10 \%$ of total estate is held in cash to compute tax liability). During the months when inheritance and gift tax was abolished (October 2001 to October 2006), we assume that $100 \%$ of above-mentioned assets are not reported.

\section{P.2 Internal total: total net wealth identified from tax returns corrected for the wealth of the missing population}

The internal measure of total net wealth is computed by adding an estimate of the wealth of the missing population (i.e. those not represented by the inheritance tax information, scaled-up according to the mortality multiplier method ) to the net wealth of the identified population. The estimation of the wealth of the missing population is described in the Appendix H.1. 


\section{Q Alternative mortality rates}

Alternative mortality rates are obtained from the Human Mortality Database (https://mortality.org/), which gives the number of deaths and population by age on a yearly basis since 1872 and up to 2014. We make use of this database to compare the mortality multipliers described in the previous subsection. Both sources match pretty closely with the exception of the youngest cohorts for which a higher volatility is generated by very low mortality rates. Moreover, fewer data points are available for very old age above 100. This appears less relevant as mortality multipliers are very stable in this age range.

Figure Q.1: 2014 mortality multipliers across alternative databases

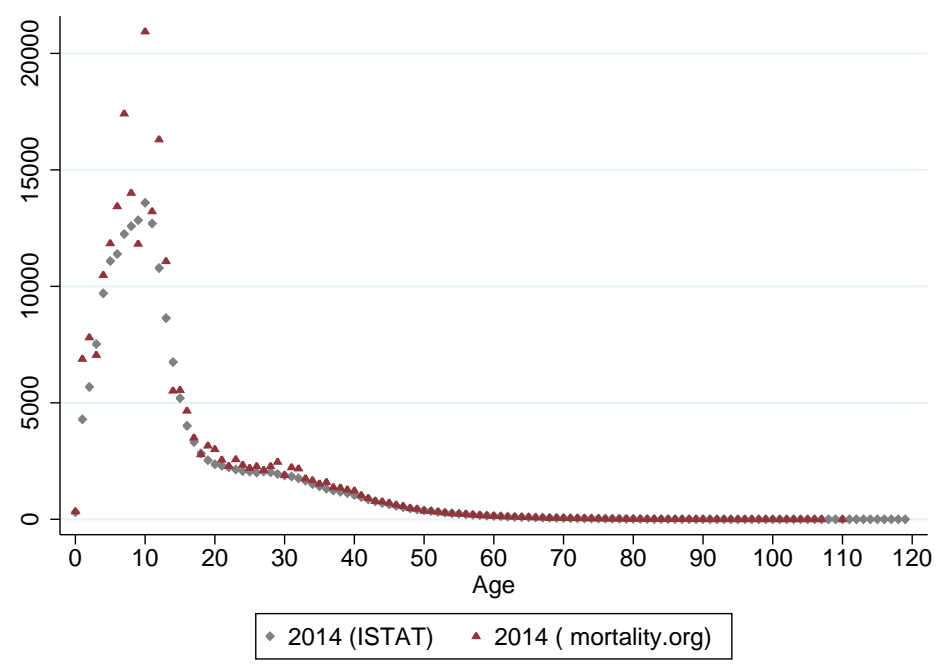

\section{Q.1 Mortality rates by education groups}


Figure Q.2: Mortality rates and life expectancy by age and education groups: 2012

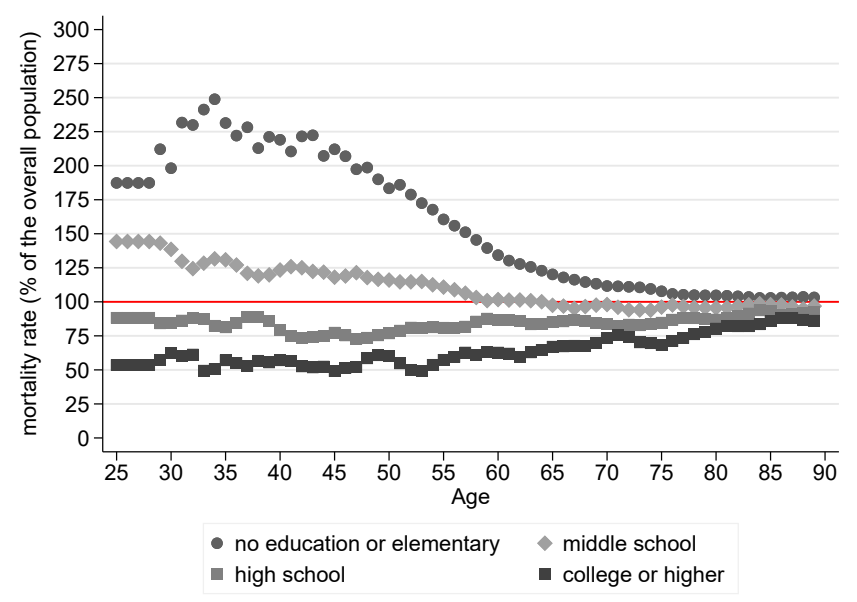

(a) Mortality rates by age and education groups (\% of the population)

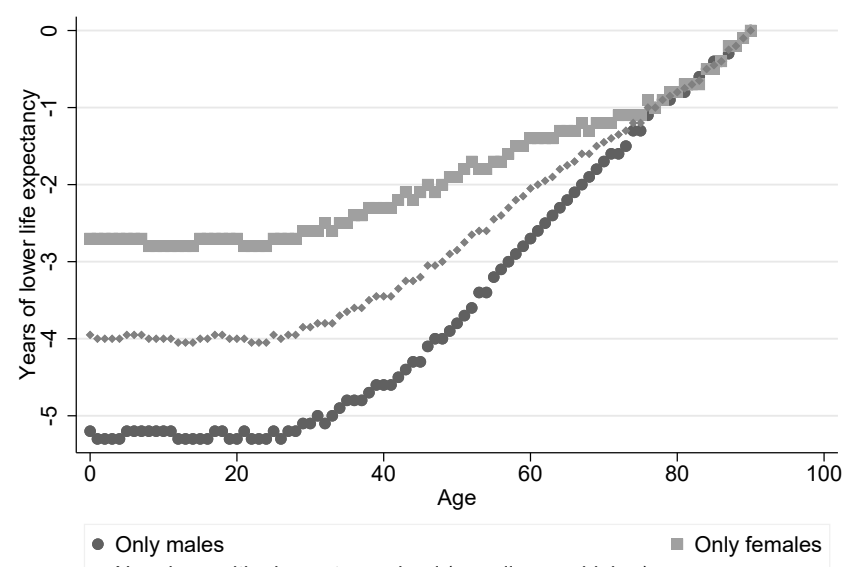

- No edu or with elementary school (vs college or higher)

(b) Number of years of lower life expectancy (low vs high education groups)

Notes: data on mortality rates and life expectation from ISTAT. Elaboration of the authors. 
Table Q.1: 2012 Mortality rates by education level as a share of overall population

\begin{tabular}{|c|c|c|c|c|c|}
\hline Age group & $\begin{array}{l}\text { Mortality rate in } \\
\text { population - percent }\end{array}$ & $\begin{array}{l}\text { No education or } \\
\text { elementary (\%) }\end{array}$ & Middle School (\%) & High school (\%) & $\begin{array}{l}\text { College or higher } \\
(\%)\end{array}$ \\
\hline \multicolumn{6}{|c|}{ All } \\
\hline 20 & 0.0005 & 208.8 & 119.9 & 92.2 & 67.6 \\
\hline 40 & 0.0013 & 196.9 & 118.8 & 77.5 & 61.7 \\
\hline 50 & 0.0034 & 150.6 & 106.6 & 83.9 & 64.3 \\
\hline 60 & 0.0090 & 115.9 & 98.6 & 87.2 & 70.6 \\
\hline 70 & 0.0252 & 106.1 & 95.3 & 85.9 & 75.9 \\
\hline 80 & 0.0948 & 102.7 & 95.7 & 91.4 & 86.6 \\
\hline \multicolumn{6}{|c|}{ Females } \\
\hline 20 & 0.0003 & 243.7 & 108.2 & 99.6 & 75.3 \\
\hline 40 & 0.0010 & 181.7 & 116.0 & 81.8 & 73.8 \\
\hline 50 & 0.0025 & 134.2 & 102.4 & 86.9 & 75.5 \\
\hline 60 & 0.0061 & 106.7 & 99.2 & 90.9 & 79.9 \\
\hline 70 & 0.0180 & 103.6 & 94.3 & 86.1 & 80.4 \\
\hline 80 & 0.0780 & 102.3 & 93.5 & 89.8 & 85.5 \\
\hline \multicolumn{6}{|c|}{ Males } \\
\hline 20 & 0.0006 & 193.8 & 125.0 & 89.0 & 64.3 \\
\hline 40 & 0.0016 & 206.0 & 120.4 & 74.9 & 54.5 \\
\hline 50 & 0.0044 & 159.8 & 108.9 & 82.3 & 58.1 \\
\hline 60 & 0.0118 & 120.5 & 98.4 & 85.4 & 65.9 \\
\hline 70 & 0.0324 & 107.4 & 95.8 & 85.7 & 73.4 \\
\hline 80 & 0.1117 & 103.0 & 97.3 & 92.5 & 87.4 \\
\hline
\end{tabular}

Notes: data on mortality rates from ISTAT. Elaboration of the authors. 